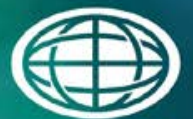

Savannah River

National Laboratory ${ }^{m}$

OPERATED BY SAVANNAH RIVER NUCLEAR SOLUTIONS

\title{
Impact of Glycolate Anion on Aqueous Corrosion in DWPF and Downstream
}

\section{Facilities}

J.I. Mickalonis

December 2015

SRNL-STI-2015-00482, Revision 0 


\section{DISCLAIMER}

This work was prepared under an agreement with and funded by the U.S. Government. Neither the U.S. Government or its employees, nor any of its contractors, subcontractors or their employees, makes any express or implied:

1. warranty or assumes any legal liability for the accuracy, completeness, or for the use or results of such use of any information, product, or process disclosed; or

2. representation that such use or results of such use would not infringe privately owned rights; or

3. endorsement or recommendation of any specifically identified commercial product, process, or service.

Any views and opinions of authors expressed in this work do not necessarily state or reflect those of the United States Government, or its contractors, or subcontractors.

\section{Printed in the United States of America \\ Prepared for U.S. Department of Energy}


Keywords: glycolic acid, formic acid, DWPF, corrosion, high-nickel alloys, stainless steels

Retention: Permanent

\title{
Impact of Glycolate Anion on Aqueous Corrosion in DWPF and Downstream Facilities
}

\author{
J.I. Mickalonis
}

December 2015

Prepared in conjunction with work accomplished under contract number DE-AC09-08SR22470 with the U.S. Department of Energy (DOE) Office of Environmental Management (EM).

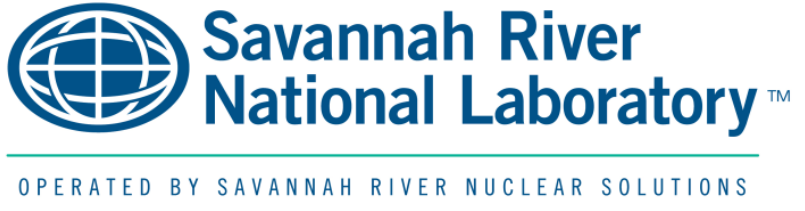




\section{ACKNOWLEDGEMENTS}

The author wishes to acknowledge the following individuals for their assistance with the experimental work and project management as well as helpful technical discussions: T. H. Murphy, J. E. Wilderman, W. C. Sexton, D. M. Missimer, T. B. Curtis, C. J. Martino, T. L. Fellinger, S. T. Isom, E. W.

Holtzscheiter, B. J. Wiersma, and K. J. Imrich. 


\section{EXECUTIVE SUMMARY}

Glycolic acid is being evaluated as an alternate reductant in the preparation of high level waste for the Defense Waste Processing Facility (DWPF) at the Savannah River Site (SRS). During processing, the glycolic acid may not be completely consumed with small quantities of the glycolate anion being carried forward to other high level waste (HLW) facilities. The impact of the glycolate anion on the corrosion of the materials of construction (MoC) throughout the waste processing system has not been previously evaluated. A literature review had revealed that corrosion data were not available for the MoCs in glycolic-bearing solutions applicable to SRS systems. Data on the material compatibility with only glycolic acid or its derivative products were identified; however, data were limited for solutions containing glycolic acid or the glycolate anion.

A test program recommended by the Savannah River National Laboratory was conducted to evaluate the MoCs of vessels, piping and components within DWPF and downstream facilities. The testing, which was performed in two phases, consisted of both accelerated tests (electrochemical and hot-wall) with coupons in laboratory vessels and prototypical tests with coupons immersed in scale-up and mock-up test systems as well as a six-month coupon immersion test with periodic removal of coupons.

The first phase for aqueous corrosion testing consisted of electrochemical tests, hot-wall tests, and a coupon exposure test performed as part of the intermediary $(22 \mathrm{~L})$ scale-up testing for the chemical process cell (CPC) flowsheet development. Test conditions simulated the service conditions for DWPF and downstream facilities. The MoCs for most vessels, components and piping were not impacted by the presence of the glycolate anion or the impact was not expected to affect the service life. The performance of the MoCs within the DWPF CPC and feed tanks was questionable due to the susceptibility to localized corrosion identified during the accelerated testing. In other hot-wall tests, localized corrosion was also observed for the MoCs of heat transfer surfaces in downstream facilities.

To address the concerns with the use of glycolic acid identified during the first phase of testing, follow-up testing was recommended to better identify waste chemistries for acceptable performance of the MoCs, especially those susceptible to localized corrosion. The testing included a series of electrochemical and hot-wall tests, and a six-month coupon immersion test. The electrochemical tests were targeted towards three areas of the DWPF: glycolic acid feed tanks, CPC components, and the remote equipment decontamination cell (REDC) components. Hot-wall tests were conducted to further clarify the observed localized corrosion during the first phase of testing for the heat transfer surfaces in the CPC and downstream facilities ( $2 \mathrm{H}$ evaporator and evaporator heater of the Effluent Treatment Facility). A sixmonth coupon immersion test was conducted to verify that the accelerated results of the electrochemical test for the CPC were substantiated for an extended exposure.

The results of the follow-up testing showed that for C276 under the CPC conditions localized corrosion (pitting, crevice and underdeposit corrosion) were found to occur at chloride and sulfate concentrations (the primary aggressive anions) as low as those processed in previous sludge batches. Deposits and coating occurred simultaneously and may be a contributing factor to the observed corrosion. These results occurred for both formic- and glycolic-based solutions with similar severity. The observed corrosion was not deep (less than $20 \mu \mathrm{m}$ ) and did not progress with time for a period up to six months. General corrosion rates in both glycolic- and formic-based solutions were found to be approximately 1 mil per year as specified in the DWPF Structural Integrity Program. Although the effect of mercury in these glycolic-based solutions was not studied extensively, mercury was found to impact the general corrosion rate but not the occurrence of localized corrosion. 
Test results (i.e. six-month coupon immersion) under CPC conditions from the second phase of testing were more limited for Ultimet and Stellite, which are wear resistant materials. The corrosion of these materials in both glycolic- and formic-based solutions was similar. The localized corrosion, which again was associated with the formation of deposits and coatings showed a slight progression with time during the six-month coupon immersion test. The impact of this corrosion on the erosion characteristics was not studied. Performance of these materials with the nitric-glycolic flowsheet is expected to be similar to the performance with the current nitric-formic flowsheet.

For other DWPF process areas, the glycolic acid feed tanks and the REDC, the impact of the glycolate anion differed. For the feed tank and associated components made of 304L stainless steel, the material was found to be susceptible to pitting in $70 \%$ glycolic acid at temperatures from room temperature up to $50{ }^{\circ} \mathrm{C}$. If $304 \mathrm{~L}$ components are chosen to handle $70 \%$ glycolic acid, an inspection program is recommended to determine if this occurs in the DWPF tanks or piping. Alternatively, tanks fabricated from 316L stainless steel should be used as the feed tanks for the $70 \%$ glycolic acid. Dilution of the glycolic acid was not investigated. For the REDC, the presence of glycolate in the cleaning solution will not impact MoC performance.

The results of both phases of testing showed that for the materials G30 and G3, the MoCs for the heating units in the $2 \mathrm{H}$ and ETF evaporators, localized corrosion was observed in the hot-wall tests regardless of the presence of the glycolate anion. Pit depths were found to be approximately 1 mil and associated with deposits whether the glycolate anion was present or not. The current operation of desalting or descaling in these facilities minimizes the formation of these deposits and would be expected to work with deposits from glycolate-containing waste.

Localized corrosion was found to occur in solutions with the glycolate anion at boiling, which simulated the conditions for CPC vessels, and in $70 \%$ glycolic acid at ambient temperature, which simulated the DWPF feed tanks and piping. This corrosion was not severe and may not impact service life. However, if components are removed from service within the CPC or a failure occurs, a failure or metallurgical analysis is recommended of the failure area or probable areas of corrosion. These data would be used to substantiate laboratory results and assess if localized corrosion would cause a leak. For the feed tanks and components which are housed outside of the CPC and are more accessible, UT inspections configured to establish localized corrosion occurrence are recommended at the start of glycolic acid service, especially for components fabricated of 304L stainless steel. These inspections would provide a baseline for determining the state of corrosion from future inspection data. Without the data from periodic inspections within the CPC, a failure after the switch to the nitric-glycolic flowsheet will make a failure assessment difficult because of the uncharacterized degradation caused during the nitric-formic flowsheet. 


\section{TABLE OF CONTENTS}

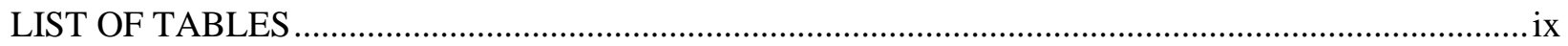

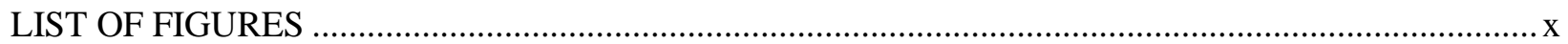

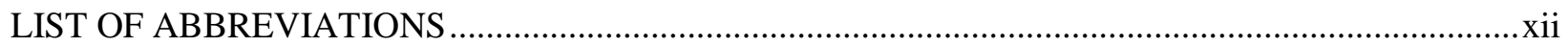

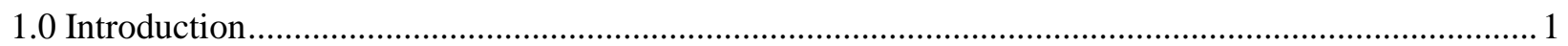

2.0 First Phase Results - Localized Corrosion Observations ................................................................ 1

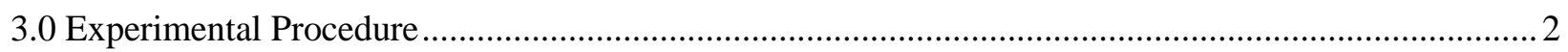

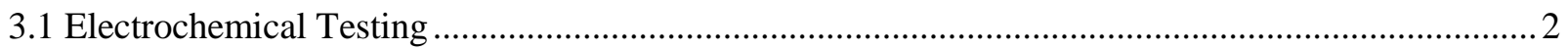

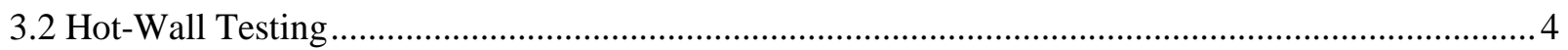

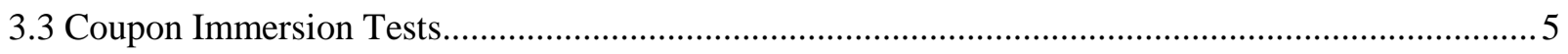

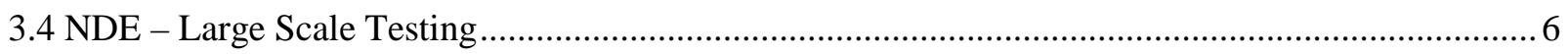

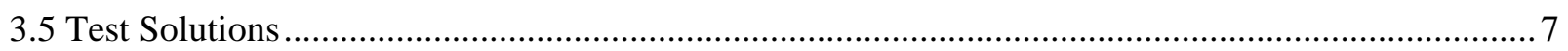

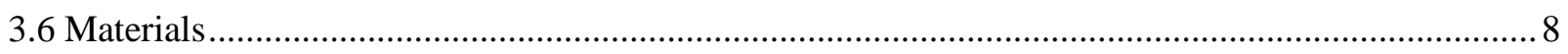

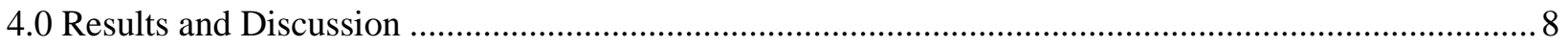

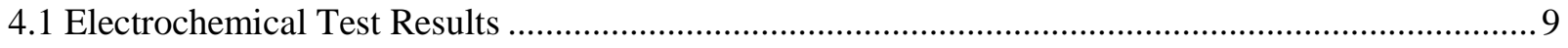

4.1.1 CPC Simulants from Flowsheet Development Testing …........................................................ 9

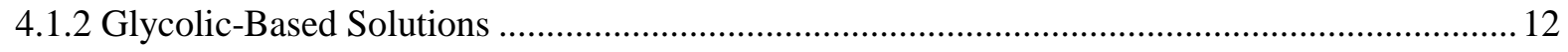

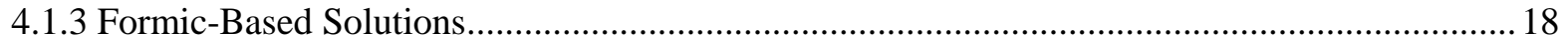

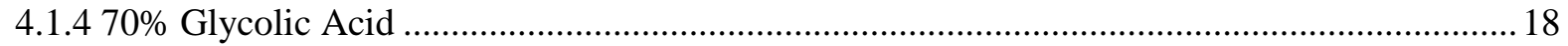

4.1.5 REDC Decontamination Solution - 12.5\% Nitric Acid ........................................................... 20

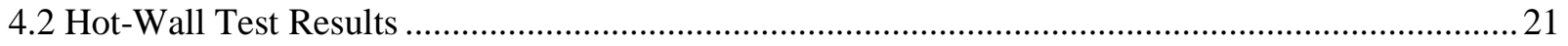

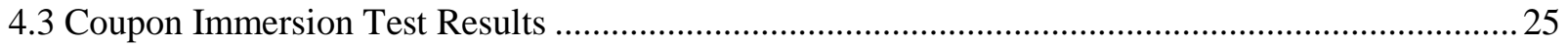

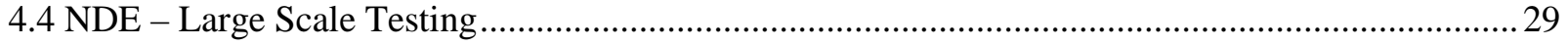

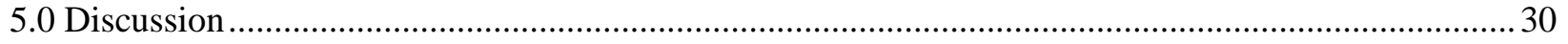

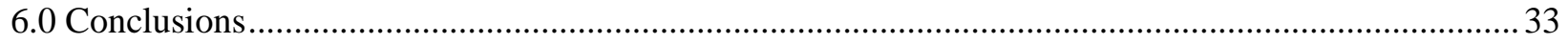

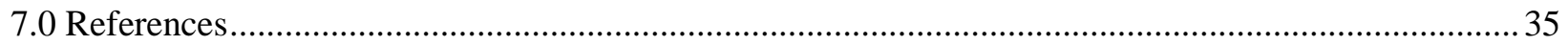

Appendix A . Test Solution Compositions .........................................................................................

Appendix B Coupon Immersion Test Results - Weight Losses and Calculated Corrosion Rates*.......... B-4 


\section{LIST OF TABLES}

Table 3-1. Material Values for Determining Corrosion Rate from Electrochemical Data ......................... 3

Table 3-2. Material Parameters for Calculating Corrosion Rate from Mass Loss.................................... 6

Table 3-3. Concentrations for Corrosive Species in Electrochemical Test Solutions ................................ 8

Table 3-4. Concentrations (ppm) for Corrosive Species in Hot-Wall (HW) and .................................... 8

Table 4-1. Material Compositions for Test Samples (wt\%) ............................................................... 9

Table 4-2. Average Electrochemical Parameters for CPC Simulants...................................................... 10

Table 4-3. DWPF Sludge Batch Concentrations for Chloride and Sulfate............................................. 13

Table 4-4. Electrochemical Solution Compositions and Results at $100{ }^{\circ} \mathrm{C}$ for Glycolate-based Solutions ${ }^{\alpha}$

Table 4-5. Electrochemical Solution Compositions and Results at $100{ }^{\circ} \mathrm{C}$ for Formic-based Solutions ${ }^{\alpha} .18$

Table 4-6. Hot-Wall Test Results from First Phase Testing [2] ..........................................................21

Table 4-7. Hot-Wall Test Results from Follow-up Testing ................................................................... 22

Table 4-8. Coupon Exposure and Mercury Addition Times during Coupon Immersion Test*................ 26

Table 4-9. Corrosion Rates for MoCs in Glycolic- and Formic-based CPC Solutions from the Six-month

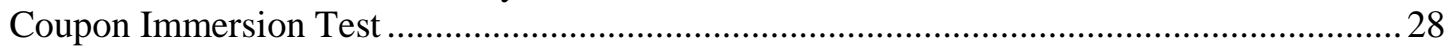

Table 4-10. Pit Count and Depth for DWPF MoC Samples from the Six-month Coupon Immersion Test 


\section{LIST OF FIGURES}

Figure 3-1. Polarization results from a ASTM G5 standardized test performed with potentiostat SN 85108 that was used during the alternate reductant testing

Figure 3-2. Hot-wall test apparatus for corrosion testing under heat transfer conditions ............................ 5

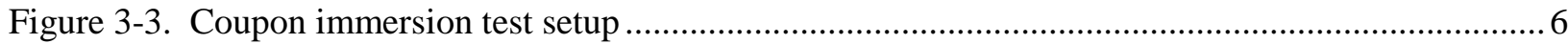

Figure 3-4. Large scale test vessel and heating coils: (A) coil photograph, (B) coil UT thickness locations, (C) vessel photograph, and (D) vessel UT thickness locations

Figure 4-1. CPP scans for CPC simulants produced using (A) a nitric-glycolic acid flowsheet (cpGNC100A and C) and (B) a nitric-formic acid flowsheet (cpSB8C100A and B)............ 10

Figure 4-2. Pitting of C276 in glycolic-based (A) and formic-based (B) CPC simulants which were produced during flowsheet development (for each simulant a micrograph and corresponding height scan, line profile, and measurement table are given) .11

Figure 4-3. Mn-rich coating that formed on C276 sample during CPP scan in formic-based CPC simulant: (A) center of coating and (B) near scratch made through coating

Figure 4-4. Open-circuit potential measurements over time in glycolic-based solutions showing the impact of mercury concentration

Figure 4-5. Cathodic polarization curves at high and low mercury concentrations 15

Figure 4-6. Effect of nitrate concentration on the CPP scans for C276 in glycolic-based solutions at boiling (arrow indicates decreasing nitrate concentration from 92,700 to 34,237 ppm) ....... 16

Figure 4-7. CPP scans for C276 in boiling glycolic-based solutions with different sulfate concentrations, ranging from 507 to $5571 \mathrm{ppm}$ (chloride concentration ranged from 0 to $35 \mathrm{ppm}$ )...... 16

Figure 4-8. CPP scans for C276 in boiling glycolic-based solutions with different chloride concentrations, ranging from 0 to 874 ppm (sulfate concentration ranged from 2000 to 2635 ppm)... 17

Figure 4-9. Chrono-current traces for potentiostatic tests at potentials within the positive hysteresis loop for boiling glycolic-based solutions with and without mercury

Figure 4-10. Open-circuit potentials of 304L stainless steel in 70\% glycolic acid at room temperature and $35^{\circ} \mathrm{C}$

Figure 4-11. CPP scans for 304L in 70\% glycolic acid at room temperature and $35^{\circ} \mathrm{C}$. 19

Figure 4-12. Micrographs of 304L stainless steel after electrochemical testing in 70\% glycolic acid at (A) room temperature and (B) $35^{\circ} \mathrm{C}$

Figure 4-13. Laser-height scan for 304L stainless steel after electrochemical testing in 70\% glycolic acid at $35^{\circ} \mathrm{C}$ (for micrograph in Figure 4-12 (B)). 20

Figure 4-14. Alloy 20 in a boiling 12.5\% nitric acid solution: (A) CPP scan for solutions with and without the glycolate anion and (B) micrograph of sample surface tested in solution containing the glycolate anion 
Figure 4-15. Post-test photographs of C276 hot-wall test samples after month exposure at boiling conditions: (A) follow-up test sample; and (B) first phase test sample

Figure 4-16. C276 hot-wall test sample after exposure to a formic-based solution showing sectioning prior to examination for localized corrosion (only one cut shown).....

Figure 4-17. C276 hot-wall sample after testing in the formic-based SRAT/SME supernate: (A) crosssectional view (400x) of Slice \#2 showing sub-surface pit; (B) cross-sectional view (400x) from Slice \#1 showing surface pit.

Figure 4-18. C276 hot-wall sample after testing in the formic-based solution: (A) profile line shown in Figure 4-17(A) through sub-surface pits; and (B) profile line shown in Figure 4-17 (B) through surface pit.

Figure 4-19. G30 hot-wall samples exposed to a boiling basic concentrated recycle solution: (A) post-test photograph showing silicon-rich film; and (B) post-cleaning photograph after removal of film (black spots showing locations of observed pitting....

Figure 4-20. Post-test photographs of G3 hot-wall sample exposed to a boiling dilute waste solution with (A) and without (B) the glycolate anion. 25

Figure 4-21. Photographs of C276 coupons from the coupon immersion test after (A) 1 month, (B) 3 months, and (C) 6 months exposure in Solution \#1

Figure 4-22. Photographs of welded C276 coupons from the coupon immersion test after six-month exposure in (A) Solution \#1, (B) Solution \#2, (C) Solution \#3, and (D) Solution \#4........... 27

Figure 4-23. Photographs of five-month exposure coupons: (A) Stellite 6B in Solution \#3; (B) Stellite 6B in Solution \#4; (C) Ultimet in Solution \#3; and (D) Ultimet in Solution \#4.

Figure 4-24. UT measurements of the $1 / 200^{\text {th }}$ scale test vessel and coils: (A) vessel diagram with arrows showing coil measurement location; and (B) UT thickness measurements for lowest $\left(1^{\text {st }}\right)$ ring of the outer coil welds along the bottom surface $\left(180^{\circ}\right.$ position $)$ 


\section{LIST OF ABBREVIATIONS}

$\begin{array}{ll}\text { AP } & \text { Applied Potential } \\ \text { ASTM } & \text { ASTM International } \\ \text { CPC } & \text { Chemical Processing Cell } \\ \text { CPP } & \text { Cyclic Potentiodynamic Polarization } \\ \text { CR } & \text { Corrosion Rate } \\ \text { DWPF } & \text { Defense Waste Processing Facility } \\ \text { E }_{\text {corr }} & \text { Corrosion Potential (V, SCE) } \\ \text { E }_{\text {pp }} & \text { Pit Protection Potential (V, SCE) } \\ \text { EDS } & \text { Energy Dispersive Spectroscopy } \\ \text { ETF } & \text { Effluent Treatment Facility } \\ \text { EW } & \text { Equivalent Weight } \\ \text { GA } & \text { Glycolic Acid } \\ \text { HLW } & \text { High Level Waste } \\ \text { i }_{\text {pass }} & \text { Passive current density (A/cm }{ }^{2} \text { ) } \\ \text { IGA } & \text { Intergranular Attack } \\ \text { LCM } & \text { Laser Confocal Microscope } \\ \text { LPR } & \text { Linear Polarization Resistance } \\ \text { MCU } & \text { Modular Caustic-side Solvent Extraction Unit } \\ \text { MFT } & \text { Melter Feed Tank } \\ \text { mo (mos) } & \text { Month(s) } \\ \text { MoC } & \text { Material of Construction } \\ \text { mpy } & \text { Mils per year } \\ \text { ND } & \text { No Data } \\ \text { NDE } & \text { Non-Destructive Testing } \\ \text { OCP } & \text { Open Circuit Potential } \\ \text { ppm } & \text { parts per million } \\ \text { REDC } & \text { Remote Equipment Decontamination Cell } \\ \text { REDOX } & \text { Reduction/Oxidation Reaction } \\ \text { SA } & \text { Surface Area } \\ \text { SCE } & \text { Saturated Calomel Electrode } \\ \text { SEM } & \text { Scanning Electron Microscope } \\ \text { SME } & \text { Slurry Mix Evaporator } \\ \text { SRNL } & \text { Savannah River National Laboratory } \\ \text { SRR } & \text { Savannah River Remediation, LLC } \\ \text { UT } & \text { Ultrasonic Thickness } \\ \text { WAC } & \text { Waste Acceptance Criteria } \\ & \end{array}$




\subsection{Introduction}

Savannah River Remediation (SRR) is preparing for a new alternate reductant flowsheet for the Defense Waste Processing Facility (DWPF), specifically a nitric acid-glycolic acid flowsheet. DWPF requested a corrosion assessment from the Savannah River National Laboratory (SRNL) for the components of the DWPF facility and the other high level waste (HLW) and low level waste processing facilities that would be exposed to glycolic acid or the glycolate anion [1]. Testing was conducted for both aqueous and glass environments [2]. Additional testing was required to further investigate several results where the corrosion behavior could not be definitely determined. This report presents and discusses the electrochemical, hot-wall, and coupon immersion test results that were performed to further clarify the corrosion in aqueous environments with the glycolate anion present. The follow-up testing for the melter refractory material will be covered in a separate report.

A literature review was conducted prior to any testing and showed that there was insufficient corrosion data available to assess the impact of glycolic acid on the DWPF and downstream waste processing facilities [3]. Data on the material compatibility with just glycolic acid or its derivative products was identified; however, data were limited for solutions containing glycolic acid and other species that would be present in the DWPF, Tank Farm, and Modular Caustic Side Solvent Extraction Unit (MCU) facilities. Corrosion testing was necessary to provide data to evaluate the corrosion compatibility for the specific materials of construction (MoC) and expected service conditions.

The first phase for aqueous corrosion testing consisted of electrochemical tests, hot-wall tests, and a coupon exposure test performed in conjunction with the intermediary ( $22 \mathrm{~L}$ ) scale-up testing for the chemical process cell (CPC) flowsheet development. The test conditions simulated the service conditions for DWPF and downstream facilities. The expected performance of the MoCs within the DWPF CPC and feed tanks was questionable due to the susceptibility to localized corrosion identified during this testing. Since the glycolate anion concentration is at the highest in the CPC for the whole HLW processing system, determining operating conditions where localized corrosion is a concern was stressed. Localized corrosion was also observed for the MoCs of heat transfer surfaces in downstream facilities.

The follow-up testing included a series of accelerated electrochemical and hot-wall tests, and a six-month coupon immersion test. These tests were recommended to better identify the waste chemistries for acceptable performance of the MoCs, especially those susceptible to localized corrosion. The electrochemical tests were targeted towards three areas of the DWPF: glycolic acid feed tanks, CPC components, and the remote equipment decontamination cell (REDC) components. Hot-wall tests were conducted to further clarify the observed localized corrosion during the first phase of testing for the heat transfer surfaces in the CPC and downstream facilities $(2 \mathrm{H}$ evaporator and evaporator heater of the Effluent Treatment Facility). A six-month coupon immersion test was conducted to verify that the accelerated results of the electrochemical test were substantiated for an extended exposure.

\subsection{First Phase Results - Localized Corrosion Observations}

During the first phase of testing, localized corrosion was identified for a few solutions tested in electrochemical and hot-wall tests. The observed localized corrosion was pitting, crevice and underdeposit corrosion. Pitting occurred during electrochemical tests with 304L stainless steel (304L) in $70 \%$ glycolic acid at $50{ }^{\circ} \mathrm{C}$ and with $\mathrm{C} 276$, Stellite ${ }^{\circledR}$ 6B, and Ultimet ${ }^{\circledR}$ in CPC simulants at $95-100{ }^{\circ} \mathrm{C}$. The CPC test solutions were based on simulants from experiments conducted during the trials on the efficacy of glycolic acid as an alternate reductant [4] and were composed of a range of aggressive species (chloride, sulfate, and mercury). For both the $70 \%$ glycolic acid and the CPC solutions, pitting was not observed on all samples during duplicate runs. 
Additional testing was needed to determine the waste chemistries, specifically the chloride and sulfate concentrations, where localized corrosion was not observed when the glycolate anion was present. Electrochemical tests were to be performed first to identify possible concentration limits of aggressive species where localized corrosion was not observed, as well as, to perform test in formic acid based solutions to establish baseline data for current DWPF operations. A coupon immersion test would follow with more limited conditions to evaluate the change over an extended period (3 to 6 months).

Pitting, crevice, and underdeposit corrosion were all observed during hot-wall tests for C276 and Ultimet ${ }^{\circledR}$ in a CPC solution, for G30 in a basic recycle simulant, and for G3 in a dilute waste simulant. Hot-wall tests are conducted at boiling conditions with heat transfer through the test sample. The occurrence of this corrosion might have been due to the large change in solution. The solution volume was $500 \mathrm{ml}$ and due to the high heat input quickly boiled down, requiring frequent replenishment. This fast volume change lead to a large amount of precipitates and surface deposits. Previous results by Chandler et al [5] also noted deposits during the hot-wall testing performed with a 2-3 L test volume, although no localized corrosion was noted. The smaller volume was initially used to minimize the generation of large quantities of hazardous waste. The follow-up hot-wall tests were recommended to determine if the small initial solution volume and large change in solution composition resulted in the observed localized corrosion. Testing in formic-based solutions was also needed to establish baseline data for current DWPF operations and comparison to data from glycolic-based solutions.

\subsection{Experimental Procedure}

The follow-up testing consisted of three primary test types: electrochemical, which included a series of techniques, hot-wall, and coupon immersion. Additionally, the vessel and coils that were used for the large scale $\left(1 / 200^{\text {th }}\right.$ scale) testing for the CPC flowsheet development were also examined using nondestructive examination (NDE). The test techniques/protocols, solutions, and materials used for these tests are discussed.

\subsection{Electrochemical Testing}

The electrochemical testing was chosen as an accelerated method to determine if the glycolic acid would impact the localized corrosion resistance of the MoCs as well as to measure a general corrosion rate. The electrochemical testing followed the guidelines given in applicable ASTM International standards [6-9]. The electrochemical testing consisted of a series of individual tests including open-circuit potential measurement, linear polarization resistance and cyclic potentiodynamic polarization.

Open-circuit potential (OCP) monitoring was used to follow the equilibration of the sample in the test solution and varied from one hour up to a maximum of three hours. In some cases the sample had not fully equilibrated within the three-hour period. Immediately at the end of the OCP monitoring, linear polarization resistance (LPR) was performed to determine a general corrosion rate. This test involves application of a scanning potential ramp $(0.2 \mathrm{mV} / \mathrm{sec})$ over a potential range of $+/-15 \mathrm{mV}$ around the OCP. From the plot of the potential and resulting current, a polarization resistance value $\left(R_{p}\right)$ is determined and Equation 1 is used to calculate a general corrosion rate (CR) for the material.

$$
\mathrm{CR}=3.2710^{3} \times \mathrm{B} \times \mathrm{EW} /\left(\mathrm{R}_{\mathrm{p}} \times \rho \times \mathrm{SA}\right)
$$

\{Equation 1$\}$

where B is a constant related to the electrochemical behavior of the material in the environment, 0.026 for this testing; EW is the equivalent weight (g) of the material; $\rho$ is the material density $\left(\mathrm{g} / \mathrm{cm}^{3}\right)$; and SA is the surface area of the sample $\left(\mathrm{cm}^{2}\right)$. The material values are given in Table 3-1 for those materials used in the follow-up testing only. 
Table 3-1. Material Values for Determining Corrosion Rate from Electrochemical Data

\begin{tabular}{|c|c|c|c|}
\hline Material & $\begin{array}{c}\text { Surface } \\
\left.\text { Area* } \mathbf{( c m}^{\mathbf{2}}\right)\end{array}$ & $\begin{array}{c}\text { Density } \\
\mathbf{( g / \mathbf { c m } ^ { 3 } )}\end{array}$ & $\begin{array}{c}\text { Equivalent } \\
\text { Weight }\end{array}$ \\
\hline 304L & 3 & 7.96 & 25.12 \\
\hline C276 & 2 & 8.8 & 27.09 \\
\hline
\end{tabular}

* Approximate values

At the conclusion of the LPR, a cyclic potentiodynamic polarization (CPP) was performed to assess the susceptibility to localized corrosion. In this technique, a potential ramp $(0.2 \mathrm{mV} / \mathrm{sec})$ is applied towards more electropositive potentials reaching a defined vertex potential where the potential scan direction is reversed back to the OCP. The potential/responding current plot provides data on the passivity and susceptibility to pitting, crevice corrosion and stress corrosion cracking. An indication of pitting susceptibility is a positive hysteresis which occurs when the reverse scan is at larger currents than those of the forward $\operatorname{scan}^{1}$. A pit protection potential $\left(E_{p p}\right)$ is defined where the reverse scan for a plot that exhibits positive hysteresis crosses the forward scan.

Potentiostatic testing was performed for some solution chemistries to investigate the occurrence of pitting. During the test a constant potential is applied to a sample for a desired time and the responding current is measured. The potential was chosen within the positive hysteresis loop observed in a CPP scan. The current-time behavior in conjunction with the sample's physical condition indicates the growth of stable pits. These tests were conducted for one hour, which is longer than the $1-2$ minutes a sample is at potentials within the positive hysteresis loop during a CPP scan.

The electrochemical tests were performed using Ametek PAR Model 273A potentiostat/galvanostats in conjunction with a laptop computer and Scribner Associates Inc. CorrWare ${ }^{\circledR}$ software. The test cell consisted of borosilicate glass five-port flasks with a standard three-electrode set up: a reference, counter and working electrodes. The counter electrode was 0.25 -inch diameter graphite rods, while the reference electrode was a saturated calomel electrode (SCE, $+0.243 \mathrm{mV}$ vs Normal Hydrogen Electrode). All potentials in this report are given in reference to the SCE potential. Prior to each test, the reference electrode potential was verified against that of an unused reference maintained in a saturated potassium chloride solution. After the potential check, the reference electrode was placed in a salt bridge containing $0.1 \mathrm{M}$ sodium nitrate solution. In tests greater than $50{ }^{\circ} \mathrm{C}$, water-cooled salt bridges were used to maintain the reference electrode at a constant value.

The potentiostat performance was verified following the test guidelines given in ASTM International G5 standard test method [6]. The data shown in Figure 3-1 for one of the potentiostats demonstrates that for a standardized test condition (430 stainless steel in de-aerated $1 \mathrm{~N}$ sulfuric acid at $30{ }^{\circ} \mathrm{C}$ ) the measured currents are within the acceptable minimum and maximum ranges both prior to and at the conclusion of testing. The other potentiostats had similar acceptable behavior.

The working electrode was one of the candidate materials of construction. Each sample had a Teflon ${ }^{\circledR}$ coated copper wire attached to the back with a conductive silver epoxy. The sample with attached wire was placed in a metallurgical mount with fast-set epoxy. The mount exposed one surface of the sample for testing and facilitated surface preparation with 600-grit silicon carbide paper prior to testing. Samples were used multiple times and prepared prior to the start of each test by grinding on 600-grit paper and rinsing with the following sequence - water, acetone, water - then blowing dry. At the conclusion of the test, the samples were examined for corrosion. Pictures were taken on a laser confocal microscope (LCM) along with scans for characterizing any observed pitting (pit depths). The LCM brings a higher

\footnotetext{
${ }^{1}$ A negative hysteresis occurs when the reverse scan is at lower currents than the forward scan.
} 
level of examination for identifying surface features and measuring a depth, which may not be indicative of corrosion.

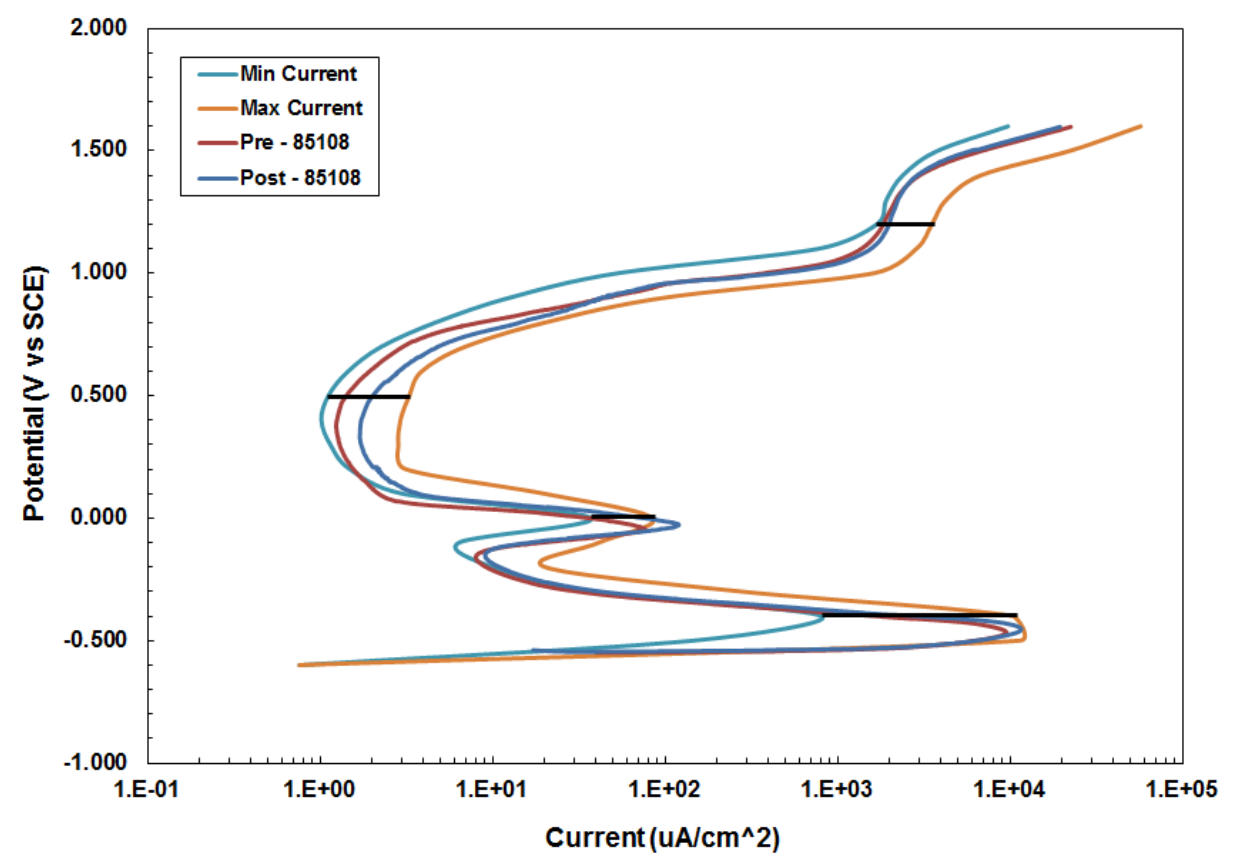

\section{Figure 3-1. Polarization results from a ASTM G5 standardized test performed with potentiostat SN 85108 that was used during the alternate reductant testing}

Test solutions were prepared just prior to performing the test and prepared in 1.2L batches. Test solutions are discussed in a following section. The solution volume for each test was approximately $600 \mathrm{ml}$. Each test condition, i.e. temperature, solution chemistry, material, was performed in duplicate. All duplicate tests were not performed with the same batch of solution, which contributed to some of the data variability. At the conclusion of testing, some deposits were generally seen in the bottom of the test cell. Measurement of the solution $\mathrm{pH}$ was made before and after each test. Tests were generally performed without mixing or bubbling of air. The natural convection of solutions due to heating from the bottom provided for solution mixing, especially at boiling conditions.

\subsection{Hot-Wall Testing}

Hot-wall tests are performed to determine corrosion rates for materials exposed to solutions under heat transfer conditions. The hot-wall test was discussed in greater detail in Reference 5. The hot-wall apparatus is shown in Figure 3-2. The sample is clamped in position with the heater block on one side and the glass vessel, which contains the solution, on the other. A gasket made of ethylene propylene diene terapolymer is used to form the seal between the sample and the glass vessel. Solution volume was approximately $2.5 \mathrm{~L}$. Solution levels dropped during testing due to evaporation and were replenished on an alternating schedule between fresh solution and distilled water so as not to concentrate constituents.

The heater blocks were operated at full power to generate a maximum temperature on the sample surface. A thermocouple was placed through a port on the glass vessel so as to just touch the sample surface. Thermocouples, which plugged into the heater block, were used to control the operation of the heater. Once at temperature, the tests were conducted for approximately 1 month.

Testing was performed on MoC for the heating coils in the CPC vessels (C276), the tube bundle and warming coils for the $2 \mathrm{H}$ evaporator (G30) and the heater for the Effluent Treatment Facility (ETF) 
evaporator (G3). Samples, which were procured from Metal Samples (Munford, AL), had surfaces prepared with a 600-grit silicon carbide paper. Samples were 3-inch diameter and had a thickness of 1/8 to $1 / 16$ inch. The solutions used to clean the samples after testing were nitric acid solutions from $0.1 \mathrm{M}$ up to $2.0 \mathrm{M}$. The sample tested in the formic-based solution had a tenacious coating on the exposed surface at the conclusion of the test. Other cleaners, including sodium hydroxide ( $\mathrm{pH} \mathrm{14)} \mathrm{solutions} \mathrm{and}$ glycolic acid, were tried but were ineffective. At the conclusion of the hot-wall test and after cleaning, the samples were examined for corrosion using a LCM. Laser scans were taken to characterize any localized corrosion.

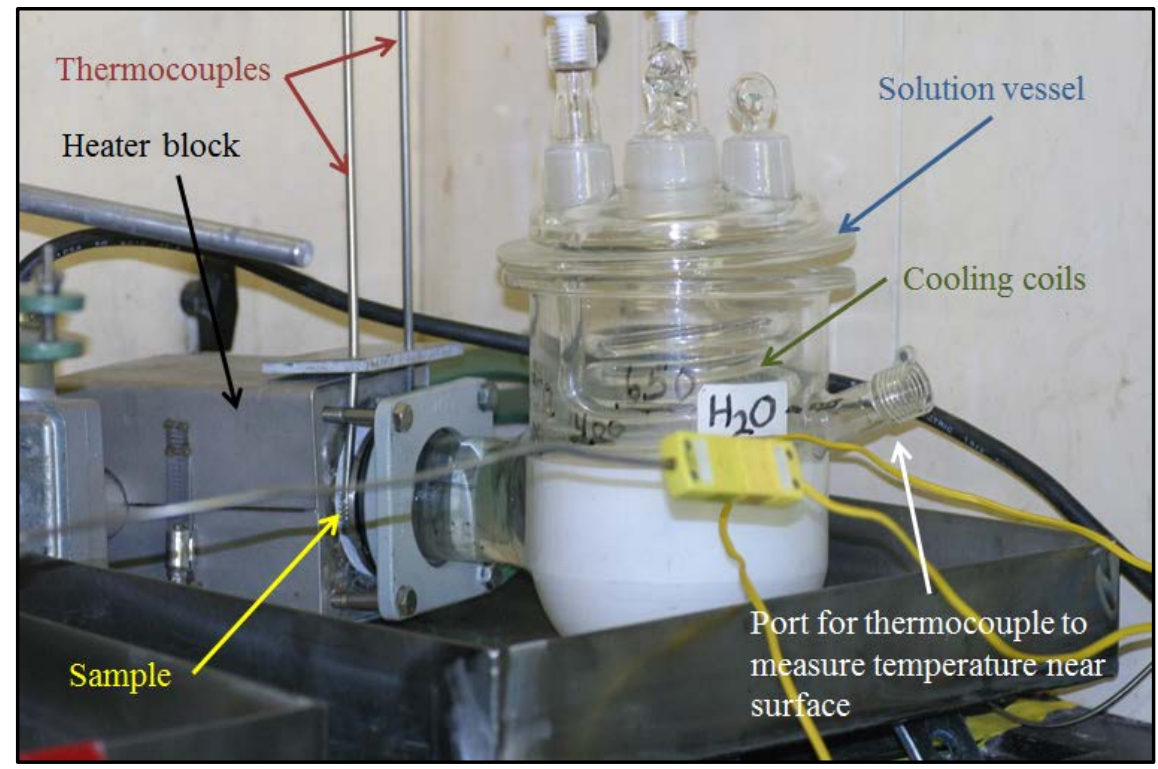

Figure 3-2. Hot-wall test apparatus for corrosion testing under heat transfer conditions

\subsection{Coupon Immersion Tests}

Laboratory coupon immersion tests are used to assess the corrosion performance of materials and to understand the influencing factors under controlled but simulated industrial environments. The SRNL coupon immersion testing followed the guidelines given in ASTM International standard G31 [10]. The coupon immersion tests were performed to evaluate the corrosion in the CPC vessels over an extended period (up to 6 months) with simulated CPC supernates and typical operating temperatures (i.e. boiling). The tests were conducted in borosilicate glass containers using laboratory digital hot-plates for temperature control. Figure 3-3 shows the laboratory set up where four different solutions were tested. Each container had a condenser to minimize evaporative losses.

The test solutions were based on the results from the electrochemical testing and were chosen to bracket a range of sulfate concentration since it was shown to be the dominant aggressive species for localized corrosion. The chloride concentration has typically been below $100 \mathrm{ppm}(\mathrm{mg} / \mathrm{L})$ for the DWPF sludge batches and HLW processing at the Savannah River Site is not expected to introduce additional chloride species to increase the concentration in the waste. Three glycolic-based compositions and one formicbased composition were chosen. Besides the reductant, the sulfate, nitrate, chloride, and mercury concentrations were also variables. The solution chemistries are discussed further in Section 3.5. 


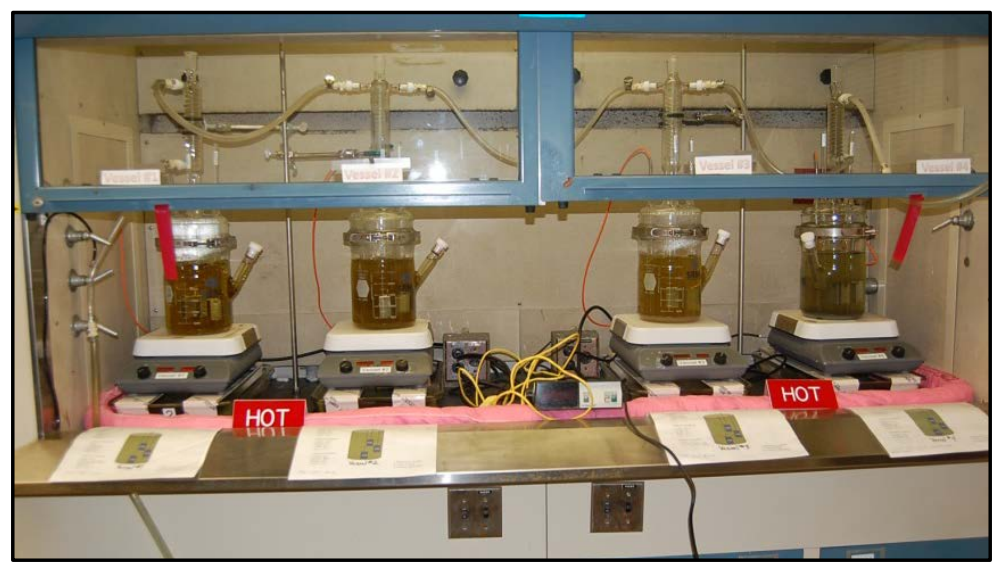

Figure 3-3. Coupon immersion test setup

The materials tested were those that are the MoCs within the CPC and at high temperatures, i.e. C276, Ultimet, and Stellite. C276 is used for the vessels and most components exposed to the waste at elevated temperatures. Ultimet cover plates are used on the heating coils adjacent to the supports to minimize wear in the slurry mix evaporator (SME). Stellite is used around the cooling coil guides in the SME, sludge receipt adjustment tank (SRAT) and the melter feed tank. Coupons were procured from Metal Samples (Munford, AL) and had surfaces prepared with a 600-grit silicon carbide paper. A welded C276 sample was also included for this testing. Coupon dimensions are shown in Table 3-2.

Coupons were exposed on borosilicate supports that were hung from the container lid. Sets of coupons were exposed for $1,3,4,5$, and 6 months. Coupons were cleaned with a mild alkaline cleaner, thoroughly rinsed with water, rinsed with ethyl alcohol and blown dry before testing. After exposure, the coupons were cleaned using nitric acid solutions $(0.1 \mathrm{M})$. Coupons were weighed before and after testing to calculate corrosion rates through mass loss according to Equation 2.

$$
\mathrm{CR}=(\mathrm{K} \times \mathrm{W}) /(\mathrm{SA} \times \mathrm{T} \times \rho)
$$

\{Equation 2\}

Where $\mathrm{K}$ is a constant $\left(3.45 \times 10^{6}\right.$ for units of mils per year (mpy)), $\mathrm{W}$ is mass loss (grams (g)), SA is the surface area of the coupon $\left(\mathrm{cm}^{2}\right)$, $\mathrm{T}$ is exposure time (hours (hr)), and $\rho$ is the material density $\left(\mathrm{g} / \mathrm{cm}^{3}\right)$. The values for the materials used in this testing are shown in Table 3-2.

Table 3-2. Material Parameters for Calculating Corrosion Rate from Mass Loss

\begin{tabular}{|c|c|c|c|}
\hline Material & $\begin{array}{c}\text { Dimensions } \\
(\mathbf{c m})\end{array}$ & $\begin{array}{c}\text { Surface Area } \\
\left(\mathbf{c m}^{\mathbf{2}}\right)\end{array}$ & Density $\mathbf{( g / \mathbf { c m } ^ { 3 } )}$ \\
\hline C276 & $5.08 \times 2.54 \times 0.32$ & 31.22 & 8.8 \\
\hline C276W & $5.08 \times 2.54 \times 0.32$ & 31.22 & 8.8 \\
\hline Stellite & $5.08 \times 2.54 \times 0.15$ & 28.34 & 8.52 \\
\hline Ultimet & $5.08 \times 2.54 \times 0.15$ & 28.34 & 8.47 \\
\hline
\end{tabular}

\subsection{NDE - Large Scale Testing}

The vessel and coils for the large scale testing during the CPC flowsheet development were used as large coupons. Ultrasonic thickness (UT) measurements were made to evaluate the erosion/corrosion loss during this two-week test [11]. Measurement locations are shown in Figure 3-4 for both the vessel and 
coils. The MoC is 14 gage 304L stainless steel. Baseline measurements were made prior to testing at several locations including in areas where corrosion or erosion might be more probable. For the coils, 249 measurements were made around the circumference of approximately four rings and on inlets and outlets that were above the liquid level. Near the outer radius, thickness measurements were typically 0.033 inch and at the inner radius 0.035 inch. The thinnest reading was 0.03 inch. Thickness values at 7 circumferential welds were also obtained ranging from 0.022 to 0.035 inch (lowest values may be associated with less than full penetration welds). The twenty-four baseline vessel thickness measurements ranged from 0.049 to 0.073 inch.

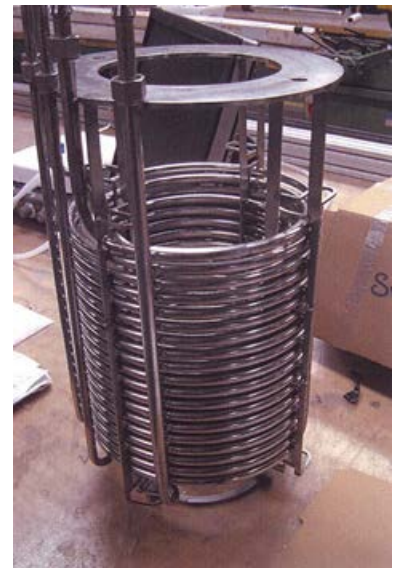

(A)

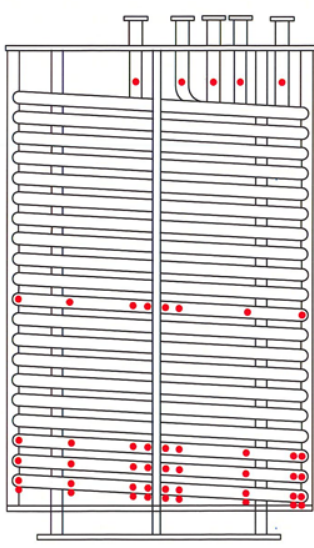

(B)

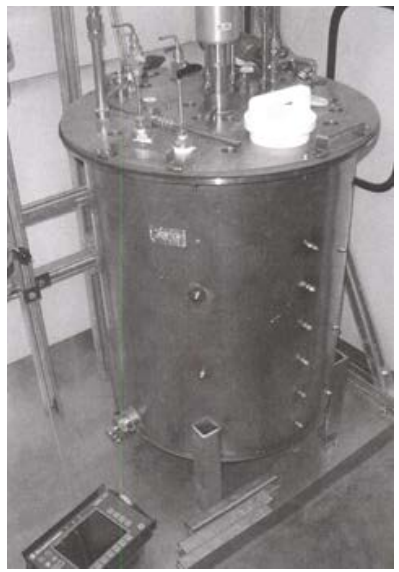

(C)

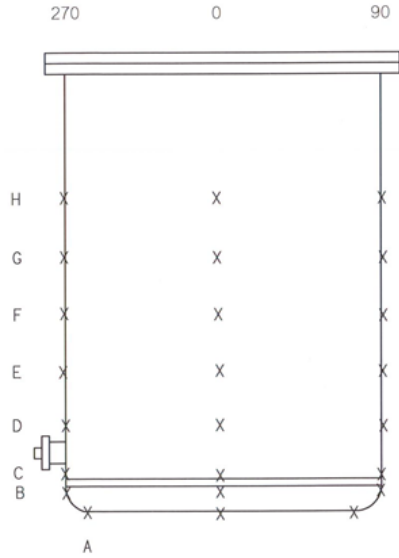

(D)

Figure 3-4. Large scale test vessel and heating coils: (A) coil photograph, (B) coil UT thickness locations, (C) vessel photograph, and (D) vessel UT thickness locations

\subsection{Test Solutions}

The test solutions were either $70 \%$ glycolic acid or multi-component CPC solutions based initially on a simulant supernate chemistry generated during the first phase of the nitric acid-glycolic acid flowsheet development. The glycolic acid was used as provided by the supplier (stock bottle, reagent grade) and is the expected starting concentration for use in DWPF.

The baseline CPC simulant composition from the flowsheet development is shown in Appendix A, Table A-1. The primary component concentrations that were altered for this testing were the corrosive species, chloride, sulfate, nitrate and mercury, since these species affect the corrosion of the MoCs. Mercury was not in the baseline compositions since this composition was based on a SME supernate after mercury reduction. Mercury, however, will be present in sludge batches that are fed to the DWPF and be present in the process solution during reduction carried on in the SRAT. Test solutions were made with standard reagent grade chemicals and distilled water. Chemicals were added in the order given in Appendix A, Table A-2, allowing a chemical to completely dissolve prior to adding the next chemical. The highest used mercury addition was near the solubility limit of the solution, i.e. an additional quantity would not dissolve ( $\sim 7$ grams), although most quantities were far less ( 300 mg). Most solutions were made one day ahead of use.

For the electrochemical tests a range of the corrosive species were tested to determine limits for the occurrence of localized corrosion in glycolic-based solutions as well as obtain baseline data for formicbased solutions. The concentration ranges for these species are shown in Table 3-3. 
Table 3-3. Concentrations for Corrosive Species in Electrochemical Test Solutions

\begin{tabular}{|c|c|}
\hline Species & Range $\mathbf{( p p m )}$ \\
\hline Chloride & $100-823$ \\
\hline Sulfate & $1300-5200$ \\
\hline Nitrate & $27500-92700$ \\
\hline Mercury & $0-300$ \\
\hline
\end{tabular}

The test solutions for the hot-wall (HW) and coupon immersion (CI) tests were based on the results from the electrochemical tests. The concentrations (ppm) of corrosive species for these solutions are shown in Table 3-4. For the hot-wall tests, a single composition was used for both glycolic-based and formic-based solutions, which were the same compositions also used as part of the coupon immersion test. For the coupon immersion, three different compositions were used for the glycolic-based solutions and one for the formic-based solution. Initially, mercury was present in only one solution (Glycolic \#1), however, after three months of testing mercury was added to the remaining solutions to assess the impact of mercury on the corrosion of the CPC MoCs.

Table 3-4. Concentrations (ppm) for Corrosive Species in Hot-Wall (HW) and Coupon Immersion (CI) Tests Solutions

\begin{tabular}{|c|c|c|c|c||}
\hline \multirow{2}{*}{ Species } & \multicolumn{2}{|c|}{ HW and CI Solutions } & \multicolumn{2}{c||}{ CI Solutions } \\
\cline { 2 - 5 } & Glycolic \#1 & Formic \#1 & Glycolic \#2 & Glycolic \#3 \\
\hline Chloride & 97 & 50 & 50 & 97 \\
\hline Sulfate & 5570 & 2000 & 2000 & 2635 \\
\hline Nitrate & 98347 & 42000 & 43350 & 98347 \\
\hline Mercury & $\sim 300$ & $*$ & $*$ & $*$ \\
\hline
\end{tabular}

* After three months of testing in the CI test, 300 ppm was added to these solutions

Two other test solutions used for the hot-wall tests were a dilute waste chemistry and basic concentrated recycle, which were representative of feed solutions for the ETF heaters and the $2 \mathrm{H}$ evaporator, respectively. In the first phase of testing these solutions with the glycolate anion present resulted in localized corrosion for the MoCs of these components. The occurrence of the corrosion was hypothesized to have resulted from the significant change in the solution due to the small volume of test solution used ( $500 \mathrm{ml}$ versus the standard 2-2.5 L). These changes lead to numerous deposits. Two hot-wall tests were performed for each MoC with and without the glycolate anion present. The compositions of these solutions are shown in Appendix A, Tables A-3 and A-4.

\subsection{Materials}

The materials for testing were the MoCs for the DWPF feed tanks and piping, CPC vessels and components, the REDC soak tank, the $2 \mathrm{H}$ evaporator, and the ETF evaporator. Samples were obtained from Metal Samples, Inc. (Munford, AL). The material compositions (wt\%) for the electrochemical samples were verified through $\mathrm{x}$-ray fluorescence and are shown in Table 3-5. All samples were prepared with a final surface finish from 600-grit silicon carbide grinding paper and cleaned with a mild detergent and ethyl alcohol prior to use.

\subsection{Results and Discussion}

The experimental work during this follow-up testing centered on the DWPF vessels and components and included electrochemical, hot-wall and coupon immersion testing. NDE also was performed on the $1 / 200^{\text {th }}$ scale vessel and heating coils used with the scale up testing for the flowsheet development. These measurements were made to assess the erosion/corrosion potential of the glycolic-based simulants. 
Follow-up hot-wall test were also performed for the downstream facilities of the $2 \mathrm{H}$ evaporator and ETF evaporator heat transfer surfaces.

Table 4-1. Material Compositions for Test Samples (wt\%)

\begin{tabular}{||c|c|c|c|c|c|c|c|c|c||}
\hline \hline Material & Cr & Ni & Fe & Mn & Mo & Si & W & Co & Other \\
\hline C276 & 15.5 & 57.8 & 6.3 & 0.5 & 14.2 & 0.3 & 3.3 & 1.8 & \\
\hline 304L & 18.5 & 8.8 & 69.7 & 1.8 & 0.2 & 0.5 & - & - & $0.3 \mathrm{Cu}$ \\
\hline Stellite ${ }^{\circledR} 6$ & 30.4 & 2.3 & 2.1 & 1.6 & 0.8 & 0.5 & 4 & 57.2 & \\
\hline Ultimet ${ }^{\circledR}$ & 25.2 & 9.2 & 3.2 & 0.8 & 5.1 & 0.4 & 2 & 53.9 & \\
\hline G30 & 28.8 & 40.4 & 14.9 & 1.1 & 5 & 0.3 & 3.1 & 3.6 & $1.9 \mathrm{Cu}, 0.7 \mathrm{Nb}, 0.2 \mathrm{Al}$ \\
\hline G3 & 22.3 & 44 & 19.8 & 0.8 & 7.6 & 0.5 & 0.9 & 1.9 & $2 \mathrm{Cu}$ \\
\hline Alloy 20 & 20 & 35 & Bal & 2 & 1.5 & 1 & - & - & $3.5 \mathrm{Cu}, 1 \mathrm{Cb}+\mathrm{Ta}$ \\
\hline
\end{tabular}

\subsection{Electrochemical Test Results}

Electrochemical tests were performed to better understand the occurrence of localized corrosion with a glycolic-based solution and to generate baseline data in formic-based solutions for comparison. These data were used to establish the solution compositions for the hot-wall and coupon immersion testing, which are performed to evaluate corrosion over time. The electrochemical tests were focused on C276, the primary MoC of the DWPF CPC. Additionally, electrochemical testing was also performed for the MoC of some feed tanks (304L) with 70\% glycolic acid and of the decontamination cell soak tank (Alloy 20 ) located in the REDC which uses a $12 \%$ nitric acid solution.

\subsubsection{CPC Simulants from Flowsheet Development Testing}

During the follow-up testing, two CPC simulants from flowsheet development testing ${ }^{2}$ were evaluated to create baseline data for C276 from these processed simulants for comparison to data from solutions prepared from stock chemicals [2]. One simulant came from processing of a simulated Sludge Batch \#7 waste using the nitric-glycolic acid flowsheet, while the other simulant was produced using the current nitric-formic acid flowsheet and a Sludge Batch \#8 feed. Both simulants were made with higher acid stoichiometry, $110 \%$ and $140 \%$ for Sludge Batches \#7 and \#8, respectively. The analyzed chemistries for the simulants are shown in Appendix A, Table A-1. A mercury concentration was not available, but since the experimental processing included SME processing, soluble mercury was believed to be minimal.

The chemistries for the two CPC simulants were similar for most elements and compounds. Besides the expected differences in glycolate and formate concentrations, differences were noted for potassium, sodium, copper, manganese, nickel, chloride, nitrate, and carbonate. These differences are attributed to differences or variations in sludge batch compositions, processing conditions, and experimental feed chemistries. Chloride, sulfate and nitrate are the species primarily involved in the corrosion of the MoCs. Sulfate was at a similar concentration for both simulants while chloride and nitrate were higher in the glycolic-based simulant.

The CPP scans for both CPC simulants are shown in Figure 4-1; pitting was noted on samples for both simulants after the test. A quasi-passive behavior was noted for both simulants with the glycolic-based simulant (Figure 4-1 (A)) results shifted to higher current densities than those for the formic-based simulants (Figure 4-1 (B)). The scans both have a small positive hysteresis, which indicates possible

\footnotetext{
${ }^{2}$ CPC simulants were from the 22L scale up testing for the nitric-glycolic acid flowsheet development and from Sludge Batch \#8 qualification testing using the nitric-formic acid flowsheet.
} 
pitting susceptibility. Average values for the corrosion potential $\left(\mathrm{E}_{\text {corr }}\right)$, general corrosion rate $(\mathrm{CR})^{3}$, passive current density ${ }^{4}\left(\mathrm{i}_{\text {pass }}\right)$, and pit protection potential $\left(\mathrm{E}_{\mathrm{pp}}\right)$ are given in Table $4-1$. From these results the glycolic-based simulant appeared to be slightly more corrosive with a slightly higher general corrosion rate and $\mathrm{i}_{\text {pass }}$. Both these factors may be associated with the higher concentrations of chlorides and nitrates in solution. The effect of nitrate on the CPP scan will be discussed more fully below. The actual difference in corrosion rates between the glycolic-based and formic-based simulants is small. The general corrosion rates are considered excellent at approximately 1 mpy or less. The $\mathrm{E}_{\mathrm{pp}}$ value defines the potential below which pits are not expected to initiate and grow. For both simulants this value is greater than $200 \mathrm{mV}$ from $\mathrm{E}_{\text {corr }}$, which is an indication that pitting would not be expected during service [12].

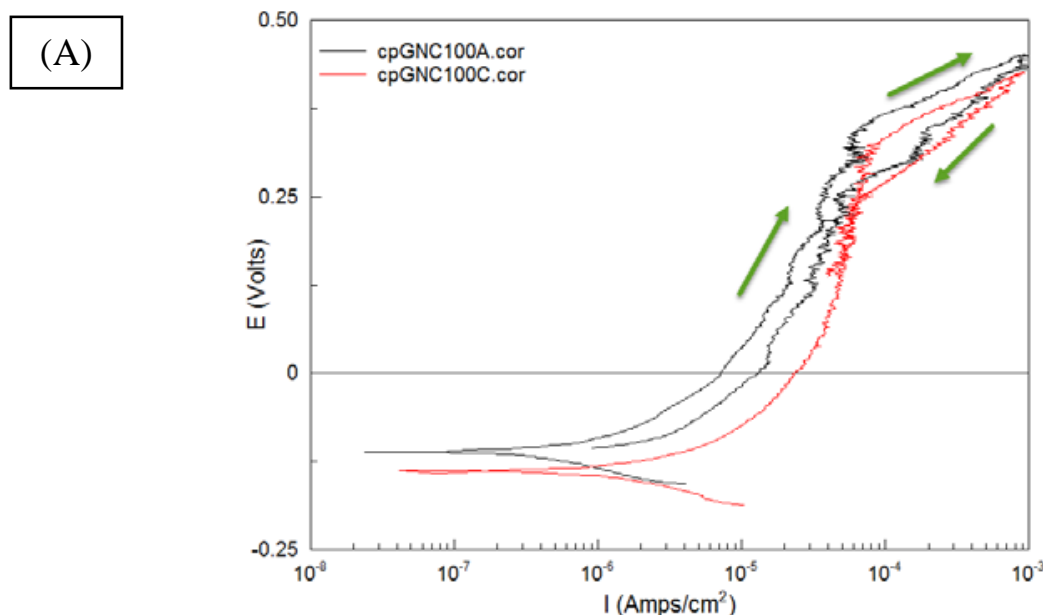

\section{(B)}

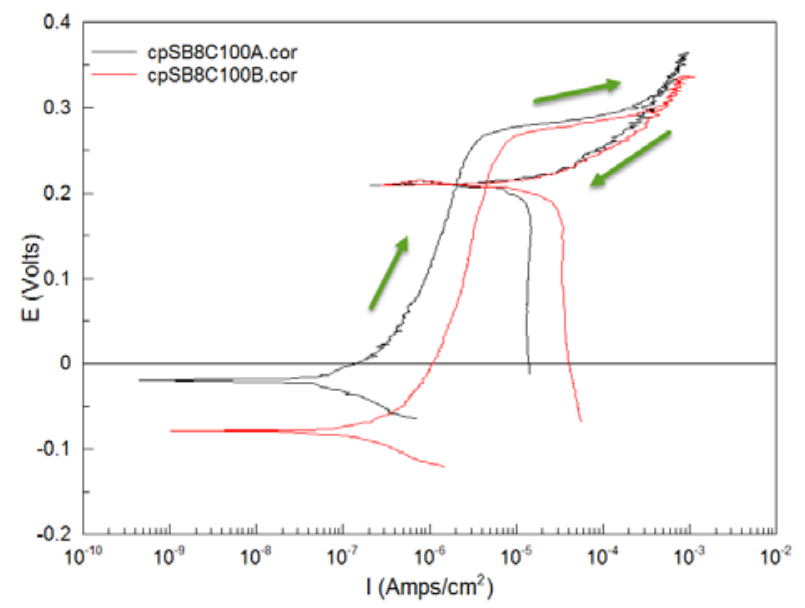

Figure 4-1. CPP scans for CPC simulants produced using (A) a nitric-glycolic acid flowsheet (cpGNC100A and C) and (B) a nitric-formic acid flowsheet (cpSB8C100A and B)

Table 4-2. Average Electrochemical Parameters for CPC Simulants

\begin{tabular}{|c|c|c|c|c|}
\hline Simulant & $\mathbf{E}_{\text {corr }} \mathbf{( V , ~ S C E )}$ & $\mathbf{C R}$ (mpy) & $\mathbf{i}_{\text {pass }} \mathbf{( A / \mathbf { c m } ^ { 2 } )}$ & $\mathbf{E}_{\mathbf{p p}} \mathbf{( V , ~ S C E )}$ \\
\hline Glycolic-based & -0.113 & 1.2 & $3.2 \mathrm{E}-5$ & 0.336 \\
\hline Formic-based & -0.035 & 0.2 & $0.2 \mathrm{E}-5$ & 0.206 \\
\hline
\end{tabular}

\footnotetext{
${ }^{3}$ General corrosion rates(CR) are calculated from the results of the LPR testing.

${ }^{4}$ The passive current density value is taken at a potential $200 \mathrm{mV}$ more electropositive than the corrosion potential.
} 


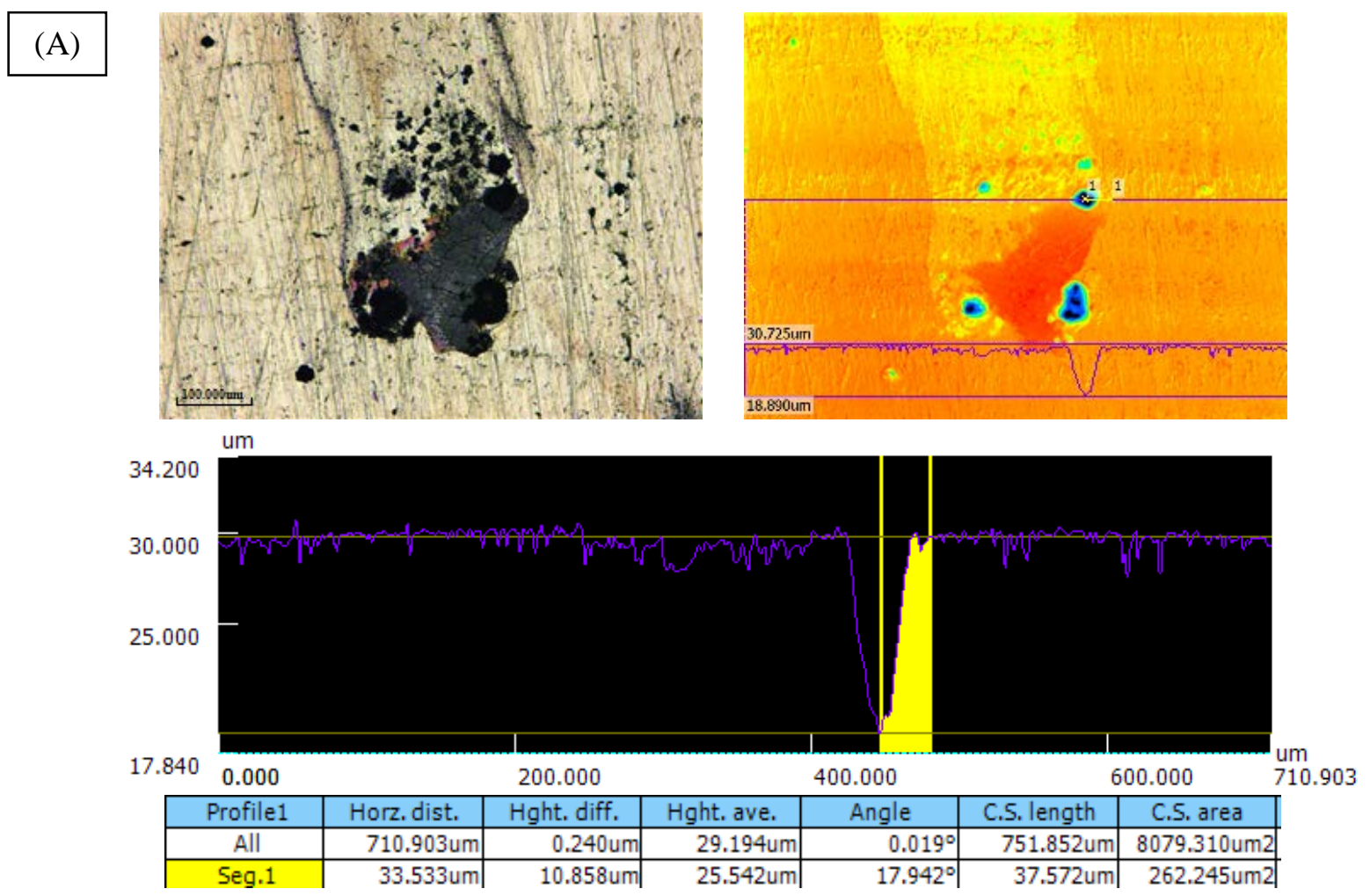

(B)
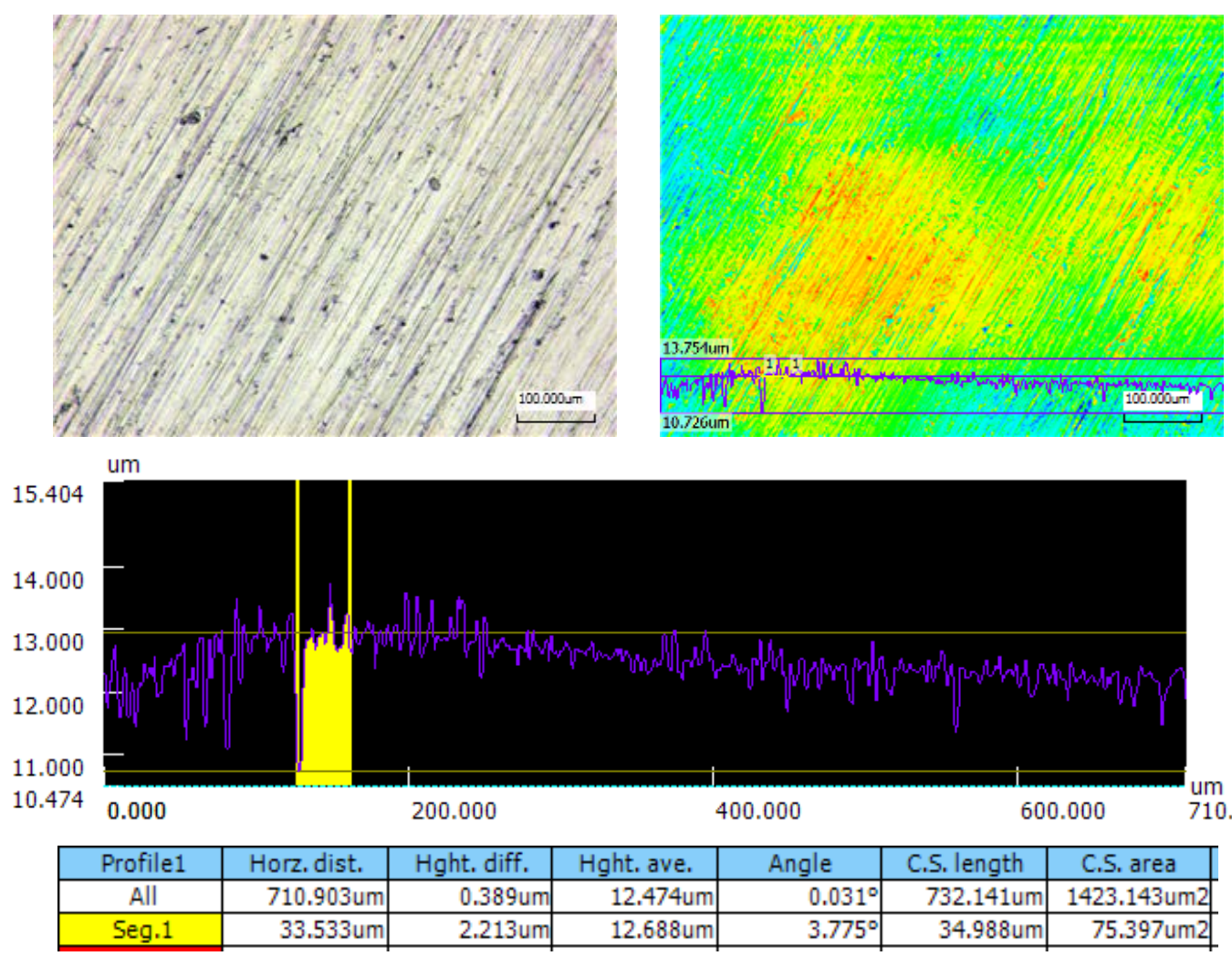

Figure 4-2. Pitting of C276 in glycolic-based (A) and formic-based (B) CPC simulants which were produced during flowsheet development (for each simulant a micrograph and corresponding height scan, line profile, and measurement table are given) 
The number of pits that occurred during the CPP scans was small. For the glycolic-based simulant, only one C276 sample had pits ranging from 4 to $11 \mu \mathrm{m}^{5}$. Only small pits (on the order of 1-3 $\mu \mathrm{m}$ ) were found for samples tested in the formic-based simulant. LCM height scans are given in Figure 4-2 and show the pit depth measurements (Hght. diff. for Seg.1 in tables). Both simulants, however, have chloride concentrations that exceed those seen in the DWPF (approximately one order of magnitude) [13].

The C276 samples tested in the formic-based simulant developed a coating, which needed to be removed prior to examination for pits. The coating was 1.5-3 $\mu \mathrm{m}$ thick. Based on x-ray fluorescence data, the coating had a significant manganese peak. This coating had pores and openings as shown in the photograph in Figure 4-3 (A). The determination of openings and pores was made through laser confocal height scans near edges and scratches made in the coating as shown in Figure 4-3 (B). These openings may have allowed crevice-type conditions to occur that led to the observed pitting.

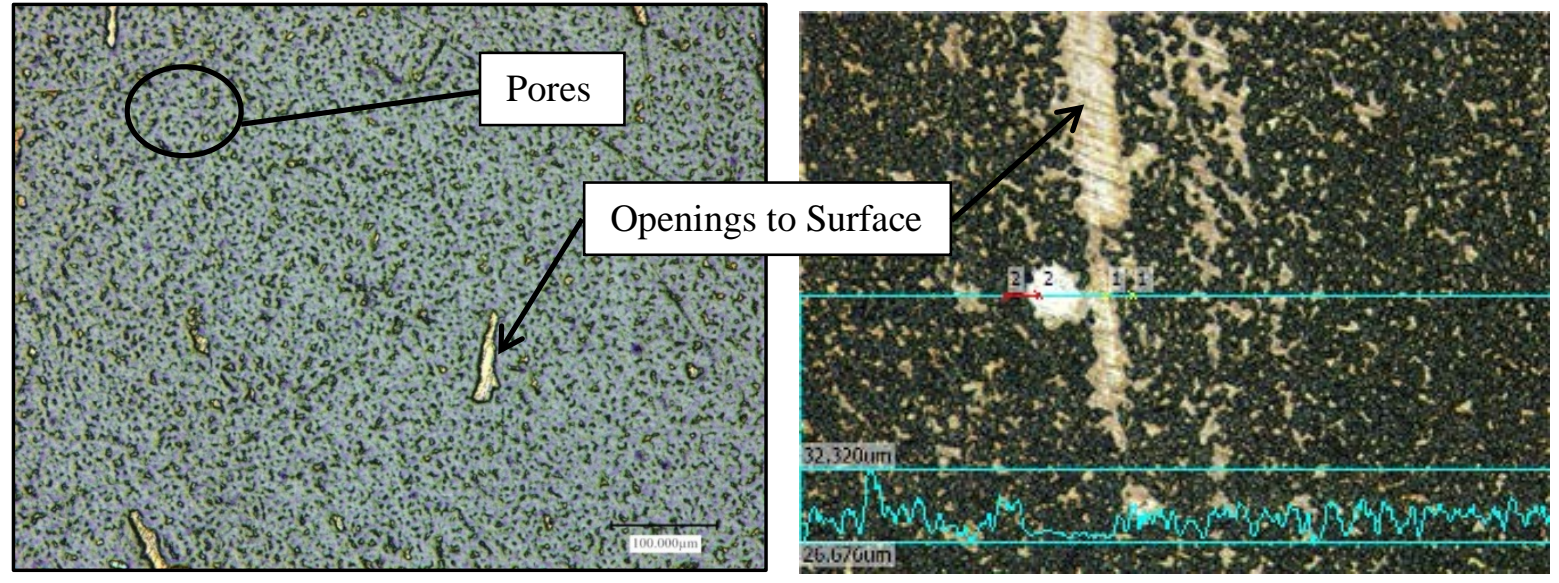

Figure 4-3. Mn-rich coating that formed on C276 sample during CPP scan in formic-based CPC simulant: (A) center of coating and (B) near scratch made through coating

\subsubsection{Glycolic-Based Solutions}

After analyzing the chemistry of the glycolic-based CPC simulant, the occurrence of pitting could be attributed to the simultaneous high levels of chloride $(874 \mathrm{ppm})$ and sulfate $(2636 \mathrm{ppm})$. These levels were greater than those measured for previous DWPF Sludge Batches. Chloride and sulfate concentrations from previous Sludge Batches are shown in Table 4-2 [13]. In many cases, the chloride concentration was below the detection level of the instrument. Sulfate concentrations were consistently below 2000 ppm and much lower than the Waste Acceptance Criteria (WAC) level of 0.058M [14]. The current processing protocol that requires sulfate be washed below the glass solubility limit also reduces the chloride concentration and resulted in extended lifetimes for most components in the CPC.

A series of electrochemical tests were performed which varied the concentration of chloride and sulfate as well as nitrate and mercury, which are also known to affect corrosion. A list of these tests, the calculated concentrations of the corrosive species (based on added quantities of chemicals) and average electrochemical parameters $\left(E_{\text {corr, }}, i_{\text {pass }}\right.$, and $\left.C R\right)$ are shown in Table 4-3. The corrosion rates come from the results of the LPR test, while $\mathrm{E}_{\text {corr }}$ and $\mathrm{i}_{\text {pass }}$ were taken from the CPP scans. As can be seen from an initial review of the data presented in Table 4-3, there were only a few instances in which pitting was found in these electrochemical tests. That is, pitting is avoided by lowering either the chloride or sulfate concentration to historic DWPF operating values.

\footnotetext{
${ }^{5}$ Note that $25.4 \mu \mathrm{m}$ is equivalent to $1 \mathrm{mil}$ or 0.001 inch so a $5 \mu \mathrm{m}$ pit is equivalent to 0.2 mil or 0.0002 inch.
} 
Table 4-3. DWPF Sludge Batch Concentrations for Chloride and Sulfate

\begin{tabular}{||c|c|c||}
\hline Sludge Batch & Chloride (mg/Kg) & Sulfate (mg/Kg) \\
\hline $1 \mathrm{~B}$ & 12 & 665 \\
\hline 2 & 7.4 & 849 \\
\hline 3 & $<27$ & 1790 \\
\hline 4 & $<52$ & 1173 \\
\hline 5 & $<310$ & 790 \\
\hline 6 & 46 & 834 \\
\hline $7 \mathrm{a}$ & $\mathrm{ND}$ & 1466 \\
\hline $7 \mathrm{~b}$ & $<268$ & 1460 \\
\hline 8 & $<96$ & 1260 \\
\hline
\end{tabular}

Table 4-4. Electrochemical Solution Compositions and Results at $100{ }^{\circ} \mathrm{C}$ for Glycolate-based Solutions $^{\alpha}$

\begin{tabular}{|c|c|c|c|c|c|c|c|c|}
\hline \multirow{2}{*}{ Test } & \multicolumn{4}{|c|}{ Calculated concentrations (ppm) } & \multirow{2}{*}{ Pitting } & \multicolumn{3}{|c|}{ Average Electrochemical Data } \\
\hline & Chloride & Sulfate & Nitrate & Mercury $^{\beta}$ & & $E_{\text {corr }}(V)$ & CR (mpy) & $i_{\text {pass }}\left(A / \mathbf{c m}^{2}\right)$ \\
\hline $\mathrm{CPC}^{\gamma}$ & 874 & 2635 & 92700 & 0 & $\mathrm{Y}^{\mathrm{E}}$ & -0.113 & 1.17 & $3.20 \mathrm{E}-05$ \\
\hline 1 & 100 & 5572 & 57463 & 0 & $\mathrm{~N}$ & -0.212 & 0.85 & $3.90 \mathrm{E}-05$ \\
\hline $1-\mathrm{Hg}$ & 100 & 5572 & 57463 & $\sim 300$ & $\mathrm{~N}$ & -0.229 & 1.41 & 4.20E-05 \\
\hline 2 & $<1$ & 5571 & 57463 & 0 & $\mathrm{~N}$ & -0.205 & 0.77 & $1.60 \mathrm{E}-05$ \\
\hline $2-\mathrm{Hg}^{\delta}$ & $<1$ & 5571 & 57463 & 59 to 21 & $\mathrm{~N}$ & -0.26 & 0.5 & $1.80 \mathrm{E}-05$ \\
\hline 3 & 50 & 2000 & 57251 & 0 & $\mathrm{~N}$ & -0.236 & 0.83 & $2.60 \mathrm{E}-05$ \\
\hline 3-Hg & 50 & 2000 & 57251 & $\sim 300$ & $\mathrm{~N}$ & 0.294 & 34 & $6.00 \mathrm{E}-05$ \\
\hline 4 & 0 & 1921 & 57251 & 0 & $\mathrm{~N}$ & -0.154 & 0.75 & 5.80E-06 \\
\hline $4-\mathrm{Hg}^{\delta}$ & 0 & 1921 & 57251 & 323 & $\mathrm{~N}$ & 0.299 & 24.4 & $1.08 \mathrm{E}-05$ \\
\hline 5 & 35 & 507 & 57463 & 0 & $\mathrm{~N}^{\mathrm{E}}$ & -0.158 & 0.99 & $8.80 \mathrm{E}-06$ \\
\hline 6 & 100 & 5572 & 98558 & 0 & $\mathrm{~N}$ & -0.215 & 0.83 & $2.20 \mathrm{E}-05$ \\
\hline 6-Hg & 100 & 5572 & 98558 & $\sim 300$ & $\mathrm{~N}$ & -0.273 & 0.76 & $2.10 \mathrm{E}-05$ \\
\hline 7 & 86 & 2636 & 98347 & 0 & $\mathrm{~N}$ & -0.173 & 1 & $1.60 \mathrm{E}-05$ \\
\hline 7-Hg & 86 & 2636 & 98347 & $\sim 300$ & $\mathrm{~N}$ & -0.26 & 1 & $2.70 \mathrm{E}-05$ \\
\hline 8 & 35 & 1921 & 34237 & 0 & $\mathrm{Y}^{\mathrm{E}}$ & -0.045 & 0.46 & 4.30E-06 \\
\hline 9 & 36 & 1128 & 34025 & 0 & $\mathrm{Y}^{\mathrm{E}}$ & -0.163 & 1.38 & $3.70 \mathrm{E}-05$ \\
\hline 10 & 821 & 423 & 57463 & 0 & $\mathrm{~N}$ & -0.218 & 0.76 & $1.4 \mathrm{E}-05$ \\
\hline
\end{tabular}

$\alpha$ Shading indicates solutions that are paired, such that one contains mercury and the other is mercury free.

$\beta$ Estimated mercury concentrations are denoted by the symbol $\sim$. Estimated values are based on the correlation of added gram quantities and measured values performed previously.

$\gamma$ This test was the CPC simulant produced during flowsheet development.

$\delta$ Measured values of mercury

$£$ Samples had deposits at end of testing

Although mercury did not adversely impact the localized corrosion susceptibility in these solutions, mercury did increase the general corrosion rate and alter the electrochemical response. The results were at first confusing since comparable additions of mercury nitrate to different batches of the same solution chemistry did not yield the same electrochemical results. This problem resulted from the source of mercury used. Mercury was added from an in-stock bottle of mercury nitrate salt $\left(\mathrm{Hg}\left(\mathrm{NO}_{3}\right)_{2}\right)$, which had absorbed water over time, so concentrations were lower than expected. Verification of mercury concentration was only performed for two tests (Tests \#2 and \#4 in Table 4-3). 
The results of Tests \#3 through \#4-Hg in Table 4-3 clearly show that the presence of a large concentration of mercury does not lead to an increased susceptibility to localized corrosion. Pitting of the C276 coupon was not observed after testing in the mercury-containing solutions and the CPP scans showed negative hystereses. The general corrosion rate, however, is definitely impacted with an order of magnitude increase from less than 1 mpy to greater than 10 mpy.

When mercury is present in a sufficiently high concentration, the OCP, $\mathrm{E}_{\text {corr }}$ and the entire CPP scan are shifted to more electropositive potentials. In Figure 4-4, the OCP measurements prior to CPP scans are shown for three different mercury concentrations (Tests \#2 (0 ppm Hg), \#2-Hg (59 ppm Hg), and \#4-Hg (323 ppm Hg) in Table 4-3). For Test \#2-Hg, the initial mercury concentration was 59 ppm and after electrochemical testing was $21 \mathrm{ppm}$. When sufficient mercury is present the OCP is maintained at values greater than $0.0 \mathrm{~V}$. When no mercury is present the OCP values always stayed below $0.0 \mathrm{~V}$. At intermediate concentrations, the OCP values transition from greater than $0.0 \mathrm{~V}$ to less than $0.0 \mathrm{~V}$. The inference from this data is that the soluble $\mathrm{Hg}^{+2}$ is reduced with time (i.e. possibly the formation of mercuric chloride $\left(\mathrm{HgCl}_{2}\right)$, although these particular solutions had low to no chloride) and not replenished.

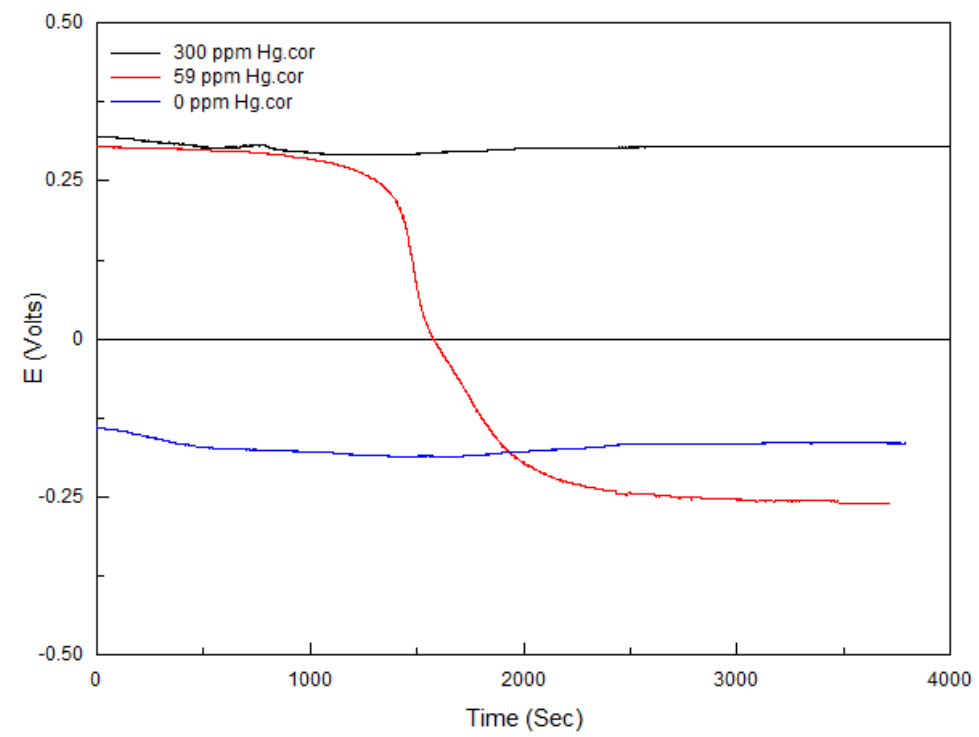

Figure 4-4. Open-circuit potential measurements over time in glycolic-based solutions showing the impact of mercury concentration

Cathodic polarization scans were performed to investigate the difference in cathodic reactions that might be occurring under these different conditions. The same solutions that were used for the CPP scans were used for these tests. The after test concentration of mercury was not measured for Test \#4 so the initial is given in the figure. The two batches of solution for Test \#4 (300 ppm Hg initial A and B), however, appear to have slightly different mercury concentrations as indicated by the lower starting potential for A than B. The presence of mercury in solution at sufficient concentration appears to aid in the depolarization of the surface for the oxygen reduction reaction, which may be the driver for the higher corrosion rate observed in mercury-containing solutions. Mercury reduction on the surface is not expected since it was not observed on the surface after testing, thereby localized cathodes do not form to drive pitting corrosion. 
SRNL-STI-2015-00482

Revision 0

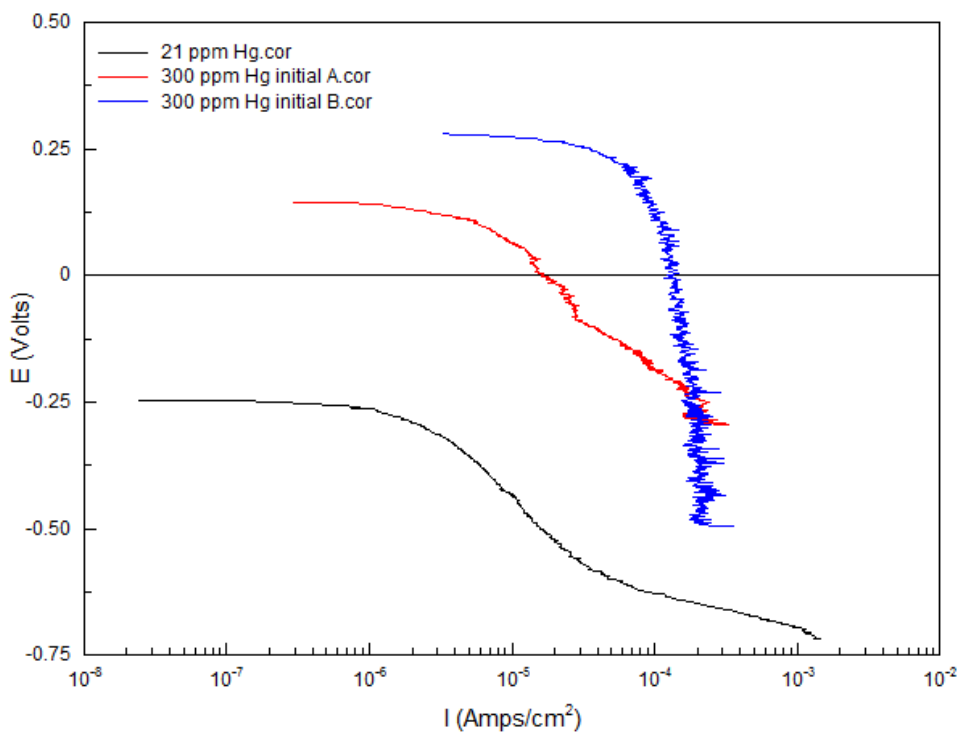

Figure 4-5. Cathodic polarization curves at high and low mercury concentrations

A review of Table 4-3 shows that once the chloride concentration was dropped to 100 ppm or below pitting was nearly eliminated. There were two exceptions (Tests \#8 and \#9) and these will be discussed further below. One test (Test \#10) was performed while maintaining a high chloride concentration but greatly reducing the sulfate concentration to investigate if any synergy existed between these two species. This condition is not likely to occur for the SRS sludges to be processed through the DWPF. Although these data are minimal, the results from Test \#10 showed that pitting was not observed along with low general corrosion rates when a high chloride $(821 \mathrm{ppm})$ concentration was maintained with a very low sulfate concentration (423 ppm), indicating some type of synergy between these species to drive pitting corrosion.

For the low chloride solutions where pitting was observed (Tests \#8 and \#9 in Table 4-3), deposits formed during the test. These solutions had low nitrate concentrations. In making these low nitrate solutions, the glycolate concentration was also reduced by molar equivalents which appeared to have reduced the complexing capability of the solution and led to the formation of deposits on the surface. With chlorides and a crevice present from deposits, pitting or localized breakdown occurred during the polarization test. The pits ranged from 5 to $20 \mu \mathrm{m}$ on these samples.

As can be seen from the corrosion rates for the low nitrate solutions, which do not contain mercury, the average corrosion rates ( 0.46 and $1.38 \mathrm{mpy}$ ) bracket the rates for the higher nitrate solutions ( 0.75 to 1 mpy). While not affecting the corrosion rate, the reduced nitrate concentration on average shifted CPP scans to lower current densities in these glycolic-based solutions as shown in Figure 4-6 for C276, although the range of $i_{\text {pass }}$ values overlapped for different nitrate concentrations (see Table 4-3).

Although the chloride and sulfate concentrations had a significant impact on the occurrence of pitting if their concentrations were sufficiently high, there were no measurable, correlated changes in the electrochemical response of C276 to variations in their concentrations. Figures 4-7 and 4-8 show CPP scans for solutions containing different concentrations of sulfates and chlorides, respectively. These scans do not show consistent changes in $\mathrm{E}_{\text {corr }}$ or $\mathrm{i}_{\text {pass }}$ with respect to the concentration changes. The effect may be obfuscated by changes in the concentration of other constituents.

The CPP scans shown in Figures 4-6 through 4-8 for glycolic-based solutions have positive hystereses similar to that observed for the CPC glycolic-based simulant from the 22-L scale up testing (Figure 4-3). 
The potentials at which reverse scan currents are greater than the forward scan currents are close to the vertex potential (potential at which the scan reverses direction) and not $\mathrm{E}_{\text {corr }}$, i.e. $\mathrm{E}_{\mathrm{pp}}$ is greater than 200 $\mathrm{mV}$ from $\mathrm{E}_{\text {corr }}$. Therefore, pitting would not be expected during service in these type solutions [12].

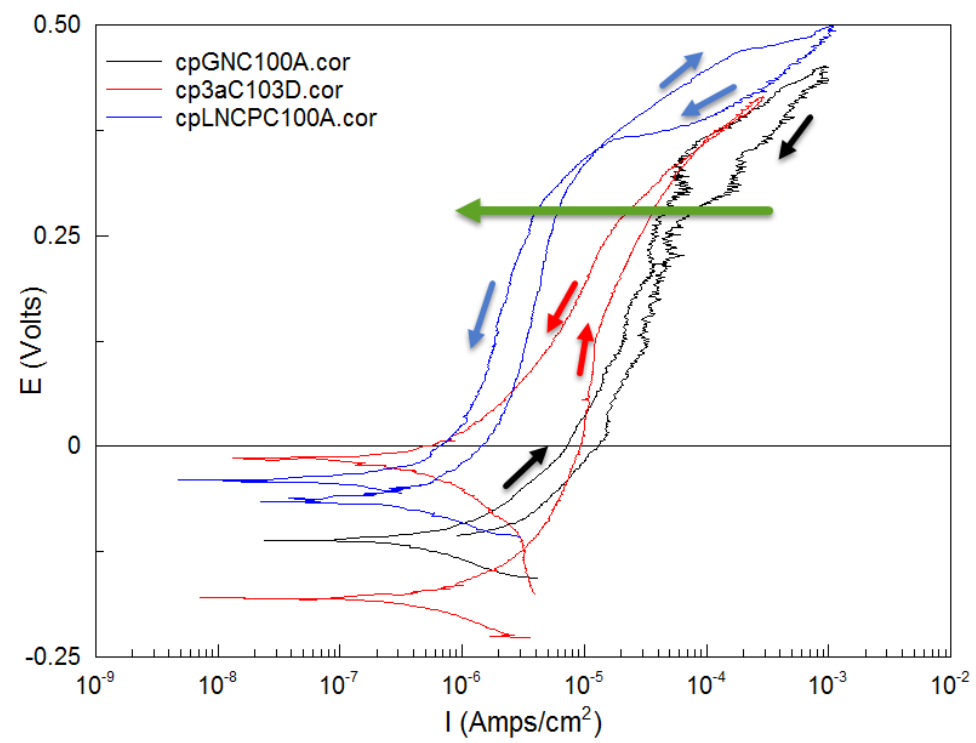

Figure 4-6. Effect of nitrate concentration on the CPP scans for C276 in glycolic-based solutions at boiling (arrow indicates decreasing nitrate concentration from 92,700 to 34,237 ppm)

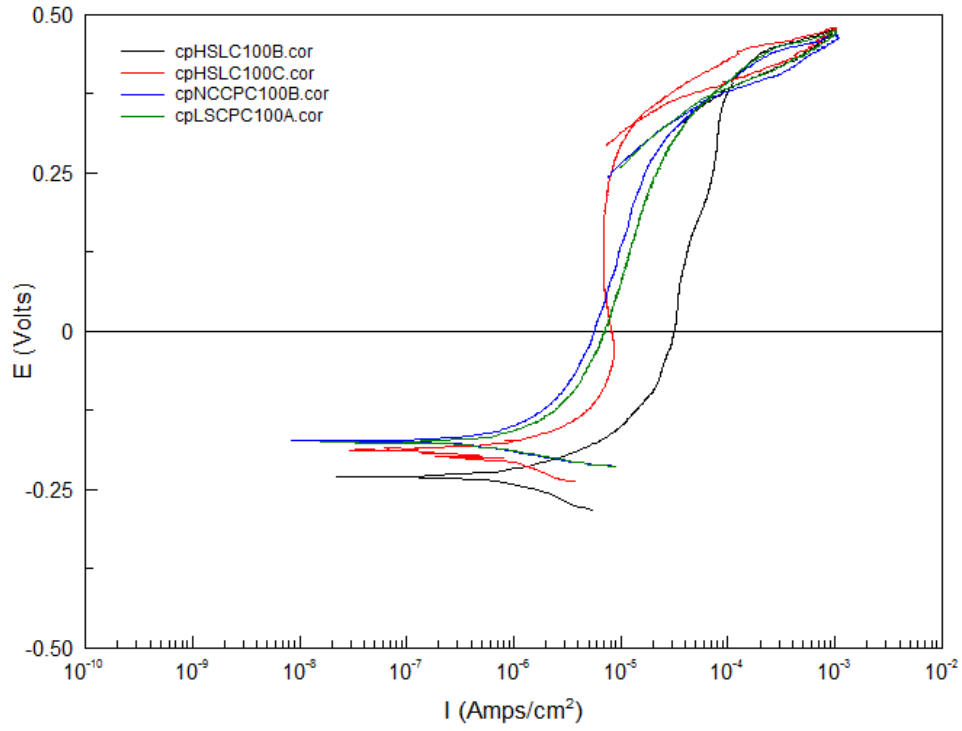

Figure 4-7. CPP scans for C276 in boiling glycolic-based solutions with different sulfate concentrations, ranging from 507 to $5571 \mathrm{ppm}$ (chloride concentration ranged from 0 to $35 \mathrm{ppm})$ 
SRNL-STI-2015-00482

Revision 0

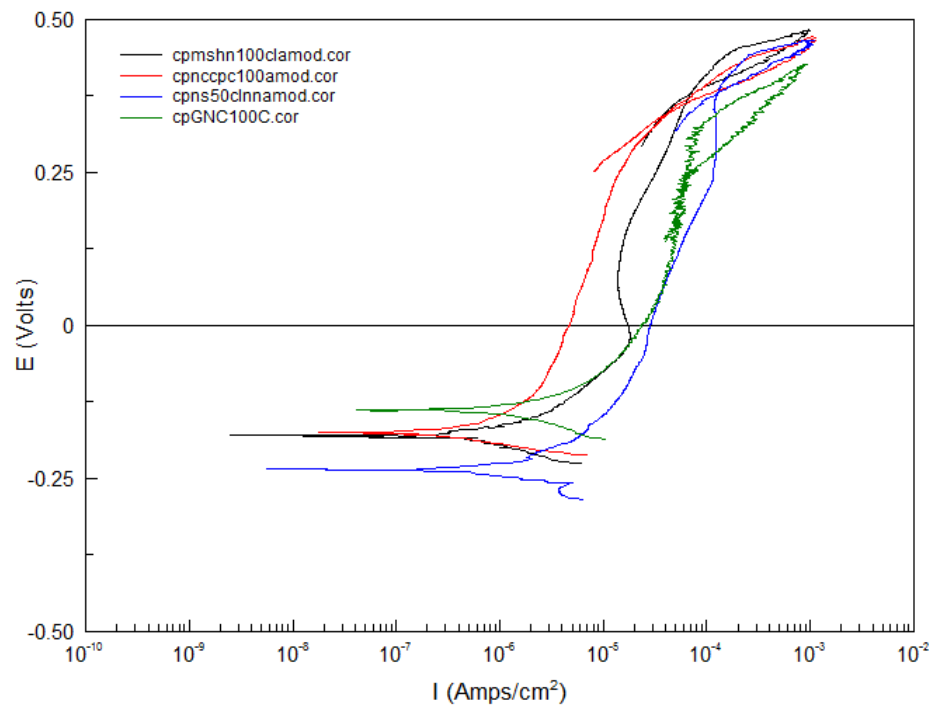

Figure 4-8. CPP scans for C276 in boiling glycolic-based solutions with different chloride concentrations, ranging from 0 to $874 \mathrm{ppm}$ (sulfate concentration ranged from 2000 to 2635 ppm)

A series of potentiostatic test were conducted at applied potentials (AP) within a positive hysteresis loop (greater than the $\mathrm{E}_{\mathrm{pp}}$ ) to determine if pitting was found to occur at times longer (one hour) than during a CPP scan (1-2 minutes to pass through the potential range of the loop). The test solutions contained approximately $57500 \mathrm{ppm}$ nitrate, $5600 \mathrm{ppm}$ sulfate, and $100 \mathrm{ppm}$ chloride, and were with and without mercury (Solutions from Tests \#1 and \#1-Hg in Table 4-3). Figure 4-9 shows the chrono-current traces, which in general started at the highest current value for the trace and quickly dropped to a lower constant value. This type of trace is consistent with a material undergoing general corrosion. A chrono-current trace for pitting would be increasing because as pits develop more current is generated at the expanding surface area.

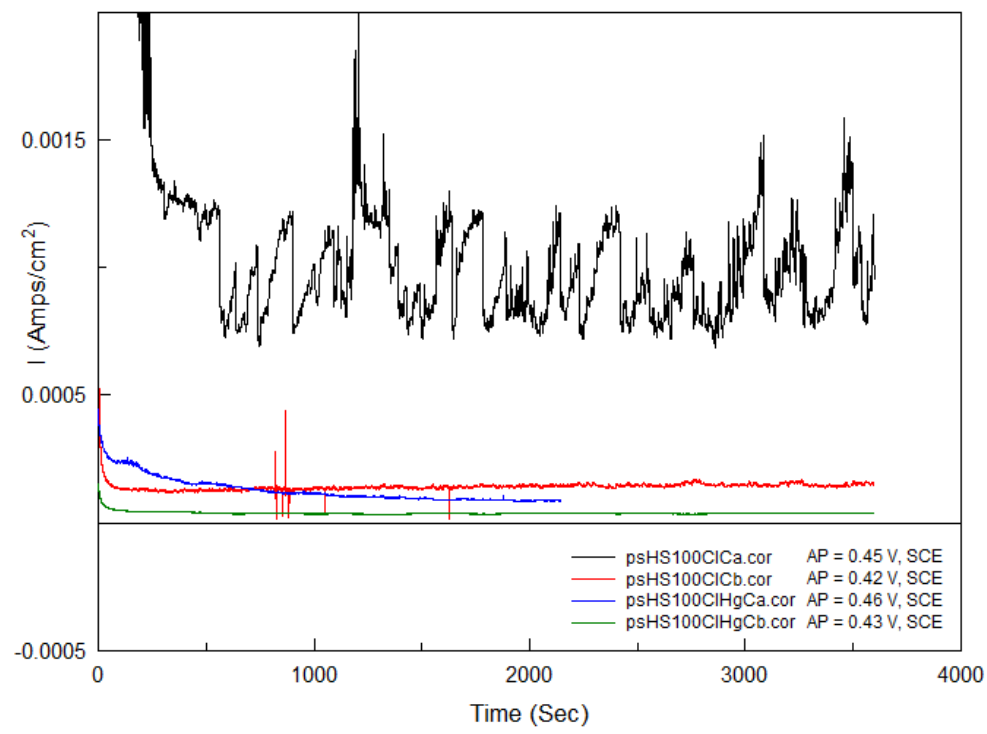

Figure 4-9. Chrono-current traces for potentiostatic tests at potentials within the positive hysteresis loop for boiling glycolic-based solutions with and without mercury 
The chrono-current trace in the mercury-free solution at an AP of $0.45 \mathrm{~V}$ differed slightly from the others in that large current transients were observed. The source of these transients is not known, however, pitting transients have similar characteristics. The current is on the order of $1 \mathrm{~mA}$ which suggests these transient could be indications of pitting. Meta-stable pitting transients or passivating pits have transients that are 1-2 orders of magnitude lower than those observed [15]. However, pitting was not observed on the sample. Other sources for these transients may be reactions of solutions species on the sample surface.

\subsubsection{Formic-Based Solutions}

Several tests were performed for C276 in formic-based solutions to assist in selection of chemistries for hot-wall and coupon immersion tests. The results are summarized in Table 4-4. The mercury source was similar to that used for the glycolic-based solutions so the actual mercury concentration is probably lower than $300 \mathrm{ppm}$ for Test \#1-Hg. The electrochemical responses also don't indicate a shift in potentials to more noble values. Test \#1 is actually the one used for the coupon immersion test and pitting was observed on those samples. The CPP scans for these were all similar in appearance to that shown in Figure 4-1 (B) for the formic-based CPC simulant, which had a slight positive hysteresis.

Table 4-5. Electrochemical Solution Compositions and Results at $100{ }^{\circ} \mathrm{C}$ for Formic-based Solutions $^{\alpha}$

\begin{tabular}{|c|c|c|c|c|c|c|c|c||}
\hline \multirow{2}{*}{ Test } & \multicolumn{4}{|c|}{ Calculated concentrations (ppm) } & \multirow{2}{*}{ Pitting } & \multicolumn{3}{|c|}{ Average Electrochemical Data } \\
\cline { 2 - 7 } & Chloride & Sulfate & Nitrate & Mercury $^{\beta}$ & & $\mathbf{E}_{\text {corr }}(\mathbf{V})$ & CR (mpy) & $\mathbf{i}_{\text {pass }}$ (A/cm2) \\
\hline CPC $^{\gamma}$ & 247 & 2550 & 27500 & 0 & $\mathrm{Y}^{\mathcal{E}}$ & -0.035 & 0.2 & $0.2 \mathrm{E}-5$ \\
\hline 1 & 50 & 2000 & 43590 & 0 & $\mathrm{~N}$ & -0.399 & 0.27 & $1.6 \mathrm{E}-5$ \\
\hline $1-\mathrm{Hg}$ & 50 & 2000 & 43590 & $\sim 300$ & $\mathrm{~N}$ & -0.406 & 0.28 & $7.1 \mathrm{E}-5$ \\
\hline 3 & 100 & 5571 & 43560 & 0 & $\mathrm{~N}^{\delta}$ & -0.303 & 0.6 & $1.1 \mathrm{E}-4$ \\
\hline 3 & 100 & 5571 & 43560 & 0 & $\mathrm{Y}^{\mathcal{\varepsilon}}$ & -0.403 & 0.46 & $3 \mathrm{E}-5$ \\
\hline
\end{tabular}

$\alpha$ Shading indicates solutions that are paired, such that one contains mercury and the other is mercury free.

$\beta$ Estimated mercury concentrations are denoted by the symbol $\sim$. Estimated values are based on the correlation of added gram quantities and measured values performed previously for glycolic-based solutions.

$\gamma$ This test was the CPC simulant produced during flowsheet development.

$\delta$ Sample bronzed over

$£$ Samples had deposits at end of testing

For Tests \#3 and \#3' in Table 4-4, which were similar test conditions, pitting was observed in one test but not the other. The pits $(2-5 \mu \mathrm{m})$ were associated with small deposits that formed on the Test \#3' sample. The sample from the Test \#3 bronzed over, but did not have any pits. The electrochemical data are similar although not identical with Test \#3 having results of a higher $\mathrm{i}_{\text {pass }}$ and more noble $\mathrm{E}_{\text {corr }}$ than the results from Test \#3'. This chemistry with a high sulfate concentration (WAC limit) appears to have surface reactions with C276 which may or may not make it susceptible to pitting. The deposits were not analyzed further to determine their composition.

\subsubsection{0\% Glycolic Acid}

The corrosion of $304 \mathrm{~L}$ in $70 \%$ glycolic acid as reported previously was found to be acceptable at temperatures of $50{ }^{\circ} \mathrm{C}$ or below [3]. During the first phase of testing, however, 304L was shown to pit at this temperature as well as have a variable electrochemical response [2]. The OCP stabilized at two different values ( 0.2 and $-0.28 \mathrm{~V}$ ) which also had different corrosion rates ( 0.2 and 6 mpy, respectively). Although CPP scans for these different OCPs had different characteristics they both showed passive behavior and negative hysteresis with samples pitting during the test. During this follow-up testing, tests were performed at $35{ }^{\circ} \mathrm{C}$ and room temperature. At $35{ }^{\circ} \mathrm{C}$, two OCPs were also found to occur, while at 
room temperature only the more noble potential occurred as shown in Figure 4-10. The different OCPs again were associated with different LPR corrosion rates, 0.05 mpy at $0.2 \mathrm{~V}$ and $0.42 \mathrm{mpy}$ at $-0.123 \mathrm{~V}$. At room temperature the average LPR corrosion rate was $0.08 \mathrm{mpy}$.

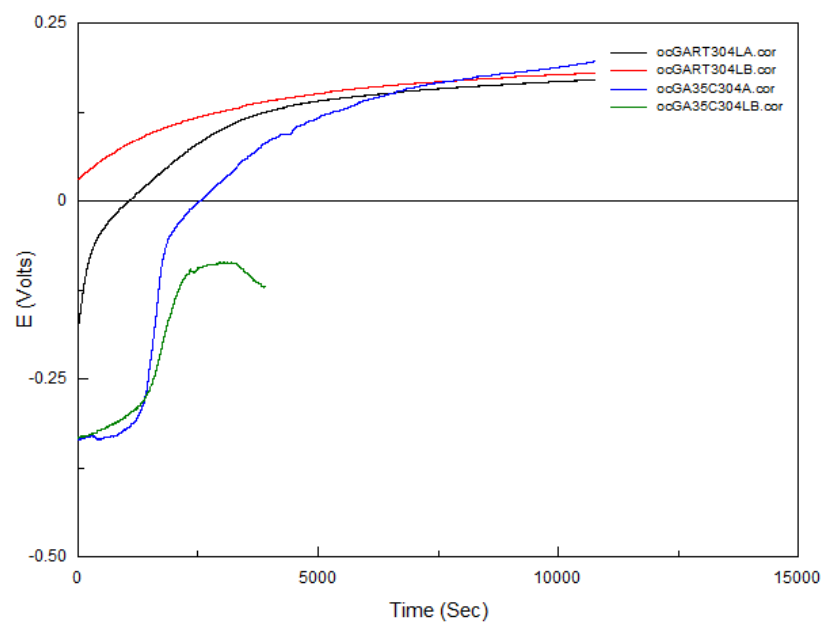

Figure 4-10. Open-circuit potentials of 304L stainless steel in $70 \%$ glycolic acid at room temperature and $35^{\circ} \mathrm{C}$

The CPP scans also depended on the initial OCP value as shown by the data in Figure 4-11. The more active OCP value ( $<0.0 \mathrm{~V}$, cpGA35C304LB.cor) has a CPP scan with a greater $\mathrm{i}_{\mathrm{P}}$ value as well as a possible transition in state of the surface oxide or cathodic reaction occurring at the surface. The CPP scan with a passive OCP (>0.0 V, cpGART304LA.cor) was independent of temperature and all showed simple passive polarization curves.

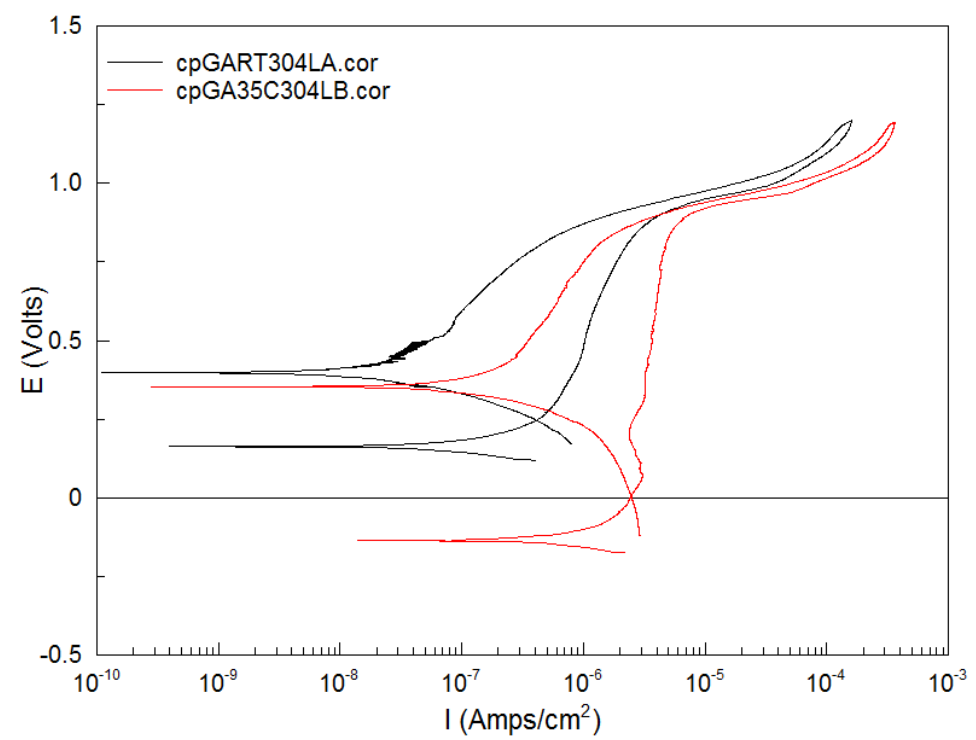

Figure 4-11. CPP scans for 304L in $70 \%$ glycolic acid at room temperature and $35^{\circ} \mathrm{C}$

Independent of temperature, small pits $(<5 \mu \mathrm{m})$ were located on all samples. The pits formed on the room temperature samples appeared to be associated with inclusions since they formed a linear array, as shown in Figure 4-12 (A), such as might results from inclusions preferentially oriented with the rolling direction. Inclusions, specifically manganese sulfides, are locations of pit initiation in austenitic stainless steels. At $35{ }^{\circ} \mathrm{C}$, the samples appeared free of pits; however, on examination at higher magnification a 
few pit-like features were located as shown by the micrograph in Figure 4-12 (B). Their depth ( $5 \mu \mathrm{m})$ was difficult to differentiate from variability in the surface morphology as shown by the laser height scan in Figure 4-13. With a negative hysteresis in the CPP scans, these pits are most likely metastable pits that initiated and passivated. Pit growth; however, is not determined from these types of electrochemical tests.
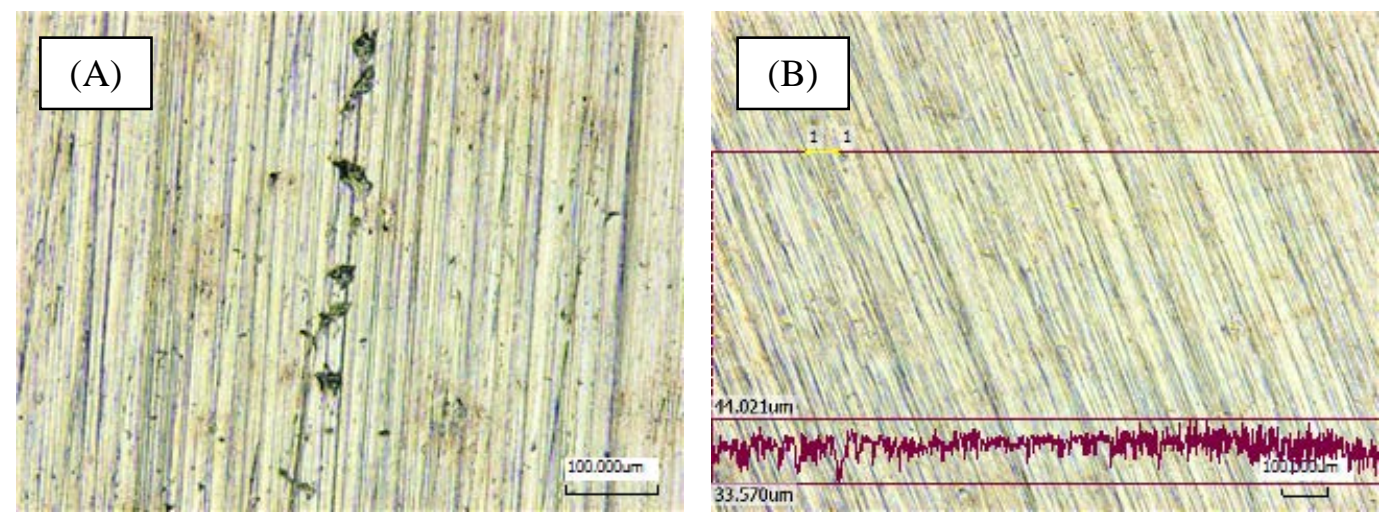

Figure 4-12. Micrographs of 304L stainless steel after electrochemical testing in $70 \%$ glycolic acid at (A) room temperature and (B) $35^{\circ} \mathrm{C}$

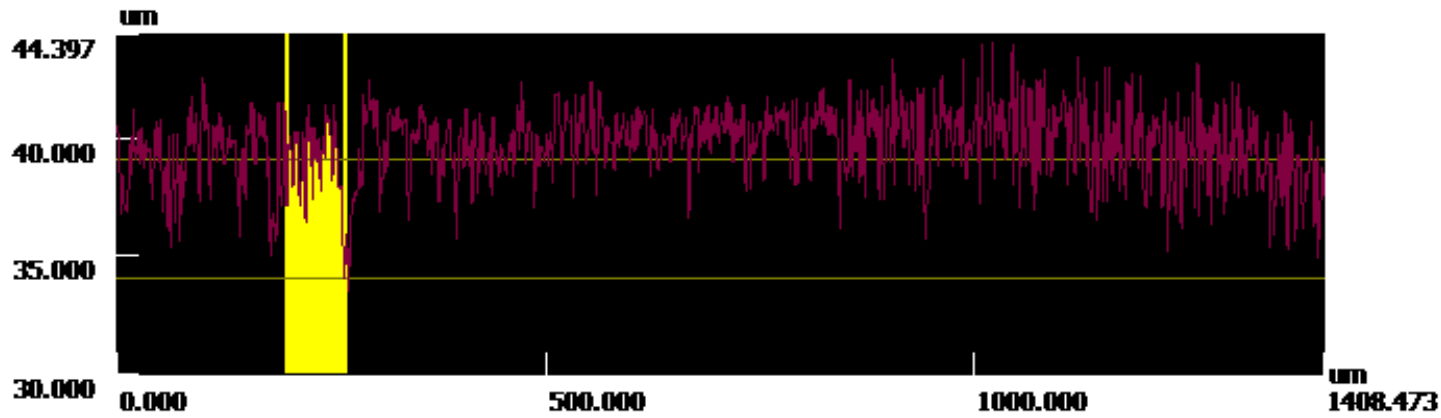

Figure 4-13. Laser-height scan for 304L stainless steel after electrochemical testing in $70 \%$ glycolic acid at $35^{\circ} \mathrm{C}$ (for micrograph in Figure 4-12 (B))

\subsubsection{REDC Decontamination Solution - 12.5\% Nitric Acid}

In the REDC, equipment is decontaminated using a $12.5 \%$ nitric acid solution. As equipment is cleaned the soak solution is expected to build up in glycolic acid at some unknown rate from residual glycolate on equipment. For testing purposes, that concentration was taken at slightly greater than the initial estimated maximum concentration that would be carried over in the off gas components of the CPC $(10 \mathrm{~g} / \mathrm{L})$. Alloy 20 is the principal MoC since it is the material for the soak tank. The test solution was boiled since future requirements may include a hot solution, which would be accomplished by using a steam lance. Electrochemical tests both with and without added sodium glycolate to the boiling $12.5 \%$ nitric acid solution showed passive behavior with no pitting observed on the sample after testing. General corrosion rates were also similar with average rates of $3.1 \mathrm{mpy}$ and $3.3 \mathrm{mpy}$ for the solutions with and without added sodium glycolate, respectively. Figure 4.14 shows the CPP curves for both sets of samples and a micrograph of a sample surface tested in the glycolate-bearing nitric acid solution. If additional contaminants and aggressive species (chloride and sulfate) are expected to increase with continual re-use of solutions, additional testing should be considered. 

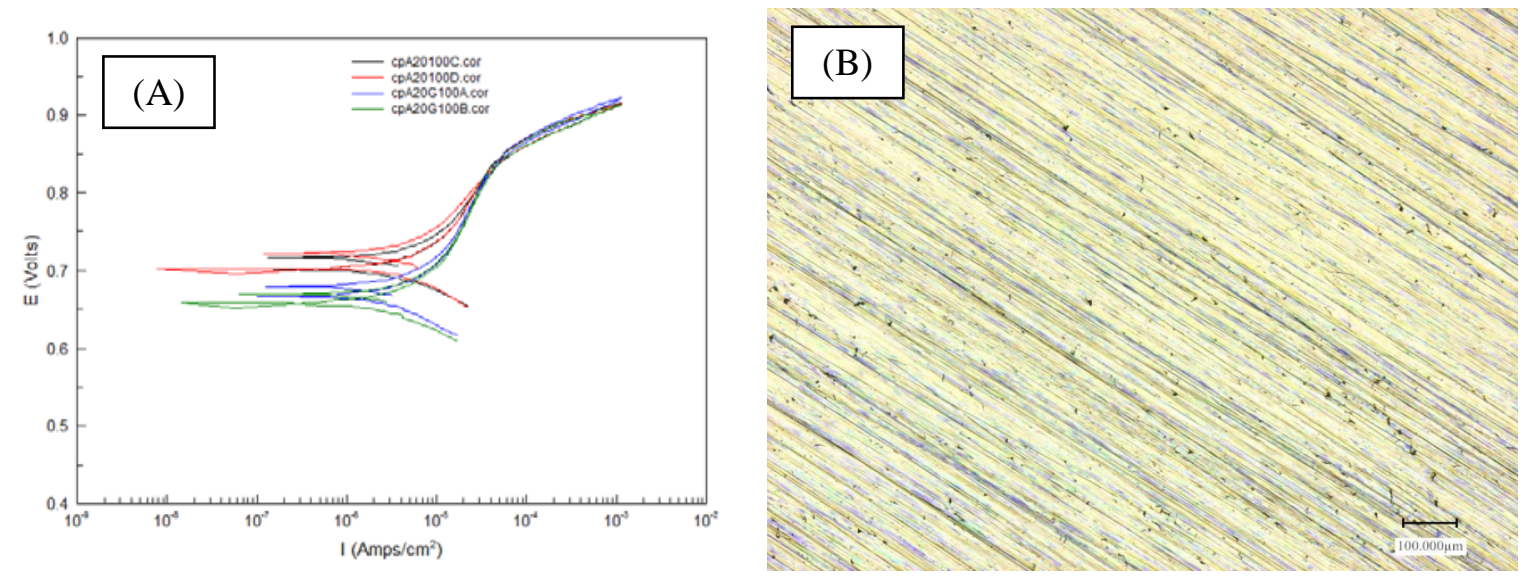

Figure 4-14. Alloy 20 in a boiling 12.5\% nitric acid solution: (A) CPP scan for solutions with and without the glycolate anion and (B) micrograph of sample surface tested in solution containing the glycolate anion

\subsection{Hot-Wall Test Results}

The hot-wall test is used to evaluate corrosion under heat transfer conditions that would be experienced during a heating cycle. The MoCs (and heat transfer components) include C276 (SRAT and SME heating coils) and Ultimet (SME heating coils clam shells adjacent to support guards), G30 (2H tube bundle and warming coils) and G3 (ETF heaters). During the first phase testing, all the MoCs were found to have degraded from pitting and crevice corrosion within a period of 22 to 34 days. The location, type and depth of corrosion are summarized in Table 4-5.

Table 4-6. Hot-Wall Test Results from First Phase Testing [2]

\begin{tabular}{|c|c|c|c|c|c||}
\hline Material & Solution & Duration (days) & Type & Location & $\begin{array}{c}\text { Depth* } \\
(\boldsymbol{\mu m})\end{array}$ \\
\hline C276 & SRAT/SME Supernate & 22 & Pitting & Center & 7 \\
\hline & & & Crevice & Gasket & 8 \\
\hline Ultimet & SRAT/SME Supernate & 34 & Pitting & Center & 20 \\
\hline & & & Crevice & Gasket & 42 \\
\hline G30 & Basic Concentrated Recycle & 22 & Pitting & Deposits & 18 \\
\hline G3 & Dilute Waste & 27 & Crevice & Gasket & 22 \\
\hline
\end{tabular}

* Deepest measured pit

These results showed that pitting and crevice corrosion were the prevalent mechanisms in the presence of glycolic acid under heat transfer conditions. Several aspects of the testing, however, made application of the test results to the current facilities difficult. The solution volume was maintained low to minimize the generation of hazardous waste, but this small volume lead to significant changes in the solution structure with deposits forming both in the solution and on the test sample and probable changes in solution chemistry. For the testing in the SRAT/SME supernate, the chloride and sulfate concentrations $(0.16 \mathrm{M}$ and $0.058 \mathrm{M}$, respectively) were near the WAC limit [14], which is well above the measured concentrations in sludge batches for DWPF (see Table 4-2). Additionally, comparative tests in glycolicfree solutions or formic-based solutions were not performed.

In this follow-up testing, six hot-wall tests were performed, including C276 in glycolate- and formatecontaining solutions with sulfate and chloride concentrations (5571 and $100 \mathrm{ppm}$, respectively) that are considered maximums and nominal concentrations, respectively, in expected sludge compositions; G3 in 
a solution with a dilute waste composition with and without glycolate anions in solution; and for G30 in a basic concentrated recycle with and without glycolate anions in solution. The test solution volume was approximately $2.5 \mathrm{~L}$. The data from the follow-up hot-wall testing are summarized in Table 4-6.

Table 4-7. Hot-Wall Test Results from Follow-up Testing

\begin{tabular}{|c|c|c|c|c|c|}
\hline Material & Solution & $\begin{array}{c}\text { Duration } \\
\text { (days) }\end{array}$ & Type & Location & $\begin{array}{c}\text { Depth } \\
(\boldsymbol{\mu m})\end{array}$ \\
\hline C276 & $\begin{array}{c}\text { Glycolic-based SRAT/SME } \\
\text { Supernate }\end{array}$ & 28 & Crevice & Deposits & $3-5$ \\
\hline C276 & $\begin{array}{c}\text { Formic-based SRAT/SME } \\
\text { Supernate }\end{array}$ & 29 & Pitting/Crevice & Deposits & 19 \\
\hline G30 & $\begin{array}{c}\text { Basic Concentrated Recycle } \\
\text { with Glycolate }\end{array}$ & 24 & Crevice & Deposits & $<13$ \\
\hline G3 & $\begin{array}{c}\text { Basic Concentrated Recycle } \\
\text { without Glycolate }\end{array}$ & 29 & Pitting/Crevice & Deposits & $3-24$ \\
\hline & $\begin{array}{c}\text { Dilute Waste with Glycolate } \\
\text { Dilute Waste without } \\
\text { Glycolate }\end{array}$ & 36 & Pitting/Crevice & Center/Gasket & $<10$ \\
\hline
\end{tabular}

The C276 sample in the glycolic-based solution during the follow-up testing had similar results to the first data set, where pitting was observed. No significant deposits formed on the surface; deposits were generally limited to the gasket perimeter as seen in the post-test photographs in Figure 4-15 for the samples from both tests. Measured pit depths of the few located on the sample were slightly smaller than those measured for the first phase data set $(7-8 \mu \mathrm{m})$ but were of the same order of magnitude. The smaller depths might be associated with the lower chloride concentration used during the follow-up testing.
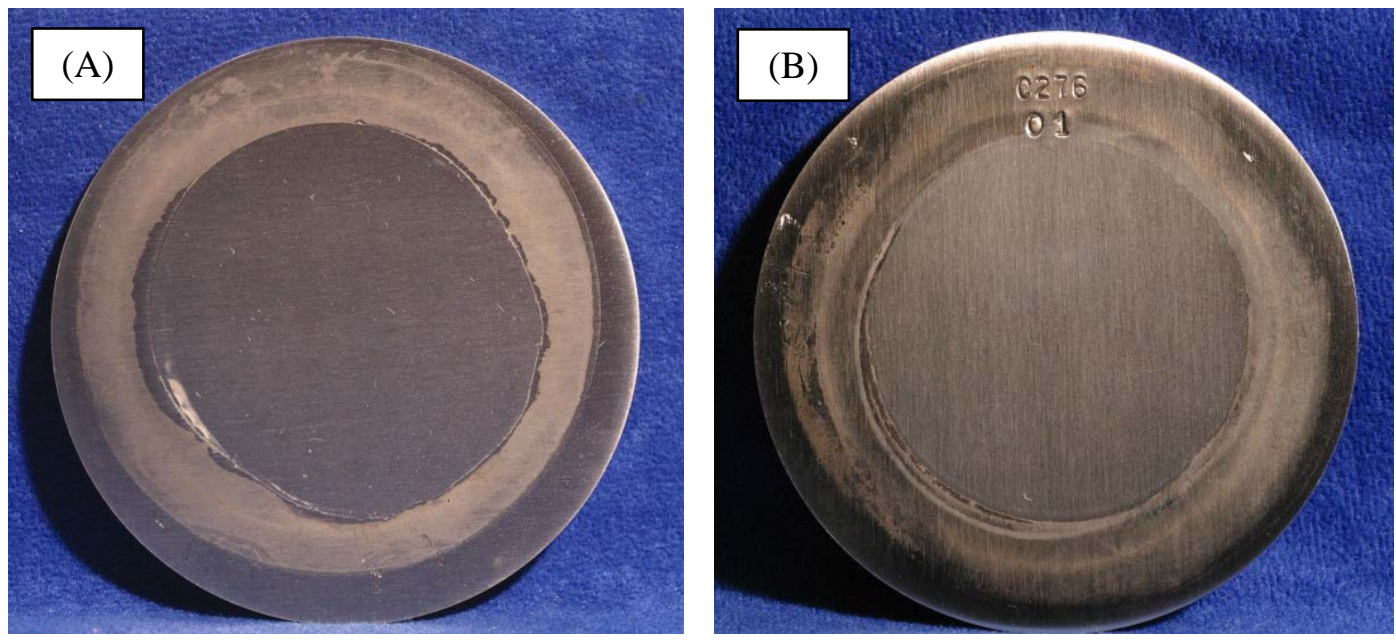

Figure 4-15. Post-test photographs of C276 hot-wall test samples after month exposure at boiling conditions: (A) follow-up test sample; and (B) first phase test sample

The C276 sample in the formic-based solution had a thick coating that formed during the 29 days at boiling. The measured coating thickness ranged from 135 to $300 \mu \mathrm{m}$. This coating could not be removed through chemical cleaning which included the use of both nitric acid and alkaline cleaning solutions. Mechanical cleaning measures were not used since the localized corrosion may have been removed. To 
obtain some indication of the presence of localized corrosion, the sample was sectioned with an electric discharge machine into a number of slices as shown in Figure 4-16. The cut edges of each slice were then examined in cross-section along the coating/metal interface for the presence of any pitting or crevice corrosion.

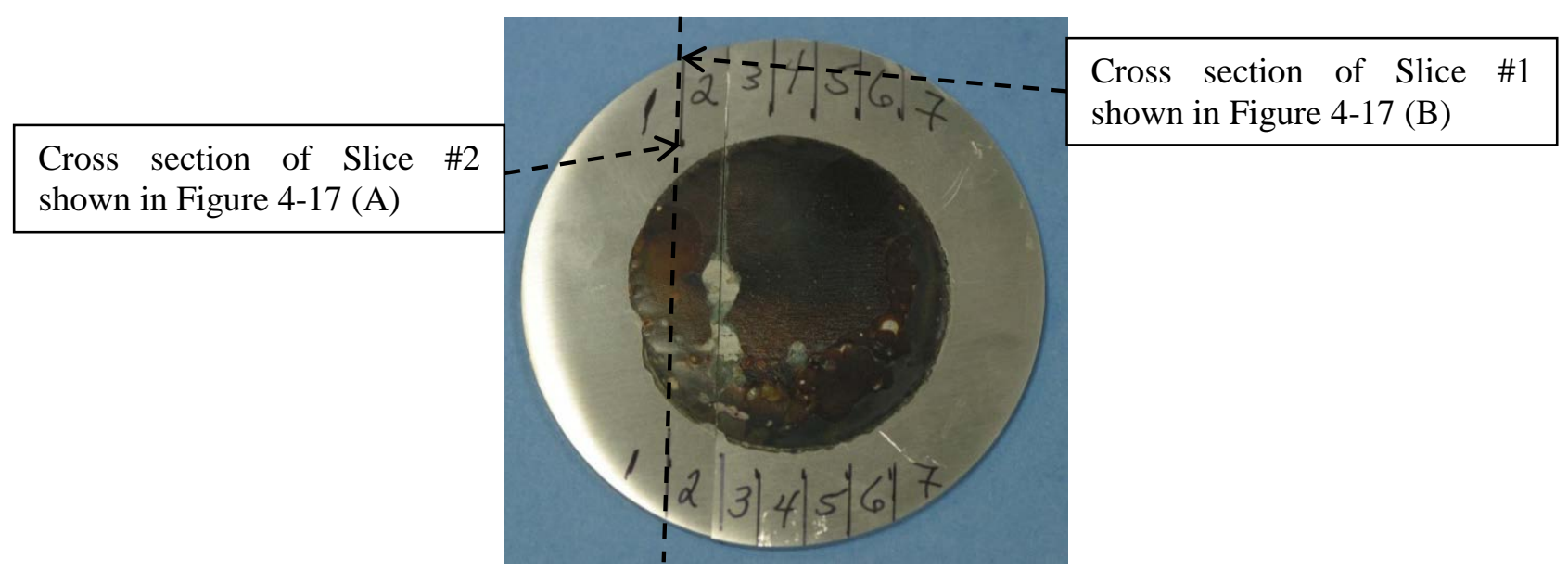

Figure 4-16. C276 hot-wall test sample after exposure to a formic-based solution showing sectioning prior to examination for localized corrosion (only one cut shown)

In the initial analysis of these slices, the sample was thought not to have pitted. This result seemed inconsistent with electrochemical results discussed previously and the coupon immersion results discussed in Section 4.3. After a review of the analysis method for the LCM data and changes in the processing of the laser data from the LCM, pitting was identified on the slices. Two examples are shown in Figure 4-17 from Slices \#1 and \#2 (shown in Figure 4-16). In Figure 4-17 (A) a subsurface pit was identified (indicated by the arrow) on Slice \#2, while in Figure 4-17 (B) a surface pit was identified on Slice \#1.
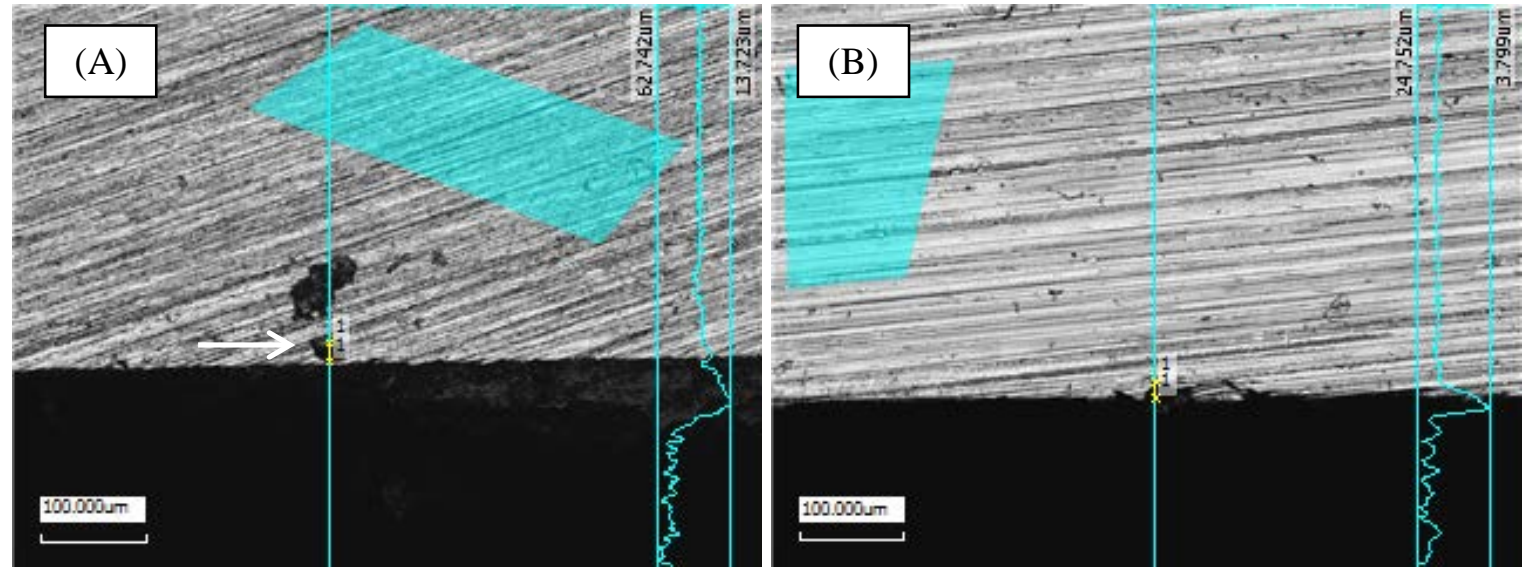

Figure 4-17. C276 hot-wall sample after testing in the formic-based SRAT/SME supernate: (A) cross-sectional view (400x) of Slice \#2 showing sub-surface pit; (B) cross-sectional view (400x) from Slice \#1 showing surface pit

In Figure 14-17 (A), the material above this pit is assumed to be some of the coating that has broken off. The line profile through the pit, shown in Figure 4-18 (A), shows a dip below the baseline indicating the pit. The rise above the profile baseline indicates the remnant piece of coating. The size of the pit in this plane is approximately $19 \mu \mathrm{m}$. In Figure 4-17 (B), the pit on the surface can be seen with the line profile through the pit shown in Figure 4-18 (B). The drop below the baseline for this pit is more difficult to 
decipher since the coating had separated from the sample, i. e. possible crevice. The pit depth was measured at approximately $11 \mu \mathrm{m}$.

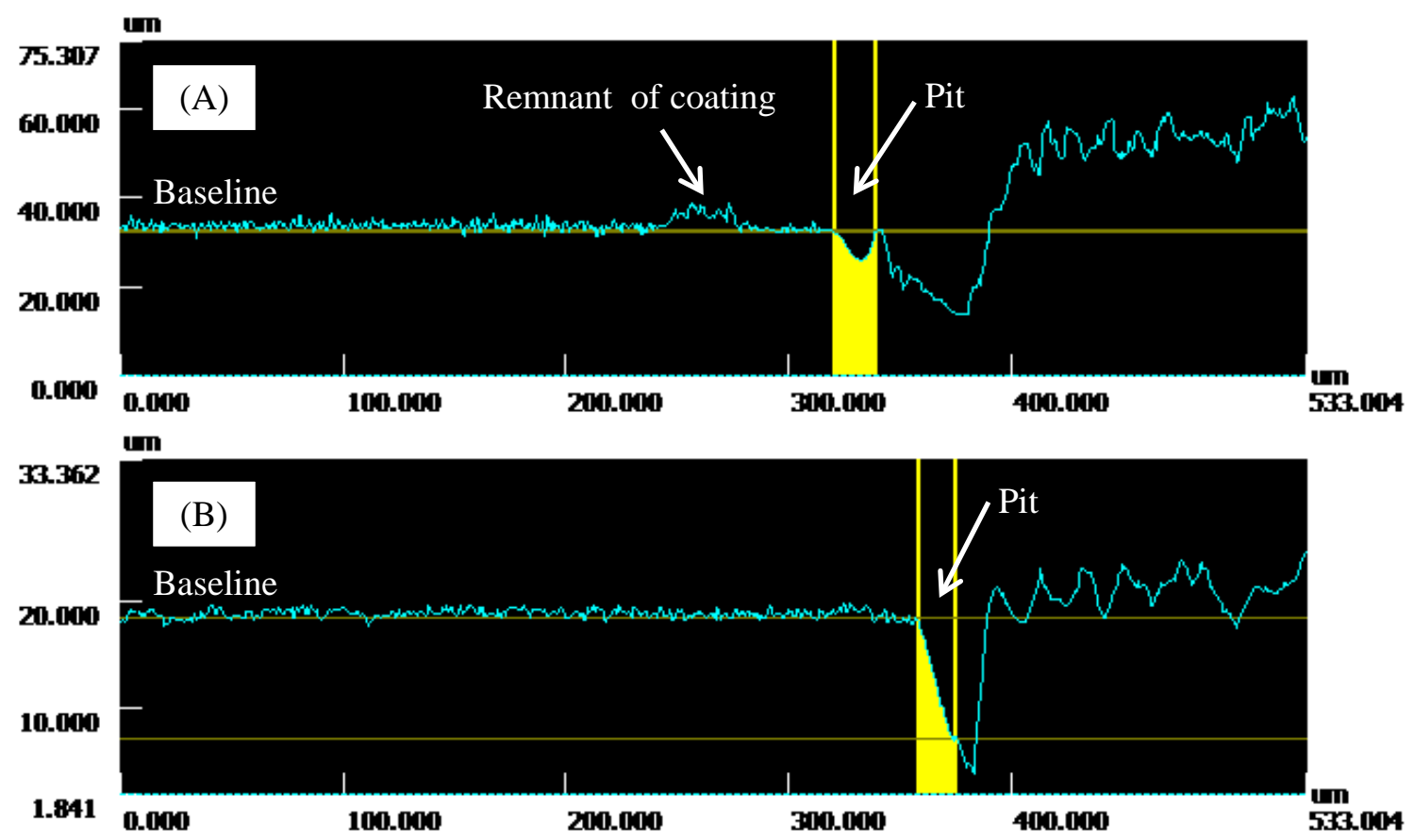

Figure 4-18. C276 hot-wall sample after testing in the formic-based solution: (A) profile line shown in Figure 4-17(A) through sub-surface pits; and (B) profile line shown in Figure 4-17 (B) through surface pit

The G30 samples tested in basic concentrated recycle solution were used to evaluate degradation for the $2 \mathrm{H}$ evaporator. In both tests (with and without the glycolate anion), a film formed on the sample. X-ray fluorescence results showed the film to be primarily composed of silicon. The silicon was likely from the glass test vessel, which was etched during the testing in these high $\mathrm{pH}$ solutions. Figure 4-19 shows the sample for the glycolate-containing solution before and after cleaning the sample.
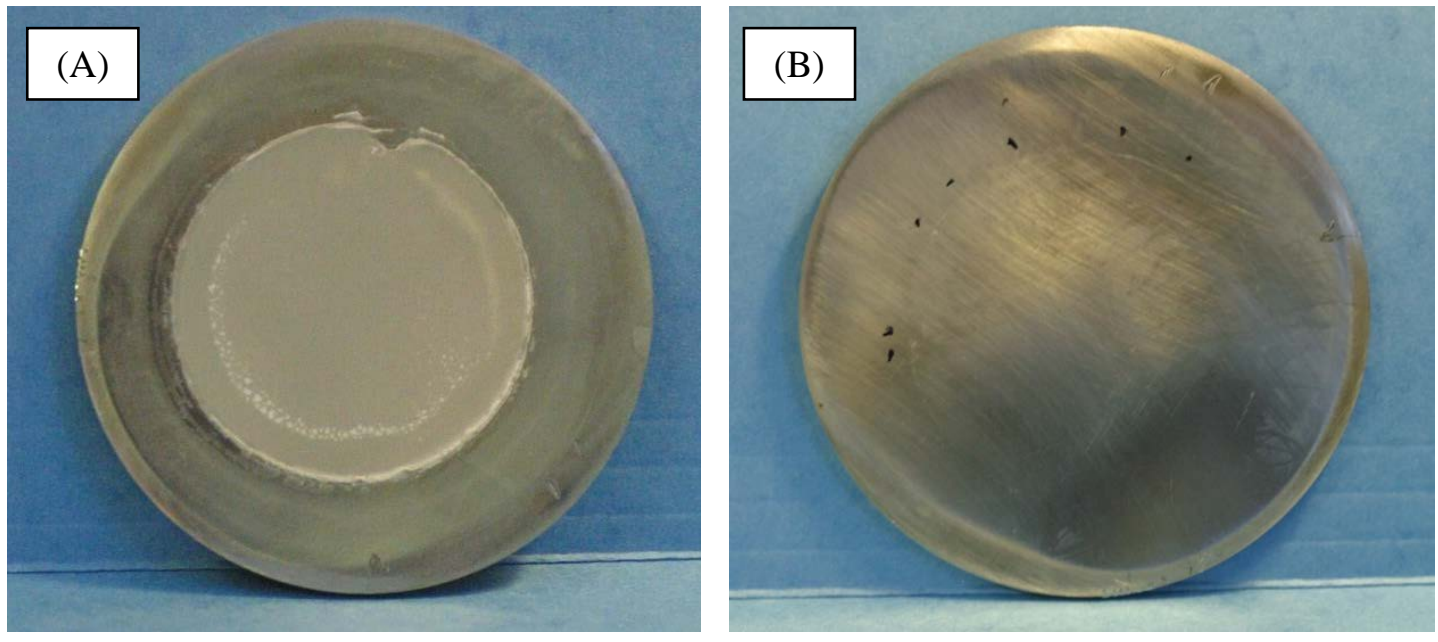

Figure 4-19. G30 hot-wall samples exposed to a boiling basic concentrated recycle solution: (A) post-test photograph showing silicon-rich film; and (B) post-cleaning photograph after removal of film (black spots showing locations of observed pitting 
As can be seen from the G30 data in Table 4-6, localized corrosion was associated with deposits on the surface in both the presence and absence of the glycolate anion. Measured pit depths were also similar between these two tests. The slight difference in depth may be associated with the difference in test duration. These results are similar to those from the first phase test data summarized in Table 4-5, indicating the alloy is susceptible to underdepoist corrosion in these solutions.

Similar to the G30 hot-wall samples, the G3 hot-wall samples tested in a dilute waste solution with and without the glycolate anion had a similar post-test appearance as well as pit characterization. Figure 4-20 shows the post-test photographs of the G3 hot-wall samples. Their appearance was also similar to the G3 sample tested initially [2]. The spots in the center had pits in only some cases and only after exposure to the solution with the glycolate anion. Most of the pits were generally associated with deposits. The pit depths as shown in Tables 4-5 and 4-6 for the follow-up tests as well as the first phase data set are of the same order of magnitude and not considered different.
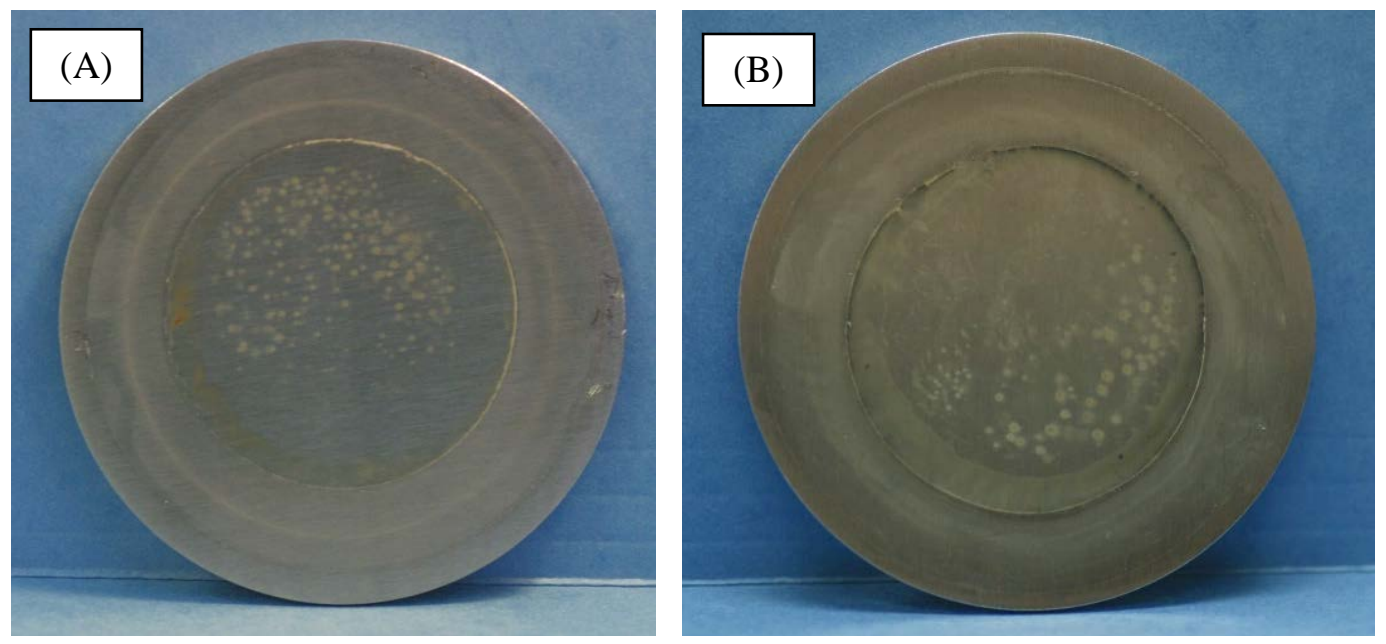

\section{Figure 4-20. Post-test photographs of G3 hot-wall sample exposed to a boiling dilute waste solution with (A) and without (B) the glycolate anion}

For the G30 and G3 samples, deposits on the samples appear to be a major contributor to the presence of localized corrosion independent of the presence of the glycolate anion. The hot-wall tests do not replicate the facility conditions, that is, the operating conditions for the $2 \mathrm{H}$ evaporator or the ETF heating coils. In both cases, a part of the operation is a procedure for removing scale and salt, which minimizes or eliminates the buildup of deposits on the heat-transfer surfaces. This type of procedure was not part of the hot-wall testing. These results indicate the importance of cleaning in maintaining these units in an operational condition whether the glycolate anion is present or not.

\subsection{Coupon Immersion Test Results}

The six-month coupon immersion test evaluated three chemistries of SRAT/SME supernates containing the glycolate anion and a supernate chemistry with formate present. At the half way point in the testing, mercury was added to the three solutions, which were previously mercury free, to make the solutions more aggressive since significant pitting was not observed (pit depths greater than 1 mil and pit density greater than 10). Only one solution with the highest sulfate and nitrate concentrations had mercury from the start of the test. Additionally, a set of coupons was placed in after the first set of coupons was removed after one month. The solution compositions and coupon exposure and mercury addition times are summarized in Table 4-7. Over the course of the six-month test solutions were changed five times. 
Table 4-8. Coupon Exposure and Mercury Addition Times during Coupon Immersion Test*

\begin{tabular}{|c|c|c|c|c|c|c|}
\hline \multicolumn{2}{|r|}{ Solution } & \multicolumn{5}{|c|}{ Coupon Exposure Period (Month) } \\
\hline Number & Chemistry & One & Three & Four & Five & Six \\
\hline 1 & $\begin{array}{l}\text { High sulfate and nitrate } \\
100 \text { ppm chloride }\end{array}$ & $\begin{array}{c}\text { Hg - start } \\
\text { C - start }\end{array}$ & $\begin{array}{l}\text { Hg - start } \\
\text { C - start }\end{array}$ & $\begin{array}{l}\mathrm{Hg}-\text { start } \\
\mathrm{C}-1 \mathrm{mo}\end{array}$ & No coupons & $\begin{array}{l}\mathrm{Hg} \text { - start } \\
\mathrm{C} \text { - start }\end{array}$ \\
\hline 2 & $\begin{array}{l}\text { Moderate sulfate } \\
\text { High nitrate } \\
100 \text { ppm chloride }\end{array}$ & $\begin{array}{l}\text { No Hg } \\
\text { C - start }\end{array}$ & $\begin{array}{l}\text { No Hg } \\
\text { C - start }\end{array}$ & $\begin{array}{c}\mathrm{Hg}-3 \mathrm{mos} \\
\mathrm{C}-1 \mathrm{mo}\end{array}$ & No coupons & $\begin{array}{c}\mathrm{Hg}-3 \text { mos } \\
\mathrm{C}-\text { start }\end{array}$ \\
\hline 3 & $\begin{array}{l}\text { Nominal sulfate and nitrate } \\
50 \mathrm{ppm} \text { chloride }\end{array}$ & $\begin{array}{l}\text { No Hg } \\
\text { C - start }\end{array}$ & $\begin{array}{l}\text { No Hg } \\
\text { C - start }\end{array}$ & $\begin{array}{c}\mathrm{Hg}-3 \mathrm{mos} \\
\mathrm{C}-1 \mathrm{mo} \\
\end{array}$ & $\begin{array}{c}\mathrm{Hg}-3 \mathrm{mos} \\
\mathrm{C}-1 \mathrm{mo} \\
\end{array}$ & $\begin{array}{c}\mathrm{Hg}-3 \mathrm{mos} \\
\mathrm{C}-\text { start }\end{array}$ \\
\hline 4 & $\begin{array}{l}\text { Nominal sulfate and nitrate } \\
50 \mathrm{ppm} \text { chloride }\end{array}$ & $\begin{array}{l}\text { No Hg } \\
\text { C - start }\end{array}$ & $\begin{array}{l}\text { No Hg } \\
\text { C - start }\end{array}$ & $\begin{array}{c}\mathrm{Hg}-3 \mathrm{mos} \\
\mathrm{C}-1 \mathrm{mo}\end{array}$ & $\begin{array}{c}\mathrm{Hg}-3 \mathrm{mos} \\
\mathrm{C}-1 \mathrm{mo} \\
\end{array}$ & $\begin{array}{c}\mathrm{Hg}-3 \mathrm{mos} \\
\mathrm{C}-\text { start }\end{array}$ \\
\hline
\end{tabular}

* C indicates when coupons were placed into the test, either at the start of test or at 1 month (mo); Hg indicates when mercury additions were made to a solution, either from the start or beginning at 3 months (mos)

With increasing time in the test, coupons had an increasing buildup of deposits or a coating on the surface. The coating appeared to be similar for the glycolic-based solutions and different for the formic-based solution. The formic-based supernate had the most coating, which was also the most difficult to remove during cleaning after the test. Coatings formed in glycolic-based solutions were somewhat brittle and easily removed. These features are shown in Figures 4-21 and 4-22. Figure 4-21 shows the coating development on C276 in Solution \#1 over the six-month exposure, the other MoCs had similar increases in coating coverage. Figure 4-22 shows welded C276 coupons from each solution (\#1 through \#4) at the end of the six-month exposure. The scratch on the welded C276 coupon exposed to Solution \#1 was from tweezers and is an indication of the coating ease of removal. All the six-month coupons from Solution \#3, which was a glycolic-based solution, actually produced a darker coating not previously observed on coupons removed from Solution \#3. The reason for the change is not known, but could be attributed to the mercury addition at the half way point in the test.
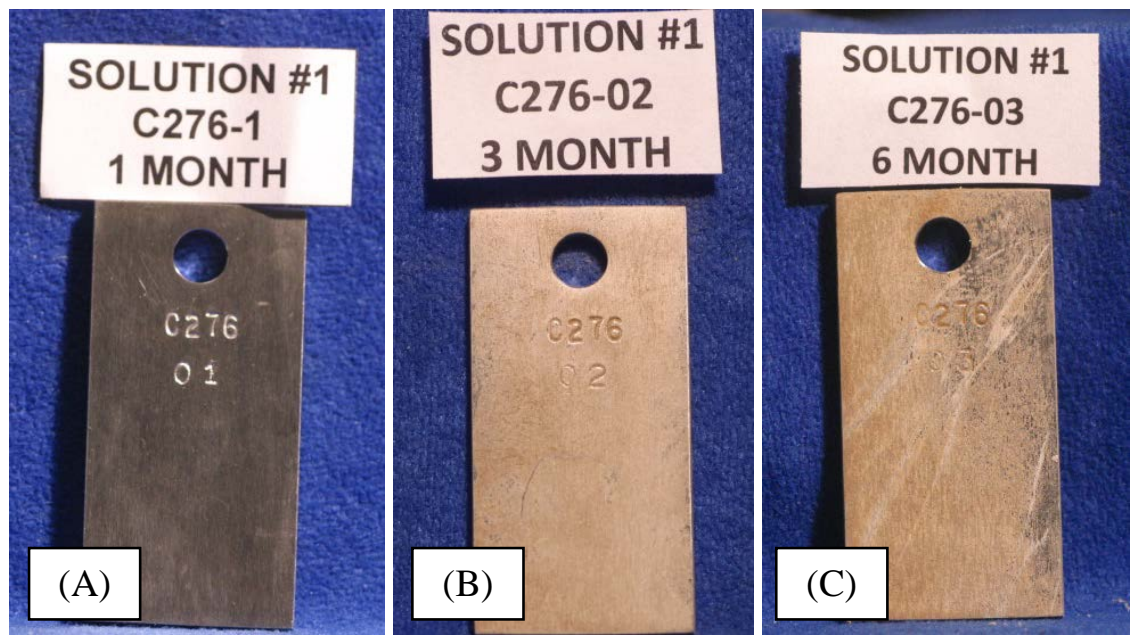

Figure 4-21. Photographs of C276 coupons from the coupon immersion test after (A) 1 month, (B) 3 months, and (C) 6 months exposure in Solution \#1 

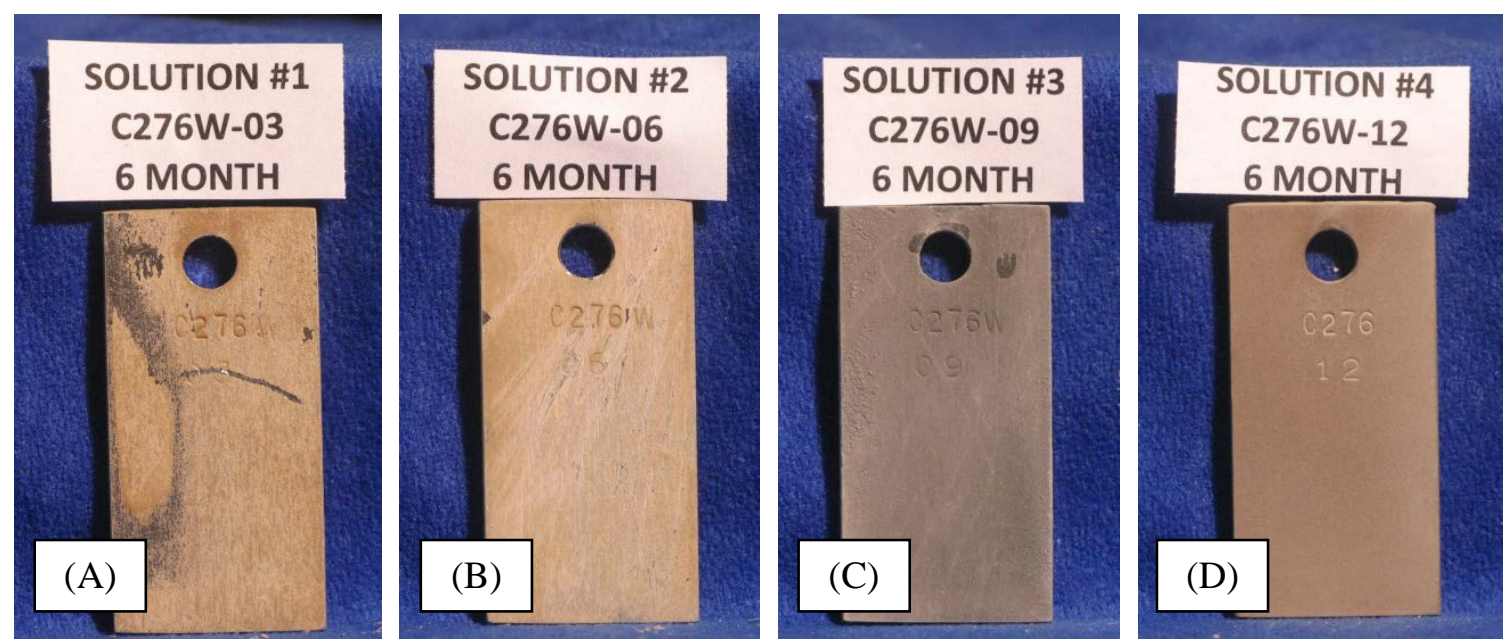

Figure 4-22. Photographs of welded C276 coupons from the coupon immersion test after six-month exposure in (A) Solution \#1, (B) Solution \#2, (C) Solution \#3, and (D) Solution \#4

On all the coupons removed during the immersion test, corrosion was not obvious. After the debris or coating was removed, grinding marks were still clear and there was minimal surface roughening. Generally, the biggest impact was from the cleaning process when plastic scrapers were needed to remove remnant coating. The lack of corrosion can be seen in the photographs shown in Figures 4-21 and 4-22 for the C276 coupons and in Figure 4-23 for Stellite and Ultimet coupons removed after five-month exposures in Solutions \#3 and \#4 (a glycolic- and formic-based solution, respectively, with $50 \mathrm{ppm}$ chloride and $2000 \mathrm{ppm}$ sulfate). Note that the coating on the coupons exposed to Solution \#3 was easily removed and came off during handling.
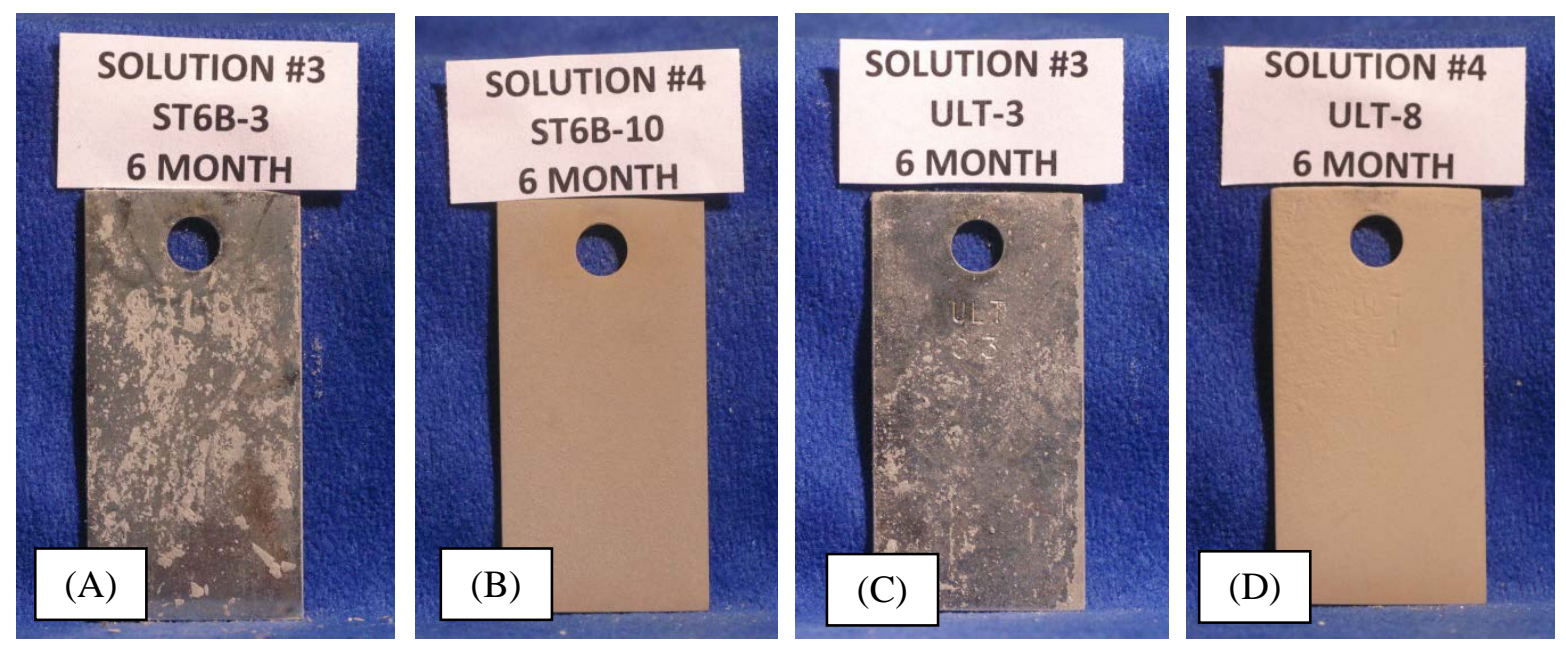

Figure 4-23. Photographs of five-month exposure coupons: (A) Stellite 6B in Solution \#3; (B) Stellite 6B in Solution \#4; (C) Ultimet in Solution \#3; and (D) Ultimet in Solution \#4

The corrosion rates measured from the weight changes during the test reflect a lack of significant general corrosion, similar to the visual observations. Table 4-8 shows the corrosion rates for the MoCs in these glycolic- and formic-based solutions during the six-month coupon immersion test. The complete listing of all the coupon weights and the calculated corrosion rates are given in Appendix B for all the different time intervals that coupons were exposed. As shown in Table 4-8, the C276 corrosion rates for these longest exposure periods are all well below the estimates of the upper bound corrosion rates for the SRAT 
and SME tanks, i.e. 1 mpy [15]. These measured corrosion rates did not correlate to expected corrosivity of the glycolic-based solutions; i.e. decreasing rates progressing from Solution \#1 to Solution \#3.

Table 4-9. Corrosion Rates for MoCs in Glycolic- and Formic-based CPC Solutions from the Sixmonth Coupon Immersion Test

\begin{tabular}{|c|c|c|c|c|}
\hline Solution \# & Solution Chemistry & Alloy & $\begin{array}{c}\text { Duration } \\
\text { (mos) }\end{array}$ & $\begin{array}{l}\text { Corrosion } \\
\text { Rate (mpy) }\end{array}$ \\
\hline \multirow{4}{*}{1} & \multirow{4}{*}{$\begin{array}{l}\text { Glycolic-based, high } \\
\text { sulfate and nitrate, } 100 \\
\text { ppm chloride }\end{array}$} & $\mathrm{C} 276$ & 6 & 0.020 \\
\hline & & C276W & 6 & 0.027 \\
\hline & & St6B & 6 & -0.008 \\
\hline & & Ult & 6 & 0.001 \\
\hline \multirow{4}{*}{2} & \multirow{4}{*}{$\begin{array}{l}\text { Glycolic-based, moderate } \\
\text { sulfate, high nitrate }, 100 \\
\text { ppm chloride }\end{array}$} & C276 & 6 & 0.011 \\
\hline & & C276W & 6 & 0.011 \\
\hline & & St6B & 6 & -0.005 \\
\hline & & Ult & 6 & -0.016 \\
\hline \multirow{4}{*}{3} & \multirow{4}{*}{$\begin{array}{l}\text { Glycolic-based, nominal } \\
\text { sulfate and nitrate, } 50 \\
\text { ppm chloride }\end{array}$} & C276 & 6 & 0.015 \\
\hline & & C276W & 6 & 0.018 \\
\hline & & St6B & 5 & -0.005 \\
\hline & & Ult & 5 & -0.004 \\
\hline \multirow{4}{*}{4} & \multirow{4}{*}{$\begin{array}{l}\text { Formic-based, nominal } \\
\text { sulfate and nitrate, } 50 \\
\text { ppm chloride }\end{array}$} & C276 & 6 & -0.017 \\
\hline & & C276W & 6 & -0.027 \\
\hline & & St6B & 5 & -0.005 \\
\hline & & Ult & 5 & -0.004 \\
\hline
\end{tabular}

Negative corrosion rates were calculated generally for Stellite 6B and Ultimet coupons in all test solutions and for all MoCs in the formic-based solution, which results from a greater weight after testing than before. This weight increase is attributed to an incomplete removal of the deposits or coatings that formed during the test. As previously stated above, the coatings that developed from the formic-based solutions were difficult to remove. A much smaller amount of residual deposits and coatings, if any, were found after cleaning coupons that were exposed to glycolic-based solutions. After most of the deposits or coatings were removed, more extensive cleaning for complete removal was not performed so as not to alter the surface morphology results from test solution exposure. Another contributing cause may have been surface oxidation although the coupon surfaces especially after glycolic-based solution exposure were fairly shiny, which would not be expected for an oxidized surface.

These data clearly demonstrate that the general corrosion rates for the different MoCs during extended exposures to glycolic-based or formic-based DWPF simulants are acceptable, i.e. < 1mpy. The other aspect of this testing was to evaluate the occurrence of localized corrosion, especially pitting corrosion. Crevice or underdeposit corrosion was also evaluated due to the formation of deposits or coatings on the surface during the test. Table 4-9 summarizes the measured pit/crevice data showing pits depths for each MoC in each solution after one-, three-, and six-month exposures. Mercury was added to Solutions \#2 \#4 after three months, whereas Solution \#1 had mercury from the start. ${ }^{6}$

\footnotetext{
${ }^{6}$ Similar to the electrochemical testing, the source of mercury used for Solution \#1 during the first three months had absorbed moisture so that actual mercury concentrations were lower than planned.
} 
The measured pit counts and depths demonstrate that pitting and crevice corrosion is not a significant issue in these DWPF SRAT/SME supernate simulants. A progressive increase in pit count and depth from the one-month to the six-month coupon exposures was not observed. Three pits were measured at greater than $1 \mathrm{mil}(25.4 \mu \mathrm{m})$. Many small pits $(<10 \mu \mathrm{m})$ were observed, more similar to metastable pits that passivate and stop progressing [16]. Stellite and Ultimet may be showing a slightly greater tendency for localized corrosion in mercury bearing solutions. A comparison of the three- and six-month exposure results shows progressively more pitting with time (greater count or depth). Although some minimal nonprogressing pitting was observed in this test, the MoCs did not show a greater susceptibility to localized corrosion in glycolic-based solutions than in formic-based solutions.

Table 4-10. Pit Count and Depth for DWPF MoC Samples from the Six-month Coupon Immersion Test

\begin{tabular}{|c|c|c|c|c|c|}
\hline \multirow{2}{*}{$\begin{array}{c}\text { Solution } \\
\quad \#\end{array}$} & \multirow{2}{*}{ Solution Chemistry } & \multirow{2}{*}{ Alloy } & \multicolumn{3}{|c|}{ 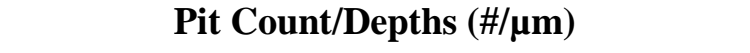 } \\
\hline & & & One-Month & Three-Month & Six-Month* \\
\hline \multirow{4}{*}{1} & \multirow{4}{*}{$\begin{array}{l}\text { Glycolic-based, high } \\
\text { sulfate and nitrate, } \\
100 \text { ppm chloride }\end{array}$} & C276 & $3 / 4-21$ & $4 / 5-16$ & $1 / 9$ \\
\hline & & C276W & $2 / 5-7$ & $2 / 6-7$ & None \\
\hline & & St6B & $1 / 27$ & None & None \\
\hline & & Ult & $4 / 2-4$ & None & $12 / 7-43$ \\
\hline \multirow{4}{*}{2} & \multirow{4}{*}{$\begin{array}{l}\text { Glycolic-based, } \\
\text { moderate sulfate, } \\
\text { high nitrate }, 100 \\
\text { ppm chloride }\end{array}$} & C276 & None & None & $4 / 5-13$ \\
\hline & & C276W & None & $3 / 7-10$ & None** \\
\hline & & St6B & None & None & 3/13-17 \\
\hline & & Ult & $1 / 6$ & $1 / 6$ & $5 / 7-12$ \\
\hline \multirow{4}{*}{3} & \multirow{4}{*}{$\begin{array}{l}\text { Glycolic-based, } \\
\text { nominal sulfate and } \\
\text { nitrate, } 50 \mathrm{ppm} \\
\text { chloride }\end{array}$} & $\mathrm{C} 276$ & None & None & 9/13-17 \\
\hline & & C276W & None & $1 / 14$ & $1 / 16$ \\
\hline & & St6B & $2 / 14-28$ & None & $3 / 10-16$ \\
\hline & & Ult & No coupon & $5 / 5-17$ & $1 / 14$ \\
\hline \multirow{4}{*}{4} & \multirow{4}{*}{$\begin{array}{l}\text { Formic-based, } \\
\text { nominal sulfate and } \\
\text { nitrate, } 50 \mathrm{ppm} \\
\text { chloride }\end{array}$} & C276 & $8 / 4-10$ & $3 / 3-9$ & None** \\
\hline & & C276W & None & $1 / 9$ & None** \\
\hline & & St6B & None & None & $5 / 5-11$ \\
\hline & & Ult & No coupon & $3 / 3-9$ & 9/6-34 \\
\hline
\end{tabular}

* For Solutions \#3 and \#4, the Stellite and Ultimet samples were exposed for five months

** These coupons were re-evaluated to measure all marks on the surface using the LCM. A population (10-15) of marks measuring less than 5 um was identified and found to be as deep as the corrosion along grinding marks.

\subsection{NDE - Large Scale Testing}

When the large-scale $1 / 200^{\text {th }}$ test was performed to assess process changes due to scale up when using glycolic acid as a reductant, the $1 / 200^{\text {th }}$ test vessel and the heating coils were used as large-scale coupons to obtain a relative assessment of the process solution aggressiveness, i.e. corrosion and erosion, to the MoCs, which were 304L stainless steel. UT wall thickness measurements were made before and after the two-week test at key areas where erosion/corrosion might be an issue as based on past failures of actual DWPF SME coil assemblies. These locations included down the vessel wall at four orthogonal locations and along several ring lengths of the inner, outer and middle coils at four orthogonal locations $[17,18]$. In Figure 4-24 (A), the locations along the coils are shown by the green arrows, which also show the 
measurement locations relative to the agitator blades positions. Measurement accuracy at these thicknesses ( 0.03-0.07 in) was +/- 0.001 inch. Measurements within this variability range were considered unchanged.

The largest wall loss was found on the inner and bottom surfaces of lowest ring of the heating coils and just below the bottom head to shell weld of the vessel $[19,20]$. Figure 4-24 (B) shows the UT measurements along the bottom surface of the lowest ring before (baseline) and after (final) the test. The ring wall losses were approximately 2-3 mils. No wall loss was measured for the coil lengths that were located between the agitator blades. The location of these losses was similar to those observed on the DWPF SME coil assemblies and where erosion is the primary degradation mode. Several circumferential welds for the coils also showed no wall loss. The loss of the vessel wall thickness below the weld was 2 mils.

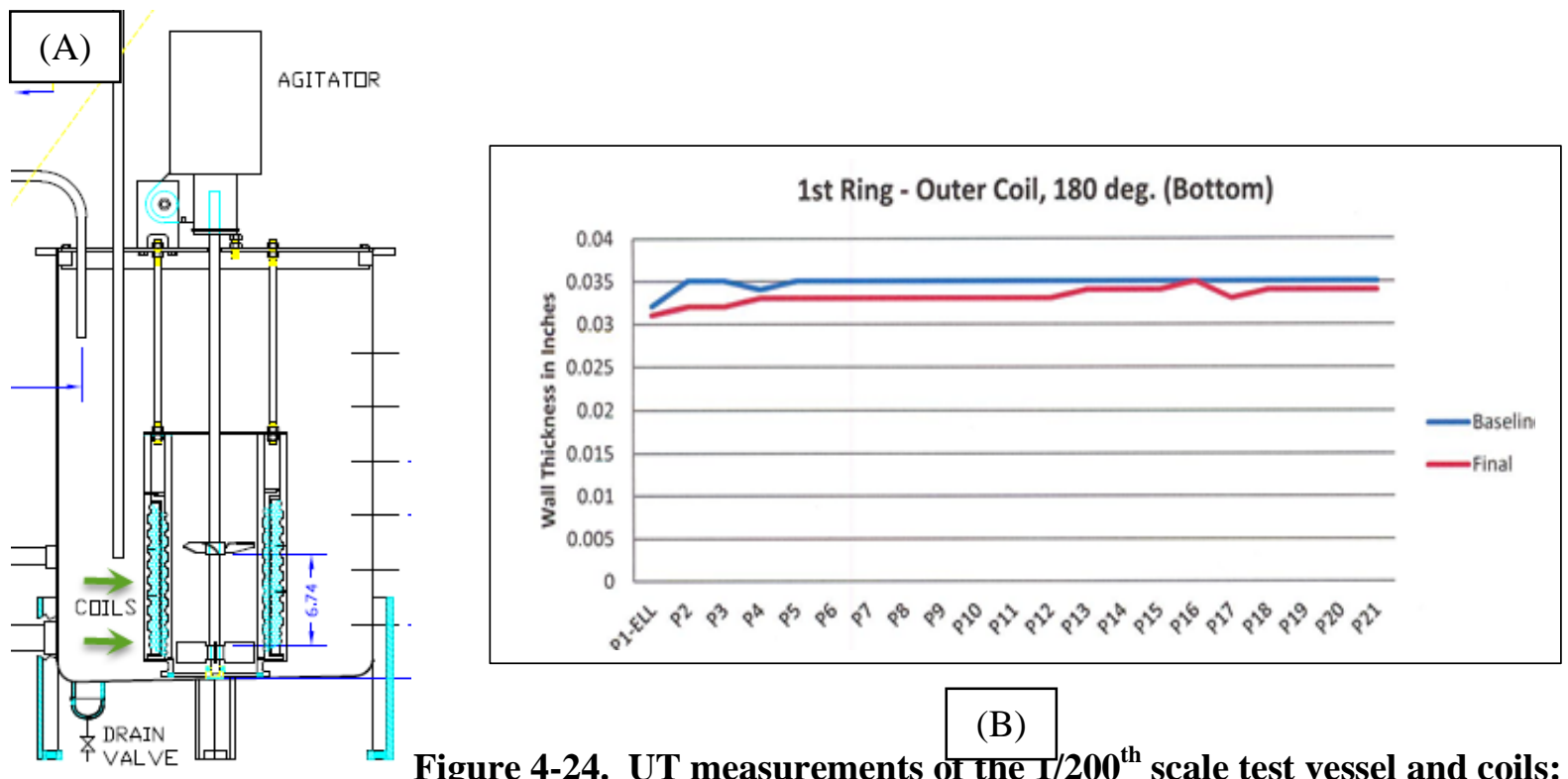
(A) vessel diagram with arrows showing coil measurement location; and (B) UT thickness measurements for lowest $\left(1^{\text {st }}\right)$ ring of the outer coil welds along the bottom surface $\left(1^{\circ} 0^{\circ}\right.$ position)

\subsection{Discussion}

This follow-up testing was conducted to address unresolved areas of concern that were identified from the first phase of testing. During the first phase of testing, the impact of the glycolate anion on the corrosion of MoCs for most vessels and components within the DWPF and downstream facilities was found not to impact the expected service life. The vessels and components of concern at the end of the first phase of testing were those associated with the DWPF CPC and the heating components for the $2 \mathrm{H}$ evaporator and the ETF. An additional area raised later was the effect of the glycolate anion in the REDC.

The primary focus for this follow-up testing was on the DWPF CPC and understanding the different impacts on the MoCs of both formic and glycolic acids, the current and alternate DWPF reductants. The testing was not targeted at the rapidly changing conditions when the acidic reductant is added to the caustic sludge or the impact of erosion; so while DWPF processes are dynamic, laboratory tests simulated static operating conditions. The test solutions were based on chemistries from SME simulants determined during flowsheet development. The primary MoC is C276, which is the containment barrier for CPC vessels and components. Testing with Ultimet and Stellite, alloys used for erosion protection in the SRAT and SME, was limited to the coupon immersion test with only corrosion being evaluated. 
The results in the formic-based solutions establish a point of comparison between actual service history of the CPC vessels and components and the laboratory data for the glycolic-based solutions. The effect of formic acid on the MoCs using the current test scheme of electrochemical, hot-wall and coupon immersion had not previously been determined. The correspondence of these laboratory data to actual service performance in the DWPF CPC is limited since regular or periodic inspection of the vessels and components in the CPC has not been performed.

For the formic-based solutions in both the hot-wall and coupon immersion tests, samples were covered with a tenacious coating. The measured pits found beneath these coatings ranged between 10 and $20 \mu \mathrm{m}$ for the hot-wall tests and $<20 \mu \mathrm{m}$ for the coupon immersion test. ${ }^{7}$ The smaller pits $(<5 \mu \mathrm{m})$ were of depths that were similar to corrosion along grinding marks so these pits may have also started from small surface imperfections. The larger pits $(>10 \mu \mathrm{m})$ may be indicative of some localized growth of a pit, although the progression of pit depth with time in the coupon immersion was not observed. Based on the coupon immersion test, pitting is not expected to grow under CPC conditions of boiling formic-based solutions although pits may initiate. Since heating coils have been removed from service in the SRAT, these coils provide an opportunity to validate the surface condition resulting from processing with formic acid as a reductant. Inspection of the coil surface is recommended to determine actual material performance.

In the limited number of electrochemical test for the formic-based solutions, localized corrosion, i.e. pitting and possibly crevice corrosion, occurred with deposits. The deposits corresponded to either high chloride $(247 \mathrm{ppm})$ or high sulfate $(5571 \mathrm{ppm})$ conditions. If the sample did not pit in the high sulfate condition, the surface reacted with the solution since the sample had a bronze appearance. For the formic-based solutions, sufficient tests were not conducted to establish a cause and effect with either the deposits on or bronzing of the sample. Both conditions where deposits and pitting were observed have not occurred in the DWPF as based on the sludge feed chemistries shown in Table 4-2. The electrochemical results for the solution chemistry used in the coupon immersion tests indicated no pitting.

In the glycolic-based solutions, the follow-up electrochemical testing for C276 showed that at a chloride concentration less than $100 \mathrm{ppm}$ localized corrosion was not an issue unless the nitrate/glycolate concentration was low $(\sim 35,000 / 25,000 \mathrm{ppm})$, which resulted in deposits forming on the sample. For the Sludge Batch \#8, nitrate concentrations with the current nitric-formic acid flowsheet are $\sim 30,000 \mathrm{ppm}$ which for a nitric-glycolic acid flowsheet would have an expected nitrate concentration of $\sim 50,000 \mathrm{ppm}$ [21]. Deposits would not be expected to form, but for future flowsheets the nitrate concentration will depend in part on the noble metal concentration since these metals catalyze the destruction of nitrate.

In the hot-wall tests in support of the nitric-glycolic flowsheet, pits associated with deposits were found on the C276 sample after one month at boiling conditions. The pit depths for the follow-up and first phase testing were less than $5 \mu \mathrm{m}$ and $10 \mu \mathrm{m}$, respectively, after one-month of boiling. The chloride concentrations of these two tests also differed with $100 \mathrm{ppm}$ for the follow-up testing and near the WAC limit (> $5000 \mathrm{ppm}$ ) for the first phase testing. The concentration of chlorides that remain soluble in both these tests is not known since deposits formed during both tests. These tests may indicate that the observed pitting is driven more by other factors, such as surface imperfections, than the chloride concentration.

The coupon immersion tests evaluated the corrosion over an extended time unlike the other two tests. Pitting was identified during this test in the glycolic-based solutions, although as shown by the data in Table 4-9, pit depths for C276 did not show a consistent trend of increasing depth with exposure time in

\footnotetext{
${ }^{7}$ Note that $25.4 \mu \mathrm{m}$ is equivalent to 1 mil or 0.001 inch so a $5 \mu \mathrm{m}$ pit is equivalent to 0.2 mil or 0.0002 inch.
} 
any of the glycolic-based solutions. The largest measured pit depth was $17 \mu$ m, which was measured in the least corrosive solution (i.e., lowest sulfate and chloride concentrations). In the coupon immersion test, a debris or coating formed, which increased in coverage, on the test samples during the test as shown in Figure 4-21. Deposits, which may have contributed to pit formation, were observed also in both the electrochemical and hot-wall tests. The formation of these pits may be associated with surface imperfections and deposits.

In all the C276 tests with the glycolic-based solutions, pitting was observed. These data collectively show that a localized corrosion can occur in glycolic-based solutions, which may be independent of chloride concentrations. Both the hot-wall test results showing similar pit depths at different chloride concentrations and the coupon immersion test results where higher depths were found at the lowest chloride concentration support this statement and indicate other variables may be more important such as deposit formation, which was noted in all tests, or surface imperfections and inclusions. Although these pits form, the coupon immersion test results indicate that pit growth would not be expected under similar conditions.

Since the tanks and components of the DWPF CPC cannot be inspected, analyses of components or tanks removed from the canyon are recommended to determine if localized corrosion is occurring with a nitricglycolic flowsheet. This removal would most likely occur after a failure and a subsequent failure analysis would provide valuable data on the condition of these tanks or components, realizing that they also were exposed to the nitric-formic flowsheet. Without the data from periodic inspections within the CPC, a failure after the switch to the nitric-glycolic flowsheet will make a failure assessment difficult because of the uncharacterized degradation caused during the nitric-formic flowsheet.

The results for general corrosion for both the glycolic- and formic-based solutions show low corrosion rates. The coupon immersion test results after six months had rates $<<1 \mathrm{mpy}$, while the electrochemicalmeasured corrosion rates were around 1 mpy for glycolic-based solutions and $<0.5$ mpy for formic-based solutions.

Ultimet and Stellite are used in the SRAT and SME to provide wear resistance to agitator blades and the coil supports. The results from the coupon immersion test for these MoCs showed negligible general corrosion loss but a slight increase in localized corrosion susceptibility after six-month exposures versus the shorter times. Some depths are significant $(1 \mathrm{mil})$ for Ultimet in both Solution \#1 (glycolic-based, highest concentration of aggressive species) and \#4 (formic-based). These depths are similar to those observed during the first phase hot-wall testing where the deepest pit was slightly less than 1 mil, although deeper pits were found near the gasket. Since the performance is similar between the formic and glycolic-based solutions, these MoCs would be expected to perform as well with the nitric -glycolic acid flowsheet as they currently perform with nitric-formic flowsheet in the DWPF.

Further investigation was also performed for 304L in $70 \%$ glycolic acid at temperatures less than $50{ }^{\circ} \mathrm{C}$. $304 \mathrm{~L}$ is the MoC for some of the formic acid feed tanks and components as is 316L stainless steel. In the first phase of testing $316 \mathrm{~L}$ performed well at $50{ }^{\circ} \mathrm{C}$ with no localized corrosion susceptibility, while 304L showed some tendency to pit. Testing at $35{ }^{\circ} \mathrm{C}$ and room temperature showed that $304 \mathrm{~L}$ still showed some tendency for localized corrosion, especially in the presence of inclusions. For the 304L components in the glycolic acid feed system, baseline and future inspections are recommended to determine if 304L is susceptible to pitting. No testing was performed to assess lower dilutions of glycolic acid.

The testing in the decontamination solution (12.5\% nitric acid) for the REDC clearly showed that independent of the presence of the glycolate anion at a concentration of $10 \mathrm{~g} / \mathrm{L}$ Alloy 20 showed passive corrosion behavior. The tests were performed at boiling since future plans include using a steam lance in 
the REDC soak tank if needed. Alloy 20 is expected to show no adverse effect from the presence of the glycolate anion even at high temperatures.

Hot-wall tests were also performed for G30 and G3, which are the materials of construction for the coils in the $2 \mathrm{H}$ evaporator and the heater in ETF evaporator, respectively. In the first phase of testing, which had the glycolate anion present, the samples pitted especially near deposits and the gasket. Similar results were found during this follow-up testing both with and without the glycolate anion present, so the presence of the glycolate anion in the system will not impact the MoCs differently. These tests were performed continuously without a cleaning step as is periodically performed in both evaporators. For the $2 \mathrm{H}$ evaporator, a desalting/descaling is performed every 180 days when an inspection is due. These tests results show that the cleaning steps are necessary for deposit removal and optimal performance.

\subsection{Conclusions}

To address the concerns with the use of glycolic acid identified during the first phase of testing, a second phase or follow-up testing was conducted to better identify temperature and waste chemistry conditions for acceptable performance of the MoCs, especially those susceptible to localized corrosion. The testing included a series of electrochemical and hot-wall tests, and a six-month coupon immersion test. The electrochemical tests were targeted towards three areas of the DWPF: glycolic acid feed tanks and piping, CPC components, and the REDC components. Hot-wall tests were conducted to further clarify the observed localized corrosion during the first phase of testing for the heat transfer surfaces in the CPC and downstream facilities (2H evaporator and evaporator heater of the ETF). A six-month coupon immersion test was conducted to verify that the accelerated results of the electrochemical test are substantiated for an extended exposure.

The results of the follow-up testing showed that for C276 under the CPC conditions localized corrosion (pitting, crevice and underdeposit corrosion) occurred at chloride and sulfate concentrations (the primary aggressive anions) down to those processed in previous sludge batches. Deposits and coating occurred simultaneously and may be a contributing factor to the observed corrosion. These results occurred for both formic- and glycolic-based solutions with similar severity. The observed corrosion was not deep (less than $20 \mu \mathrm{m}$ or approximately $0.001 \mathrm{inch}$ ) and did not progress with time up to six months. General corrosion rates in both glycolic- and formic-based solutions were found to be approximately 1 mil per year as specified in the DWPF Structural Integrity Program. Although the effect of mercury in these glycolic-based solutions was not studied extensively, mercury was found to impact the general corrosion rate but not the occurrence of localized corrosion.

Test results (i.e. six-month coupon immersion) under CPC conditions from the follow-up testing were more limited for Ultimet and Stellite, which are wear resistant materials. The corrosion of these materials in both glycolic- and formic-based solutions was similar. The localized corrosion, which again was associated with the formation of deposits and coatings, showed a slight progression with time in the sixmonth coupon immersion test. The impact of this corrosion on the erosion characteristics was not studied. Performance of these materials during glycolic-based processing is expected to be similar to the performance during formic-based processing.

For other DWPF process areas, the glycolic acid feed tanks and the REDC, the impact of the glycolate anion differed. For the feed tanks and associated components made of 304L stainless steel, the material was found to be susceptible to pitting in $70 \%$ glycolic acid at temperatures from room temperature up to $50{ }^{\circ} \mathrm{C}$. If $304 \mathrm{~L}$ components are chosen to handle $70 \%$ glycolic acid, an inspection program is recommended to determine if this corrosion occurs. Alternatively, 316L should be used in the feed tanks for the $70 \%$ glycolic acid. Dilution of the glycolic acid was not investigated. For the REDC, the presence of glycolate in the cleaning solution of the REDC will not impact MoC performance. 
The results of both phases of testing showed that for the materials G30 and G3, the MoCs for the heating units in the $2 \mathrm{H}$ and ETF evaporators, localized corrosion was observed in the hot-wall tests regardless of the presence of the glycolate anion. Pit depths were found to be approximately 1 mil and associated with deposits whether the glycolate anion was present or not. The current operation of desalting or descaling in these facilities minimizes the formation of these deposits.

Localized corrosion was found to occur in this study in solutions with the glycolate anion, which simulated the conditions for CPC vessels at boiling, and at $70 \%$ concentration of glycolic acid, which simulated the DWPF feed tanks. This corrosion was not severe and may not impact service life. However, if components are removed from service within the CPC or a failure occurs, a failure or metallurgical analysis is recommended of the failure area or probable areas of corrosion. These data would be used to substantiate laboratory results and assess if localized corrosion would cause a leak. For the feed tanks and components which are housed outside of the CPC and are more accessible, UT inspections configured to establish localized corrosion occurrence are recommended at the start of glycolic acid service, especially for components fabricated of 304L stainless steel. These inspections would provide a baseline for determining the state of corrosion from future inspection data. 


\subsection{References}

1 Task Technical Request: Impact of Nitric-Glycolic Acid Flowsheet - Material Evaluation for DWPF and Downstream Tank Farm Processes, HLW-DWPF-TTR-2013-0004, Revision 0, October 31, 2012

2 J. I. Mickalonis et al, "Corrosion Impact of Alternate Reductant on DWPF and Downstream Facilities,” SRNL-STI-2014-00281, Revision 0, December 2014

3 J. I. Mickalonis and T. E. Skidmore, "Material Compatibility Evaluation for DWPF NitricGlycolic Acid - Literature Review,” SRNL-STI-2013-00281, Revision 0, June 2013

4 D.P. Lambert, M.E. Stone, J.D. Newell, D.R. Best, and J.R. Zamecnik, “Glycolic-Nitric Acid Flowsheet Demonstration of the DWPF Chemical Process Cell with Sludge and Supernate Simulants, SRNL-STI-2012-00018, Revision 1, August 2012

5 G. T. Chandler, P. E. Zapp, and J. I. Mickalonis, "Hot-Wall Corrosion Testing Of Simulated High-Level Nuclear Waste,” CORROSION/95, Paper no. 431 (Houston, TX: NACE International), 1995

6 G5 - 13, "Standard Reference Test Method for Making Potentiodynamic Anodic Polarization Measurements,” ASTM International, West Conshohocken, PA 2014

7 G59 - 97 (Reapproved 2009), "Standard Test Method for Conducting Potentiodynamic Polarization Resistance Measurements,” ASTM International, West Conshohocken, PA 2014

8 G61 - 86 (Reapproved 2009), "Standard Test for Conducting Cyclic Potentiodynamic Polarization Measurements for Localized Corrosion Susceptibility of Iron-, Nickel-, or CobaltBased Alloys” ASTM International, West Conshohocken, PA 2014

9 G102 - 89 (Reapproved 2010), "Standard Practice for Calculation of Corrosion Rates and Related Information from Electrochemical Measurements,” ASTM International, West Conshohocken, PA 2014

10 G31 - 72 (Reapproved 2004), "Standard Practice for Laboratory Immersion Corrosion Testing of Metals,” ASTM International, West Conshohocken, PA 2014

11 NDEP 7.1, “Ultrasonic Thickness Examination,” SRS Procedure Manual Y23, "Nondestructive Examination Processes,” Revision 1, March 30, 2015

12 D.C. Silverman, "Practical Corrosion Prediction Using Electrochemical Techniques," R. W. Revie (ed), Uhlig’s Corrosion Handbook, $2^{\text {nd }}$ Ed, J. Wiley \& Sons, 2000

13 Personal communications from T. L. Fellinger, February 2015

14 A. R. Shafer, "Waste Acceptance Criteria for Sludge, ARU, and MCU Process Transfers to 512-S and DWPF,” X-SD-G-00008, Revision 3, October 2008

15 W. L. Daugherty, "Evaluation of Potential for Materials Degradation of DWPF Safety Class and Safety Significant Components,” WSRC-TR-95-0385, Revision 0, September 1995

16 M.H. Moayed and R.C. Newman, "Evolution of Current Transients and Morpholoy of Metastable and Stable Pitting on Stainless Steel near the Critical Pitting Temperature,” Corr Science, Vol 48, pp 1004-1018, 2006 
17 W. R. Hinz, "Nondestructive Examination Condition Report,” Job\#A20140207, February 18, 2014

18 W. R. Hinz, “Nondestructive Examination Condition Report,” Job\#A20140469, July 28, 2014

19 W. R. Hinz, "Nondestructive Examination Condition Report," Job\#A20150085, November 20, 2014

20 W. R. Hinz, "Nondestructive Examination Condition Report,” Job\#A20150084, November 20, 2014

21 Personal communications with D. P. Lambert, November 16, 2015 


\section{Appendix A. Test Solution Compositions}

Table A-1 CPC Simulants - Analyzed Chemistries*.

\begin{tabular}{|c|c|c|c|}
\hline Element/Compound & Analysis & Glycolic-based & Formic-based \\
\hline $\mathrm{Ag}$ & ICPES & $<1.00$ & ND \\
\hline $\mathrm{Al}$ & & 137 & 94 \\
\hline $\mathrm{B}$ & & 53.0 & 23.8 \\
\hline $\mathrm{Ba}$ & & 0.652 & 0.383 \\
\hline $\mathrm{Ca}$ & & 1930 & 1885 \\
\hline $\mathrm{Cd}$ & & ND & 4.736 \\
\hline $\mathrm{Cr}$ & & 0.712 & 0.359 \\
\hline $\mathrm{Cu}$ & & 14.0 & 233.8 \\
\hline $\mathrm{Fe}$ & & 89.4 & ND \\
\hline $\mathrm{K}$ & & 418 & 1345 \\
\hline $\mathrm{La}$ & & ND & 6.443 \\
\hline $\mathrm{Li}$ & & 298 & 164 \\
\hline $\mathrm{Mg}$ & & 575 & 360 \\
\hline $\mathrm{Mn}$ & & 13700 & 6820 \\
\hline $\mathrm{Na}$ & & 37500 & 57850 \\
\hline $\mathrm{Ni}$ & & 1320 & 82 \\
\hline $\mathrm{P}$ & & $<1.00$ & $<1.00$ \\
\hline $\mathrm{Pb}$ & & $\mathrm{ND}$ & $<1.00$ \\
\hline $\mathrm{Pd}$ & & $<1.00$ & $<1.00$ \\
\hline $\mathrm{Rh}$ & & 26.6 & 1.8 \\
\hline $\mathrm{Ru}$ & & 164 & 752 \\
\hline $\mathrm{S}$ & & 953 & ND \\
\hline $\mathrm{Si}$ & & 93.8 & 59.2 \\
\hline Sn & & 8.35 & ND \\
\hline $\mathrm{Ti}$ & & $<1.00$ & $<1.00$ \\
\hline $\mathrm{Zn}$ & & 18.2 & 2.5 \\
\hline $\mathrm{Zr}$ & & $<1.00$ & $<1.00$ \\
\hline $\mathrm{F}$ & IC Anion & $<100$ & $<500$ \\
\hline $\mathrm{Cl}$ & & 874 & 247 \\
\hline NO2 & & $<100$ & $<250$ \\
\hline NO3 & & 92700 & 27500 \\
\hline $\mathrm{SO} 4$ & & 2635 & 2550 \\
\hline $\mathrm{C} 2 \mathrm{O} 4$ & & 1220 & 3340 \\
\hline C2H3O3 & & 62950 & N/A \\
\hline HCO2 & & 230 & 75200 \\
\hline \multirow[t]{2}{*}{ PO4 } & & $<100$ & $<500$ \\
\hline & $\mathrm{pH}$ & 5.75 & 5.17 \\
\hline
\end{tabular}

* ND - no data 
Table A-2 Baseline CPC Simulant for Electrochemical, Hot Wall and Coupon Immersion Testing

\begin{tabular}{|c|c|c|}
\hline Component & Added Mass (g) & "Anion Concentration (ppm) \\
\hline $\begin{array}{l}\text { Aluminum Nitrate } \\
\left(\mathrm{Al}\left(\mathrm{NO}_{3}\right)_{3} \cdot 9 \mathrm{H}_{2} \mathrm{O}\right)\end{array}$ & 3.0100 & 1,493 \\
\hline $\begin{array}{l}\text { Calcium Nitrate } \\
\left(\mathrm{Ca}\left(\mathrm{NO}_{3}\right)_{2} \cdot 4 \mathrm{H}_{2} \mathrm{O}\right)\end{array}$ & 0.6423 & 337 \\
\hline $\begin{array}{l}\text { Iron Nitrate } \\
\left(\mathrm{Fe}\left(\mathrm{NO}_{3}\right)_{3} \cdot 9 \mathrm{H}_{2} \mathrm{O}\right)\end{array}$ & 1.0164 & 468 \\
\hline $\begin{array}{l}\text { Potassium Nitrate } \\
\left(\mathrm{KNO}_{3}\right)\end{array}$ & 0.8288 & 508 \\
\hline $\begin{array}{l}\text { Magnesium Nitrate } \\
\left(\mathrm{Mg}\left(\mathrm{NO}_{3}\right)_{2} \cdot 6 \mathrm{H}_{2} \mathrm{O}\right)\end{array}$ & 2.1416 & 1,036 \\
\hline $\begin{array}{l}\text { Manganese Nitrate (50 wt \% } \\
\left.\mathrm{Mn}\left(\mathrm{NO}_{3}\right) 2+5 \text { wt } \% \mathrm{HNO}_{3}\right)\end{array}$ & 17.3892 & 6,881 \\
\hline $\begin{array}{l}\text { Nickel Nitrate } \\
\left(\mathrm{Ni}\left(\mathrm{NO}_{3}\right)_{2} \cdot 6 \mathrm{H}_{2} \mathrm{O}\right)\end{array}$ & 0.4955 & 211 \\
\hline $\mathrm{RuCl}_{3}(41.74 w \mathrm{w} \% \mathrm{Ru})$ & 0.0217 & 0 \\
\hline $\begin{array}{l}\text { Rhodium Nitrate (4.933 wt \% } \\
\text { solution) }\end{array}$ & 0.5285 & 47 \\
\hline $\begin{array}{l}\text { Zirconium Nitrate } \\
\left(\mathrm{ZrO}\left(\mathrm{NO}_{3}\right)_{2} \cdot \mathrm{xH}_{2} \mathrm{O}, \mathrm{x} \sim 6\right)\end{array}$ & 0.0840 & 31 \\
\hline $\begin{array}{l}\text { Sodium Nitrate } \\
\left(\mathrm{NaNO}_{3}\right)\end{array}$ & 63.6692 & 46,450 \\
\hline $\begin{array}{l}\text { Sodium Glycolate } \\
\left(\mathrm{NaC}_{2} \mathrm{H}_{3} \mathrm{O}_{3}\right)\end{array}$ & 63.4888 & 48,600 \\
\hline $\begin{array}{l}\text { Sodium Oxalate } \\
\left(\mathrm{Na}_{2} \mathrm{C}_{2} \mathrm{O}_{4}\right)\end{array}$ & 5.7851 & 3,800 \\
\hline $\begin{array}{l}\text { Sodium Sulfate } \\
\left(\mathrm{Na}_{2} \mathrm{SO}_{4}\right)\end{array}$ & 3.8960 & 2,635 \\
\hline $\begin{array}{l}\text { Sodium Chloride } \\
\text { (NaCl) }\end{array}$ & 1.3532 & 821 \\
\hline $\begin{array}{l}\text { Mercury Nitrate } \\
\left(\mathrm{HgNO}_{3}\right)_{2} \cdot \mathrm{H}_{2} \mathrm{O}\end{array}$ & 0 & 0 \\
\hline
\end{tabular}


Table A-3. Dilute Waste Solution.

\begin{tabular}{|c|c|}
\hline Recipe & 1L Solution Mass, $g$ \\
\hline Sodium Carbonate ( $\mathrm{Na} 2 \mathrm{CO} 3$ ) & 0 \\
\hline Calcium Nitrate $(\mathrm{Ca}(\mathrm{NO} 3) 2.4 \mathrm{H} 2 \mathrm{O})$ & 0.0061 \\
\hline Iron Nitrate $(\mathrm{Fe}(\mathrm{NO} 3) 3.9 \mathrm{H} 2 \mathrm{O})$ & 0.0024 \\
\hline Potassium Nitrate (KNO3) & 0.0015 \\
\hline Magnesium Nitrate $(\mathrm{Mg}(\mathrm{NO} 3) 2.6 \mathrm{H} 2 \mathrm{O})$ & 0.001 \\
\hline Ammonium Nitrate (NH4NO3) & 0.0051 \\
\hline Mercury Nitrate $(\mathrm{Hg}(\mathrm{NO} 3) 2 . \mathrm{H} 2 \mathrm{O}$ & 0.0064 \\
\hline Sodium Nitrate (NaNO3) & 0.0165 \\
\hline Sodium Glycolate (NaC2H3O3) & 0.033 \\
\hline Sodium Sulfate (Na2SO4) & 0.0503 \\
\hline Sodium Chloride ( $\mathrm{NaCl})$ & 0.0272 \\
\hline
\end{tabular}

Table A-4. Basic Recycle Solution

\begin{tabular}{|c|c|}
\hline Recipe & 1-L Desired Mass, $\mathbf{~}$ \\
\hline Sodium Hydroxide $(\mathrm{NaOH})$ & 0.4 \\
\hline Sodium Carbonate $(\mathrm{Na2CO})$ & 48.02 \\
\hline Sodium Sulfate $(\mathrm{Na2SO} 4)$ & 2.66 \\
\hline Sodium Phosphate $(\mathrm{Na3PO} 4 \cdot 12 \mathrm{H} 2 \mathrm{O})$ & 1.6 \\
\hline Sodium Formate $(\mathrm{NaCHO})$ & 2.4 \\
\hline Sodium Glycolate $(\mathrm{NaC} 2 \mathrm{H} 3 \mathrm{O} 3)$ & 13.06 \\
\hline Sodium Oxalate $(\mathrm{Na2C} 2 \mathrm{O} 4)$ & 0.26 \\
\hline Sodium Nitrate $(\mathrm{NaNO} 3)$ & 90.1 \\
\hline Sodium Nitrite $(\mathrm{NaNO} 2)$ & 113.62 \\
\hline
\end{tabular}


Appendix B Coupon Immersion Test Results - Weight Losses and Calculated Corrosion Rates*

\begin{tabular}{|c|c|c|c|c|c|c|c|}
\hline \multirow{2}{*}{ Solution \# } & \multicolumn{2}{|c|}{ Coupon ID } & \multicolumn{2}{|c|}{ Duration } & \multicolumn{2}{|c|}{ Average Weights (g) } & \multirow{2}{*}{$\begin{array}{c}\text { Corrosion } \\
\text { Rate }(\mathrm{mpy})^{* *}\end{array}$} \\
\hline & Alloy & Number & (Mos) & (Days) & Initial & Final & \\
\hline \multirow[t]{16}{*}{1} & C276 & 1 & 1 & 30 & 34.7366 & 34.7351 & 0.025 \\
\hline & & 2 & 3 & 87 & 34.1443 & 34.1404 & 0.023 \\
\hline & & 13 & 4 & 112 & 34.5592 & 34.5538 & 0.025 \\
\hline & & 3 & 6 & 183 & 34.6072 & 34.6000 & 0.020 \\
\hline & C276W & 1 & 1 & 30 & 31.6650 & 31.6632 & 0.030 \\
\hline & & 2 & 3 & 87 & 30.6471 & 30.6423 & 0.029 \\
\hline & & 13 & 4 & 112 & 32.4063 & 32.4057 & 0.003 \\
\hline & & 3 & 6 & 183 & 31.1502 & 31.1409 & 0.027 \\
\hline & St6B & 1 & 1 & 30 & 15.4433 & 15.4431 & 0.004 \\
\hline & & 2 & 3 & 87 & 16.0153 & 16.0164 & -0.008 \\
\hline & & $1^{\prime}$ & 4 & 100 & & 15.4698 & 0.001 \\
\hline & & 3 & 6 & 183 & 15.9195 & 15.9218 & -0.008 \\
\hline & Ult & 1 & 1 & 30 & 7.8617 & 7.8596 & 0.079 \\
\hline & & 2 & 3 & 87 & 7.9518 & 7.9541 & -0.030 \\
\hline & & 1 & 4 & 100 & 14.8689 & 14.8688 & 0.001 \\
\hline & & 3 & 6 & 183 & 8.0344 & 8.0343 & 0.001 \\
\hline \multirow[t]{12}{*}{2} & C276 & 4 & 1 & 30 & 34.2534 & 34.2525 & 0.015 \\
\hline & & 5 & 3 & 87 & 33.9067 & 33.9054 & 0.008 \\
\hline & & 14 & 4 & 112 & 33.9586 & 33.9557 & 0.013 \\
\hline & & 6 & 6 & 183 & 34.5488 & 34.5448 & 0.011 \\
\hline & C276W & 4 & 1 & 30 & 30.7130 & 30.7125 & 0.009 \\
\hline & & 5 & 3 & 87 & 29.8705 & 29.8694 & 0.007 \\
\hline & & 14 & 4 & 112 & 31.5526 & 31.5489 & 0.017 \\
\hline & & 6 & 6 & 183 & 31.6351 & 31.6312 & 0.011 \\
\hline & St6B & 4 & 1 & 30 & 16.0413 & 16.0413 & -0.001 \\
\hline & & 5 & 3 & 87 & 16.1606 & 16.1618 & -0.008 \\
\hline & & 2 & 4 & 100 & 15.4959 & 15.4957 & 0.001 \\
\hline & & 6 & 6 & 183 & 16.0347 & 16.0363 & -0.005 \\
\hline & & & & & & & \\
\hline & & & & & & & \\
\hline
\end{tabular}


SRNL-STI-2015-00482

Revision 0

\begin{tabular}{|c|c|c|c|c|c|c|c|}
\hline \multirow{2}{*}{ Solution \# } & \multicolumn{2}{|c|}{ Coupon ID } & \multicolumn{2}{|c|}{ Duration } & \multicolumn{2}{|c|}{ Average Weights (g) } & \multirow{2}{*}{$\begin{array}{c}\text { Corrosion } \\
\text { Rate }(\mathrm{mpy})^{* *}\end{array}$} \\
\hline & Alloy & Number & (Mos) & (Days) & Initial & Final & \\
\hline & Ult & 4 & 1 & 30 & 7.8495 & 7.8471 & 0.089 \\
\hline & & 5 & 3 & 87 & 7.7434 & 7.7430 & 0.006 \\
\hline & & 2 & 4 & 100 & 15.1973 & 15.1974 & -0.001 \\
\hline & & 6 & 6 & 183 & 7.8890 & 7.8915 & -0.016 \\
\hline \multirow[t]{13}{*}{3} & C276 & 7 & 1 & 30 & 34.3034 & 34.3026 & 0.013 \\
\hline & & 8 & 3 & 87 & 34.3993 & 34.3975 & 0.011 \\
\hline & & 15 & 4 & 112 & 34.4942 & 34.4895 & 0.021 \\
\hline & & 9 & 6 & 183 & 34.8625 & 34.8571 & 0.015 \\
\hline & C276W & 7 & 1 & 30 & 31.5743 & 31.5744 & -0.002 \\
\hline & & 8 & 3 & 87 & 31.5225 & 31.5200 & 0.015 \\
\hline & & 15 & 4 & 112 & 31.7389 & 31.7342 & 0.022 \\
\hline & & 9 & 6 & 183 & 31.5921 & 31.5858 & 0.018 \\
\hline & St6B & 7 & 1 & 30 & 15.8586 & 15.8587 & -0.003 \\
\hline & & 8 & 3 & 87 & 15.9217 & 15.9236 & -0.013 \\
\hline & & 3 & 5 & 141 & 16.0033 & 16.0045 & -0.005 \\
\hline & Ult & 7 & 3 & 87 & 8.0379 & 8.0401 & -0.029 \\
\hline & & 3 & 5 & 141 & 14.9532 & 14.9541 & -0.004 \\
\hline \multirow[t]{13}{*}{4} & C276 & 10 & 1 & 30 & 34.5718 & 34.5747 & -0.051 \\
\hline & & 11 & 3 & 87 & 34.3583 & 34.3628 & -0.027 \\
\hline & & 16 & 4 & 112 & 34.1133 & 34.1178 & -0.021 \\
\hline & & 12 & 6 & 183 & 35.1012 & 35.1071 & -0.017 \\
\hline & C276W & 10 & 3 & 87 & 31.2478 & 31.2509 & -0.019 \\
\hline & & 11 & 1 & 30 & 30.8441 & 30.8436 & 0.009 \\
\hline & & 16 & 4 & 112 & 31.5866 & 31.5880 & -0.007 \\
\hline & & 12 & 6 & 183 & 32.1752 & 32.1846 & -0.027 \\
\hline & St6B & 9 & 1 & 30 & 15.8251 & 15.8272 & -0.042 \\
\hline & & 10 & 3 & 87 & 15.8135 & 15.8154 & -0.013 \\
\hline & & 4 & 5 & 141 & 15.7326 & 15.7338 & -0.005 \\
\hline & Ult & 8 & 3 & 87 & 8.0514 & 8.0552 & -0.050 \\
\hline & & 4 & 5 & 141 & 15.3377 & 15.3387 & -0.004 \\
\hline
\end{tabular}

B-5 
* The table is color coded for the materials of construction for ease of comparison among the different solutions.

** A negative corrosion rate indicates a weight gain which may be associated with the incomplete removal of deposits and coating or of base metal oxidation. 


\section{Distribution:}

D. E. Dooley, 773-A

C. C. Herman, 773-A

D. H. McGuire, 773-42A

F. M. Pennebaker, 773-42A

M. E. Stone, 999-W

H. P. Boyd, 704-27S

J. M. Bricker, 704-S

J. S. Contardi, 704-56H

T. L. Fellinger, 766-H

E. J. Freed, 704-S

J. M. Gillam, 766-H

B. A. Hamm, 766-H

E. W. Holtzscheiter, 766-H

J. F. Iaukea, 704-27S

V. Jain, 766-H

C. J. Martino, 999-W

J. W. Ray, 704-27S

P. J. Ryan, 704-26S

M. A. Rios-Armstrong, 766-H

H. B. Shah, 766-H

D. C. Sherburne, 249-8H

C. Sudduth, 707-7E

S. T. Isom, 773-67A

F. M. Pennebaker, 773-42A

C. J. Martino, 999-W

K. E. Zeigler, 773-41A

B. J. Wiersma, 773-A

K. I. Imrich, 773-A 